Portland State University

PDXScholar

Civil and Environmental Engineering Master's

Project Reports

Summer 2018

\title{
Exploring the Relationship of Bikeshare and Transit in the United States of America
}

David Rafael Soto Padín

Portland State University

Follow this and additional works at: https://pdxscholar.library.pdx.edu/cengin_gradprojects

Part of the Transportation Engineering Commons

Let us know how access to this document benefits you.

\section{Recommended Citation}

Soto Padín, David Rafael, "Exploring the Relationship of Bikeshare and Transit in the United States of America" (2018). Civil and Environmental Engineering Master's Project Reports. 52.

https://doi.org/10.15760/CCEMP.51

This Project is brought to you for free and open access. It has been accepted for inclusion in Civil and Environmental Engineering Master's Project Reports by an authorized administrator of PDXScholar. Please contact us if we can make this document more accessible: pdxscholar@pdx.edu. 


\title{
EXPLORING THE RELATIONSHIP OF BIKESHARE AND TRANSIT IN THE UNITED STATES OF AMERICA
}

\author{
BY \\ DAVID RAFAEL SOTO PADÍN \\ A research project report submitted in partial fulfillment \\ of the requirement for the degree of \\ MASTER OF SCIENCE \\ IN \\ CIVIL AND ENVIRONMENTAL ENGINEERING \\ Project Advisor: \\ Kelly J. Clifton \\ Portland State University \\ ๑2018
}

Final Draft 


\section{ACKNOWLEDGMENTS}

I would like to express my gratitude for the academic guidance provided by my advisor Dr. Kelly J. Clifton. This project would not have been possible without the support and feedback of my fellow graduate students in the transportation lab of Portland State University. Any errors or omissions are the sole responsibility of the author. The author would like to thank bikeshare operators for making their data available, including Motivate and Bicycle Transportation Systems. Finally, and most importantly, I would like to recognize the invaluable support of my family who have always been there in times of extreme uncertainty and ultimately molded me to who I am today. 


\begin{abstract}
Bicycling and bike-share have been growing in US cities as transportation alternatives. Despite impressions that bikeshare systems exist solely for tourism, recreation or privileged users, research has shown that bike-share is becoming a transportation mode used by a diverse set of users for various transportation needs. Additionally, a positive relationship has been established between bike-share and transit although most studies on this matter have focused on systems outside the United States. Bike share and transit benefit each other by: (1) contributing to sustainable transportation goals by improving mobility and greenhouse gas reductions, (2) solving the "last mile" problem, (3) reduce overcrowding at a fraction of traditional capacity capital investments, and (4) extending the radius of influence of mass transit stations. While synergy between cycling and transit systems has been documented, the influence of bike-share and transit has been less covered. This study uses data gathered from 10 US cities to describe the effects bikeshare and transit have on each other. This project will explore the factors that are associated with increased bikeshare trips based on sociodemographic, built environment, and transit system characteristics and the magnitude of the effect of bikeshare on rail rapid transit boardings. Ultimately, it is of interest to address whether bikeshare linked to rapid rail transit stations has greater usage rates.
\end{abstract}




\section{TABLE OF CONTENTS}

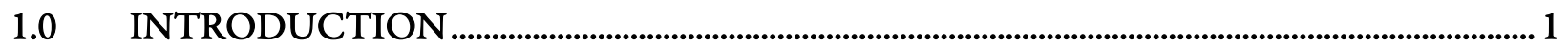

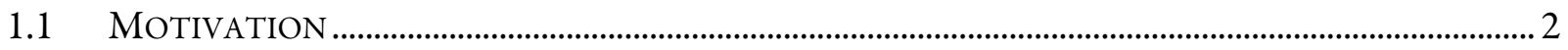

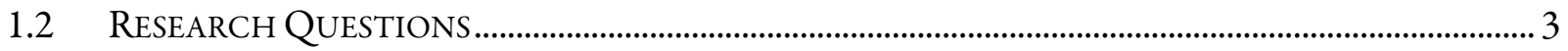

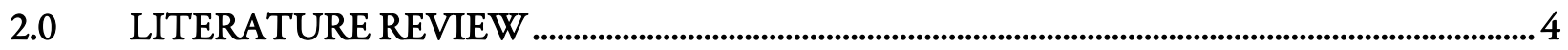

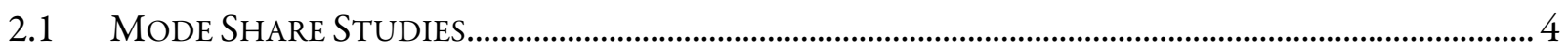

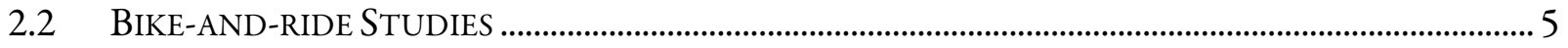

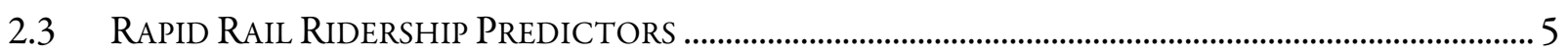

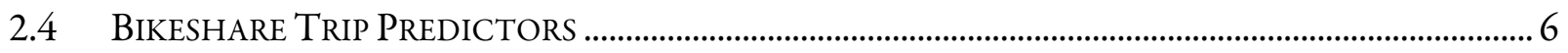

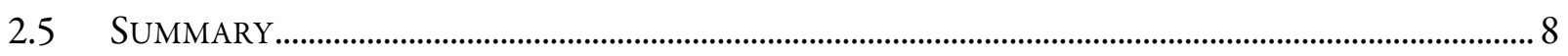

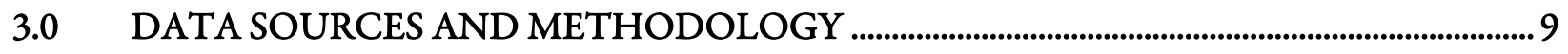

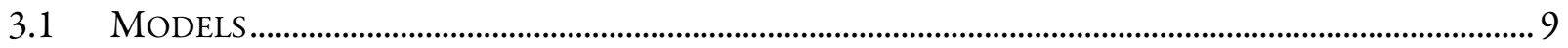

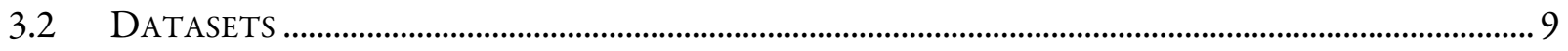

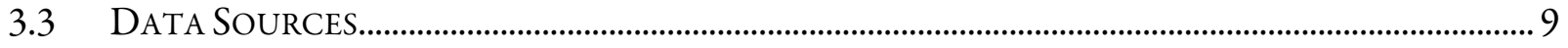

3.3.1 AMERICAN COMMUNITY SURVEY 2012-2016 5-YEAR ESTIMATES ..........................................9

3.3.2 EnVIronmental Protection Agency Smart Location Database..................................9

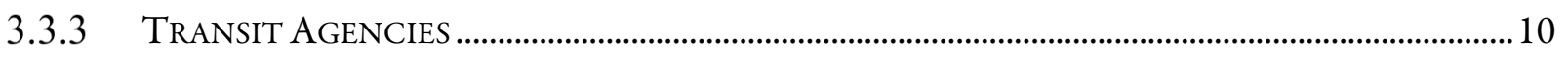

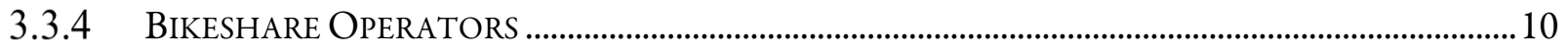

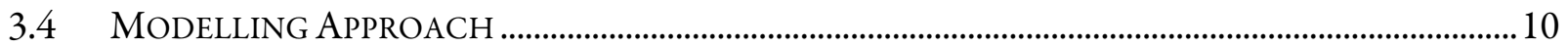

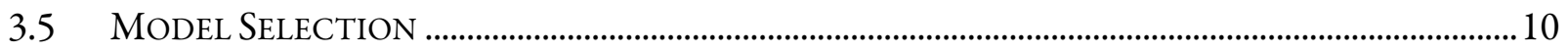

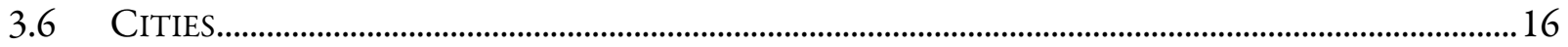

iv 


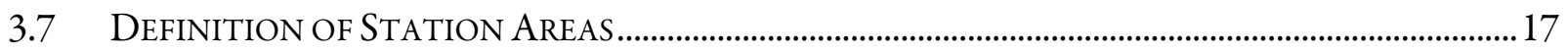

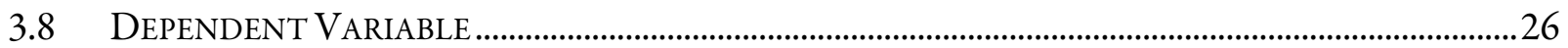

3.8.1 TRANSFORMATION OF DEPENDENT VARIABLES ...................................................................29

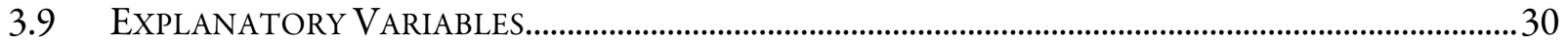

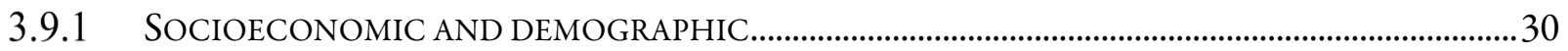

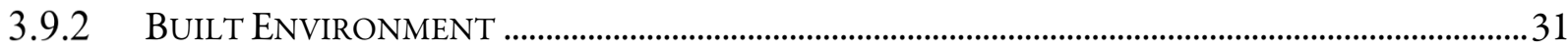

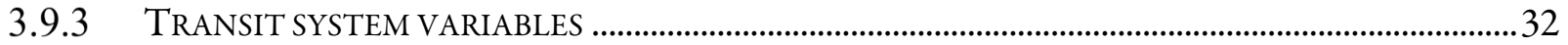

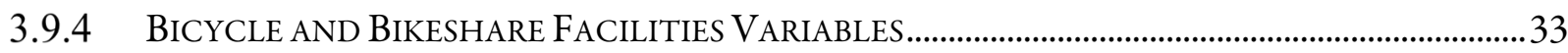

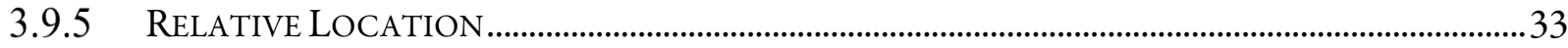

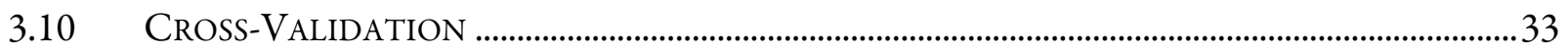

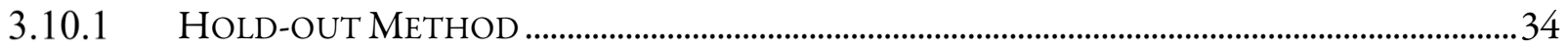

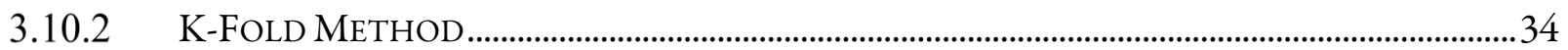

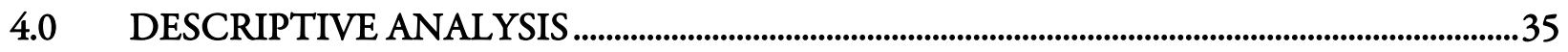

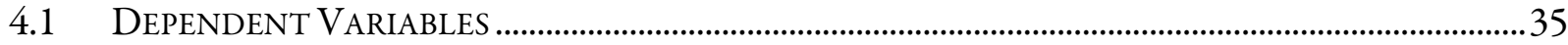

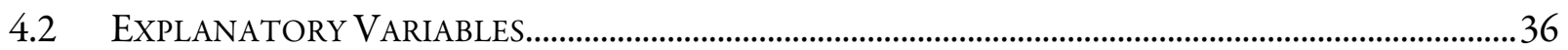

4.3 RELATIONSHIPS BETWEEN BIKESHARE AND RAIL RAPID TRANSIT VARIABLES ...........................44

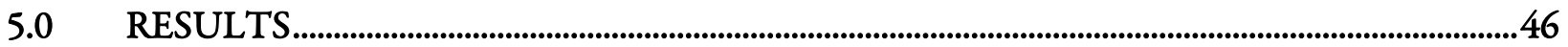

5.1 MODEL OF RAPID RAIL STATION BOARDINGS ..................................................................................

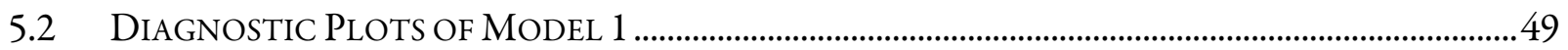

5.3 MODEL OF AVERAGE WEEKDAY BIKESHARE TRIPS .................................................................51

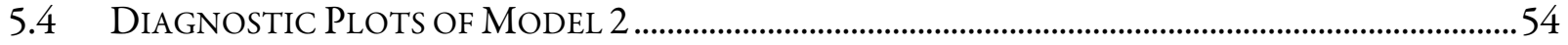


6.0 DISCUSSION

6.1 Model of AVERage WeEkday Boardings (MOdel 1) ………………………………………......56

6.2 Model of Average Weekday Bikeshare Trips (Model 2) .....................................................57

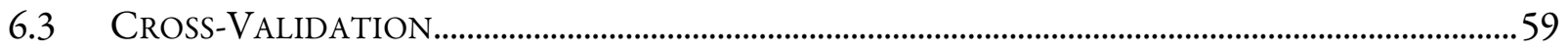

6.4 OUTLIER POINTS....................................................................................................................................6

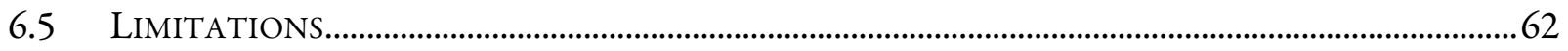

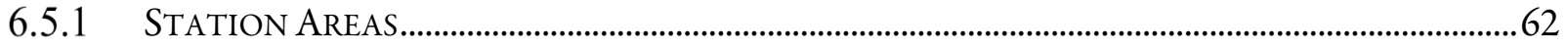

6.5.2 TRANSIT SYSTEM NETWORKS......................................................................................................62

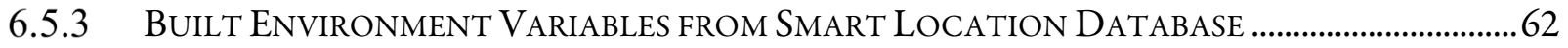

6.5.4 QUALITY OF TRANSIT SERVICE VARIABLES ................................................................................62

6.5.5 BIKESHARE SYSTEMS..............................................................................................................62

6.5.6 OTHER VARIABLES RELATED TO THE USER EXPERIENCE..................................................................63

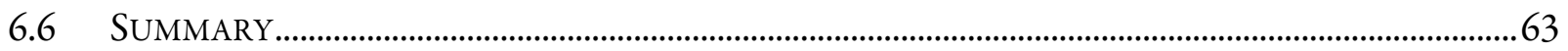

7.0 CONCLUSIONS................................................................................................................................................64

7.1 POLICY IMPLICATIONS ………………………………………………………………………………..6

7.2 WHEN SHOULD BIKESHARE COMPLEMENT RAIL RAPID TRANSIT ...................................................65

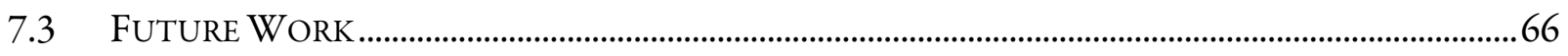

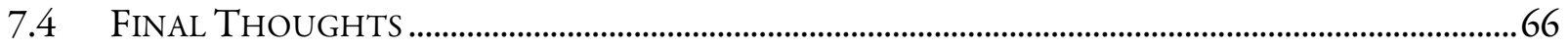

8.0 REFERENCES .............................................................................................................67

9.0 APPENDIX A: BOARDINGS AND BIKESHARE BY CITY, LINES AND CBD FLAG...69 


\section{LIST OF TABLES}

Table 3.1. Variables and data sources for rapid rail average weekday boardings (Model 1) ................................................ 12

Table 3.2. Variables and data sources for rapid rail average weekday bikeshare trips (Model 2) ....................................... 14

Table 3.3. Characteristics of US cities in the study............................................................................................................. 16

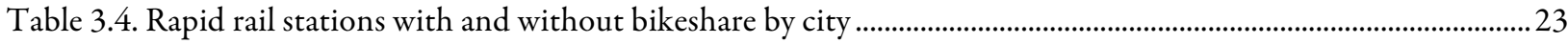

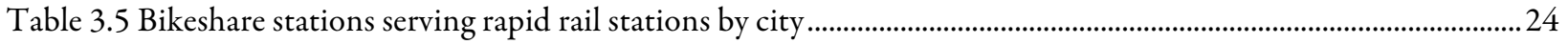

Table 3.6. Descriptive statistics of average weekday boardings by city, overall, and excluding New York City...............27

Table 3.7. Descriptive statistics of average weekday bikeshare trips by city, overall, and excluding New York City ......28

Table 4.1. Number of observations by categorical variables in Model 1..........................................................................38

Table 4.2. Number of observations by categorical variable in Model 2...............................................................................39

Table 5.1. Unadjusted model of boardings results of backward and forward selection based on AIC $(\mathrm{n}=1106) \ldots \ldots \ldots . . .46$

Table 5.2. Parsimonious model variables ........................................................................................................................ 48

Table 5.3. Unadjusted model of square root of average bikeshare trips result of backward forward selection $(\mathrm{n}=2,428)$

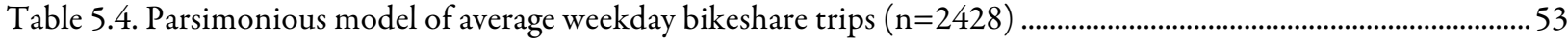

Table 6.1 Mean Absolute Error by cross-validation method ..................................................................................................59

Table 9.1. Bikeshare activity and average weekday boardings by number of rapid rail lines and location in central business district 


\section{LIST OF FIGURES}

Figure 1.1 US cities with bikeshare and rail rapid transit by inclusion in this study .......................................................... 1

Figure 3.1. Rapid rail stations and bikeshare docks by city.................................................................................................. 17

Figure 3.2. Metropolitan areas and bikeshare presence at rapid rail stations ......................................................................22

Figure 3.3 Geometric density plots of Average Weekday Boardings and Log of Average Weekday Boardings................30

Figure 3.4 Geometric density plots of Average Weekday Bikeshare Trips and log of Average Weekday Bikeshare Trips

Figure 3.5 Jobs accessible by transit in 30 minutes (UMN Accessibility Observatory 2016) ...........................................32

Figure 3.6 Transit system variables were collected at the station-level (left) and at the system-level (right)...................33

Figure 4.1. Boxplot of average weekday boardings by rail mode by city, excluding 17 outliers ............................................35

Figure 4.2 Boxplot of average weekday bikeshare trips by year of inauguration by city, excluding 9 outliers...................36

Figure 4.3. Boardings by Presence of Bikeshare by City, excluding 17 outliers …………................................................... 36

Figure 4.4 Average Weekday Bikeshare Trips by City, excluding 9 outliers …………......................................................... 37

Figure 4.5. Boxplot of average weekday boardings by commuter rail transfer ability by city............................................. 40

Figure 4.6 Boxplot of average weekday bikeshare trips by commuter rail transfer ability by city ...................................... 40

Figure 4.7. Boxplot of average weekday boardings by location of station in the central business district by city ............ 41

Figure 4.8 Boxplot of average weekday bikeshare trips by location of station in the central business district by city..... 41

Figure 4.9. Boxplot of average weekday boarding by presence of bike lanes by city........................................................... 42

Figure 4.10 Boxplot of average weekday bikeshare trips by presence of bike lanes by city ............................................... 42

Figure 4.11. Boxplot of average weekday boardings by presence of multi-use path by city ................................................ 43

Figure 4.12 Boxplot of average weekday bikeshare trips by presence of muti-use paths by city ………………………...... 43

Figure 4.13. Average Weekday Boardings by Average Weekday Bikeshare Trips ................................................................ 44

Figure 4.14 Employment Density by Average Weekday Boardings with and without bikeshare presence ...................... 45

viii 
Figure 4.15 Average Weekday Bikeshare Trips by Bikeshare Dock Capacity .45

Figure 5.1 Plot of residuals vs. fitted values of Model 1 .......................................................................................................... 49

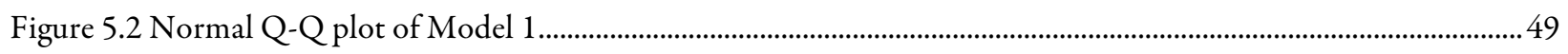

Figure 5.3 Scale-location plot of Model 1 .................................................................................................................... 50

Figure 5.4 Plot of residuals vs. leverage of Model 1 .......................................................................................................

Figure 5.5 Plot of residuals vs. fitted values of Model 2 ………………………............................................................... 54

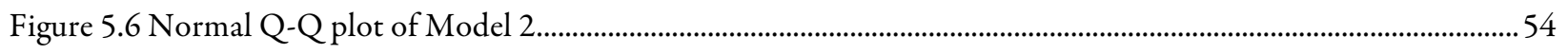

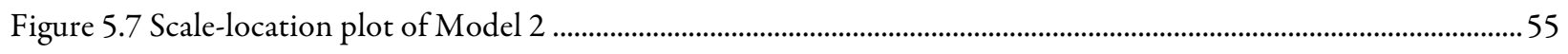

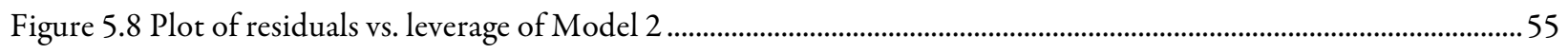

Figure 6.1 Relative Influence of Variables in Model 1A ..............................................................................................57

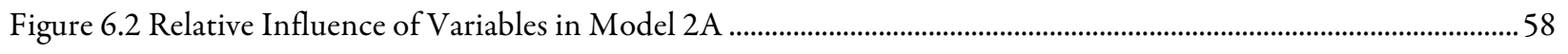

Figure 6.3. Error Magnitude by Average Weekday Boardings in Model 1A...................................................................6 60

Figure 6.4 Error Magnitude by Average Weekday Bikeshare Trips in Model 2A ...........................................................61

ix 


\subsection{INTRODUCTION}

Bikeshare systems are an important part of a rapidly evolving shared mobility landscape. Bikeshare is now a staple of modern American cities, a point that is only increasing with the entrance of private bikeshare operators into the market. According to the National Association of City Transportation Officials (NACTO), 35 million bikeshare trips took place in 2017. These services are operating in many American cities, including 26 cities in the US with light rail and/or heavy rail rapid transit systems. In fact, the only US city with rapid rail transit lacking bikeshare is San Juan, Puerto Rico, where the author is originally from.

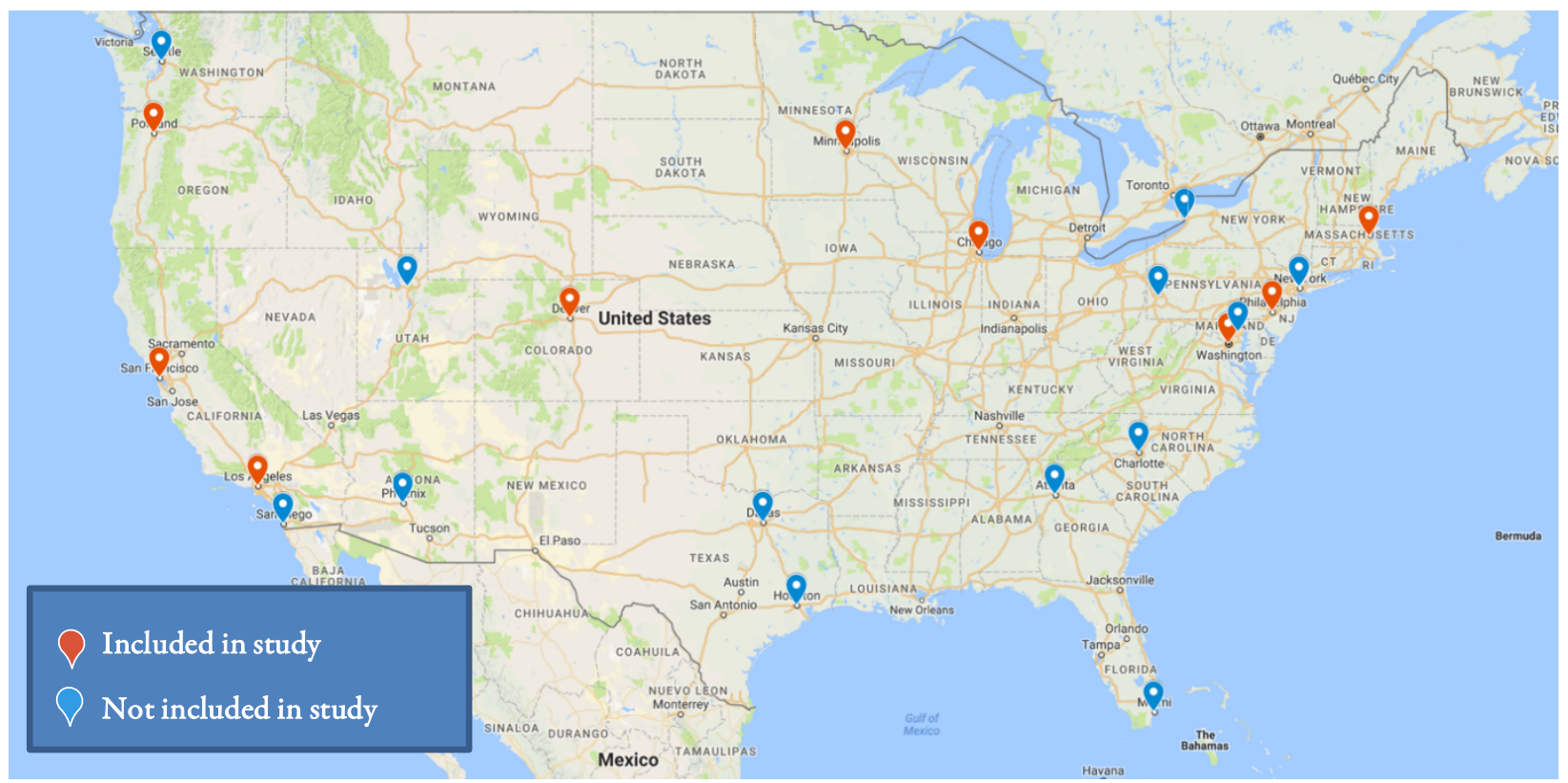

Figure 1.1 US cities with bikeshare and rail rapid transit by inclusion in this study

While bikeshare may be a niche component of urban transportation systems, scholars agree it is an important motivator in increasing bicycle to work rates (Pucher and Buehler 2008). It accomplishes this by normalizing bicycles as a form of mobility and their high-profile branding makes drivers aware of the presence of people on bicycles, thus creating a safer environment.

Since the introduction of modern bikeshare systems in 2010, many US bikeshare systems have continued to grow and, having withstood the test of time, have demonstrated that bikeshare is here to stay. Many systems have adapted to their markets by introducing new membership packages and alternative methods 
of payment other than credit cards, which had the effect of excluding communities without access to credit. Los Angeles is the first US bikeshare system to introduce transit fare integration, a method which allows users to pay with their transit card and log the bikeshare trip as a transfer.

Bikeshare and transit integration offers a number of benefits: (1) extend the coverage area of transit systems, (2) extend the utility of bikeshare systems, (3) facilitate affordable travel options in the event of changes in travel conditions (such as weather, service disruptions, facility closures, etc.), (4) fare integration enabling instant subscription ability (no need to sign up twice for complementary services), (5) the ability to shift rapidly in the event of overcrowding on transit or excessive demand in bikeshare. The results are intuitive public transportation system and a higher-quality commute.

Most recently, major bikeshare operators Motivate and Social Bicycles have been the subject of acquisitions by major players in the ride-hailing industry, Lyft and Uber. This will incorporate the ability to rent bicycles from within the ride-hailing apps, putting ride-hailing and bikeshare on equal footing, from the customer's perspective for the first time. Despite many years of continued growth in the bikesharing industry, the breadth to which planning efforts address the link between bikeshare and transit trips merits still has a long way to go in the United States (Griffin and Sener 2016).

\subsection{Motivation}

Much has been stated in guidelines about compatibility between bicycles and transit while the effects can be readily observed in countries like the Netherlands where bicycles are ubiquitous in coexistence with an extensive rail transit system. Bikeshare systems offer an abundance of data that has not been previously available offering origins, destinations, and trip durations for every single trip taken through a bikeshare service. Similarly, open data initiatives have enabled publishing of rapid transit ridership on the internet in the last few years. Finally, the growth of bikeshare offers insights on how far functionality between bike and ride trips may be generated as relationships between bikeshare and rapid rail transit systems has matured.

Initial studies (Ma et al. 2016) used data available from Capital Bikeshare and the Washington DC Metro, a heavy rail system. The underlying motivation for this research project is to develop a multi-city 
model of bikeshare and transit integration impacts using data from multiple cities to develop a robust model that can account for variables across cities with different geographic scales and distribution of socioeconomic and built environment conditions.

These findings can serve to extend the service capability of existing transit systems. In some cities like Baltimore, San Juan, Miami and Cleveland, rail transit systems that have received significant investments are experiencing stagnating ridership. Capital expansion projects are not considered due to high costs

while on the other hand solutions to the "last mile" problem are more cost-efficient solutions to increasing ridership. Developing a model that can predict the effect of launching bikeshare systems at rail transit stations can be a game changer for transit agencies interested in enhancing prior investments in heavy rail infrastructure as well as bikeshare companies aspiring to maximize the usage of bikeshare bicycles.

The methodology presented here is the first multi-city analysis of the determinants of bikeshare trips conducted to date. It complements studies that have focused on Washington, DC using Capital Bikeshare data that this method is based on (Ma et al., Daddio).

\subsection{Research Questions}

1. What effect does locating bikeshare at rapid rail transit stations have on travel outcomes?

a. What effect does the presence of bikeshare at rapid rail transit stations have on average weekday bikeshare trips?

b. What effect does locating bikeshare at rapid rail transit stations have on ridership? 


\subsection{LITERATURE REVIEW}

Previous literature on the effects of bikeshare on rail transit have explored this question by exploring bikeshare's effect on commute mode share using census data, assessing access and egress trips to transit stations whether by intercept surveys or tracking of bike-and-rail transfer fares, and exploring the generators of bikeshare trips using a combination of bikeshare and transit trips data with spatial datasets. Transit integration strategies that are commonplace in North America are as follows (Pucher and Buehler 2009):

1. Bicycle parking at transit stations

2. Bicycle service areas at transit stations

3. Bike racks on buses

4. Allowing bicycles on vehicles

5. Bike paths and routes leading to transit stations

Bikeshare has been implemented with the intention of serving as a complement to transit service as well. Few cities however, have implemented top down integration the way cities in Asia and the Netherlands have with transit fare integration. Los Angeles recently became the first city to do so.

\subsection{Mode Share Studies}

The Netherlands has an important case study on the willingness of drivers to trade their single user vehicle trips for a transit plus bicycle trips. The Dutch national railway, Nederlandse Spoorwegen (NS), implemented a public bike share system known as OV Fiets whereby commuters can receive a bicycle at their destination train station. Villwocke-Witte and van Grol (2009) noted in their case study on OV Fiets an increase in bicycle-transit trips from 30 to 50 percent.

Shaheen and Martin (2014) applied an ordinal logistic regression to examine factors associated with modal shifts due to bikeshare respondent location. This study found age, gender, commute distance, population density, and household income to be significant. This study suggests that bikeshare is more complementary in small to midsize cities where there is less density of rail transit. 


\subsection{Bike-and-ride Studies}

Cervero et al. (2013) explored what factors drove increases in access trips by bicycle at heavy rail stations in the Bay Area. The authors of this study assert that increases in access to safe and secure bicycle infrastructure were associated with the greatest gains in bike-and-ride trips, specifically measured in bicycle route lengths and bicycle route densities. Surveys conducted on bikeshare systems have also shown that most users in Chicago use bikeshare in conjunction with mass transit at least on a regular basis (Griffin and Sener 2016).

Meng et al. (2016) developed a mode choice model for transit in Singapore considering streetscape (development patterns) and operational characteristics (travel distance and time) as well as sociodemographic characteristics. The latter authors surveyed travelers intercepted at stations and found that the availability of a service and / or bicycle facilities had a strong influence on the probability respondents used bicycles for the last mile of their trip.

Altaff (2017) conducted an intercept survey and found commute distance greater than 1 kilometer, bike parking availability, availability of ride hailing modes, weather conditions, employment status, and views of climate change were significant influencers on willingness to use bikeshare in conjunction with transit. Interestingly, separated bicycle facilities were not significant in this study.

\subsection{Rapid Rail Ridership Predictors}

The main types of variables of direct ridership models are socioeconomic, built environment, transit service, and station-specific variables.

Durning and Townsend (2014) developed a direct ridership model for rail rapid transit systems in Canada. Of note, this model did not find any significant socioeconomic variables, suggesting the Canadian transit systems serve areas that have a diverse mix of different socioeconomic groups. Their final model showed density, bus connections, parking, transfer flag, peak-only stations, commercial density, and land use diversity to be significant. This study considered commuter rail boardings in the model. 
Fernández Reyes (2012) modeled heavy rail and bus rapid transit boardings in Mexico City. The final model for heavy rail average weekday boardings found employment density, transit connections, transit service frequency, and relative location variables to be significant. Interestingly the author only used population as the socioeconomic measure. In this project, Fernández Reyes details aspects of modeling rapid transit ridership describing transformation of the independent variables, model selection, interpretation of results, and cross-validation methods for this type of multiple regression model.

Currie et al. (2014) explored light rail systems in Europe, North America, and Australia to develop a robust model explaining the drivers in route-level light rail ridership. The findings indicate that service level is the most important variable while also capturing the influence of integrated ticketing.

Equation: Boardings per Route $-\mathrm{km}$

$$
\begin{aligned}
& =34,336+6.912(\text { VehicleTrips })+714,593(\text { Europe })-27,728(\text { Speed }) \\
& +25.643(\text { EmploymentDensity })+241,967 *(\text { IntegratedTicketing })
\end{aligned}
$$

Ma et al. (2015) studied the Capital Bikeshare system in Washington, DC and found a positive relationship between increased transit ridership and bike-share trips. The study presents a regression model that found Metrorail boardings as a function of the significant variables peak hour service level, employment density, number of bus stops, and median household income by the following equation:

Equation: $\log ($ Transit Boardings)

$$
\begin{aligned}
& =4.33+0.26(\text { Bikeshare Trips })+0.49(\text { Peak Hour Transit }) \\
& +0.16(\text { Employment })+0.20(\text { Bus Stops })+0.04(\text { Median Income })
\end{aligned}
$$

Barber and Starrett (2015) found a positive relationship between ridership on the Chicago metro system and the number of bikeshare stations within 400 meters of metro stations.

\subsection{Bikeshare Trip Predictors}

The determinants of bikeshare trips were a subject of interest to Buck and Buehler (2012). Their final revised multiple regression, shown below, found population, supply of bike facilities, and socio-economic characteristics to be significant predictors of average bikeshare trips per day for the Capital Bikeshare system. 
Equation: Trips per Day

$$
\begin{aligned}
& =5.78+0.00054(\text { Population })+0.11(\text { Liquor Licenses }) \\
& +0.86(\text { Bike Lanes })+0.19(\text { CarFree Households })
\end{aligned}
$$

Daddio (2012) explored a similar approach to modeling Capital Bikeshare trips and constructed the following model:

Equation: Trips per day

$$
\begin{aligned}
& =46.6+0.006(\text { Population })-0.12(\% \text { NonWhite Population }) \\
& +0.217 \text { (Liquor Licenses })+2.732 \text { (Metro Stations }) \\
& -3.362 \text { (Distance to Center })
\end{aligned}
$$

Noland et al. (2016) analyzed the effect of New York City's subway system on bikeshare trips and developed regression models by weekday/weekend and type of user (casual/subscriber). Their study found bike lanes to be significant predictors of trips by casual riders, but not necessarily for subscribers. The following variables were significant in the 2015 weekday trips model (latest data available):

Equation: Trips per day

$$
\begin{aligned}
& =1.443+0.025(\text { Bike Lane Flag })+0.167 * \ln (\text { Subway ridership }) \\
& +0.361 * \ln (\text { Bike Docks })+0.041 * \ln (\text { Bikeracks })+0.105 * \ln (\text { Population }) \\
& +0.120 * \ln (\text { Employment })
\end{aligned}
$$

Other variables that influence bikeshare use include transit service interruptions and years of bikeshare operations. Transit service interruptions are associated with increased bikeshare use (Fuller et al. 2012). As is expected, the older the bikeshare stations the more use they tend to get (Barber and Starrett 2015). 


\subsection{Summary}

The literature is in overwhelming consensus that bikeshare and transit are positively correlated. Bikeshare has a positive effect on rail transit ridership just as rail transit station locations are associated with more bikeshare trips. These relationships can be established based on the observed direction of effects after controlling for numerous variables. The density around bikeshare and rail transit stations influences the direction of effect these modes have on the usage of each other's services.

Transit benefits bikeshare for the same reason it benefits people on bicycles in general. It provides a "peace of mind" alternative to cycling should an impediment to riding take place. Bikeshare is complementary to rail transit for two reasons: (1) it is also an alternative in the event of service disruptions and, (2) it provides a faster way of completing access and egress trips from rail transit stations than competing first and last mile trip modes like walking and bus transit.

A multi-city study of bikeshare and rail was not found in the literature review. Multi-city studies of direct ridership models (Durning and Townsend 2014) and studies exploring the effect of bikeshare on first and last mile trips based on data from one city (Ma et al. 2012) were identified. In addition, no study was found that addressed the link between light rail ridership and bikeshare trips. This Masters project attempts to fill this gap in the literature considering bikeshare systems in the United States.

The variables and methods found in the literature review will inform how this project's model is structured, which variables are selected, and how the results should be interpreted. The variables that were significant in the rail rapid transit station literature were transit service connections, employment density, and relative location variables. The variables that were significant in the bikeshare model literature review were population density, employment density, bikeshare docks, and metro ridership.

The most common approach to estimate the direction and magnitude of effect is the multiple regression model. Methods described in the literature used to compare the influence of variables include the $\mathrm{r}$ squared contribution and elasticities.

Due to time limitations and the large amounts of datasets involved, some variables were not accounted for in the models. These data collection efforts and methodology are described in the next section. 


\subsection{DATA SOURCES AND METHODOLOGY}

Datasets were developed using socioeconomic, built environment, bike network, transit system, bikeshare system, and city variables for to model average weekday boardings or average weekday bikeshare trips.

\subsection{Models}

Two separate models are the subject of this project. Model 1 refers to the model of average weekday boardings as the dependent variable. Model 2 refers to the model of average weekday bikeshare trips as the dependent variable. This was done to explore whether there is a two-way effect between bikeshare and transit services.

\subsection{Datasets}

A dataset of 1,119 rail rapid transit stations was created to model average weekday boardings for "Model 1". A dataset of average weekday bikeshare trips was made for "Model 2". The database of transit stations consists of a merge of datasets obtained from the websites of 12 different transit agencies regarding average weekday boardings for the year 2016. A join of this dataset and the rail system GIS files for each city facilitated the structure of the model. In total, 1,124 observations formed the original dataset.

\subsection{Data Sources}

\subsubsection{American Community Survey 2012-2016 5-year Estimates}

The American Community Survey (ACS) is an ongoing survey program of the US Census providing data on a yearly basis, as opposed to the more comprehensive, decennial census. The 5-year estimates are compiled from 60 months of data regarding all census geographies and is the most reliable of all the ACS products.

\subsubsection{Environmental Protection Agency Smart Location Database}

The Smart Location Database (SLD) is a free resource funded by the Environmental Protection Agency (EPA) concerning built environment variables for all census geographies including variables related to 
density, design, diversity, transit, and destination accessibility (Ramsey 2012). The most recent version presents data computed based on data from between 2010 and 2012.

\subsubsection{Transit Agencies}

Transit agencies are required to publish station-level and route-level ridership data by Federal law. Station-level ridership data came in different formats by transit agency; some files were found or provided in Excel spreadsheet, others in PDF, and in the case of New York City, in HTML.

\subsubsection{Bikeshare Operators}

Bikeshare ridership data for the 2017 year was collected for each city in the study. Bikeshare operators Motivate and Bicycle Transit Systems were diligent enough to support open-source publishing of the data since the first day of operation.

\subsection{Modelling Approach}

Multiple regression was the selected modelling approach and is consistent with previous bikeshare trip generation and direct ridership model studies. Two sets of models are developed based on assessing the effect variables have on two different dependent variables, ridership and bikeshare trips. First, stationlevel ridership was modeled to test the effect of sociodemographic, built environment, and transit-supply variables on station-level ridership. Second, bikeshare trips were modeled to test the effect of sociodemographic, built environment, and bikeshare network variables on station-level bikeshare activity. The general functions are given below:

$$
\begin{gathered}
\text { ridership }=f(\text { socioeconomic }, \text { built environment }, \text { transit system, city }) \\
\text { bikeshare trips }=f(\text { socioeconomic }, \text { built environment }, \text { bikeshare system, city })
\end{gathered}
$$

\subsection{Model Selection}

The modeling method selected was ordinal least squares (OLS). This method was the most common approach in the literature. In applying the OLS method, the goal was to achieve the highest goodness of fit (or r2) possible while meeting the OLS assumptions. This meant applying stepwise, backward and 10 
forward selection based on the Akaike Information Criterion (AIC) score initially. Manual selection followed to obtain a final model.

The transformations of the independent variables were made to correct for the non-normal distribution of observations of the dependent variables. Diagnostic plots were used to detect potential problems in meeting OLS assumptions. Multicollinearity was investigated using the Variable Inflation Factor (VIF) and by removing variables with VIFs larger than 4 .

The models and their variables are outlined in tables 3.1 and 3.2 below. 
Table 3.1. Variables and data sources for rapid rail average weekday boardings (Model 1)

\begin{tabular}{|c|c|c|c|c|}
\hline SCALE & CATEGORY & VARIABLES & SOURCE & HYPOTHESIS \\
\hline \multirow{4}{*}{ Station-level } & Dependent & $\begin{array}{l}\text { Rail Transit Station } \\
\text { Entries }\end{array}$ & \multirow{7}{*}{ Transit Agencies } & \\
\hline & \multirow{6}{*}{$\begin{array}{l}\text { Transit } \\
\text { Attributes }\end{array}$} & $\begin{array}{l}\text { Number of rapid rail lines } \\
\text { served by station }\end{array}$ & & \\
\hline & & $\begin{array}{l}\text { Commuter rail transfer } \\
\text { flag }\end{array}$ & & \\
\hline & & Heavy rail transit flag & & \\
\hline Line-level & & $\begin{array}{l}\text { Miles of longest rail line } \\
\text { served by station }\end{array}$ & & \\
\hline \multirow{2}{*}{ System-level } & & $\begin{array}{l}\text { Light and heavy rail } \\
\text { ridership in } 2016\end{array}$ & & \\
\hline & & Number of stations & & \\
\hline \multirow{3}{*}{0.1 -mile buffer } & \multirow{3}{*}{$\begin{array}{l}\text { Bikeshare } \\
\text { Attributes }\end{array}$} & $\begin{array}{l}\text { Number of bikeshare } \\
\text { stations in transit coverage } \\
\text { area }\end{array}$ & $\begin{array}{l}\text { Bikeshare operator } \\
\text { data }\end{array}$ & + \\
\hline & & $\begin{array}{l}\text { Presence of bikeshare } \\
\text { facility (1) interaction } \\
\text { with Bikeshare station } \\
\text { activity }\end{array}$ & & + \\
\hline & & $\begin{array}{l}\text { Number of average } \\
\text { weekday bikeshare trips }\end{array}$ & County, City GIS & + \\
\hline \multirow{4}{*}{0.33 -mile buffer } & \multirow{3}{*}{$\begin{array}{l}\text { Bicycle } \\
\text { Network }\end{array}$} & $\begin{array}{l}\text { Presence of bikeway } \\
\text { network }(0.25,0.33 \text { miles })\end{array}$ & County, City GIS & + \\
\hline & & $\begin{array}{l}\text { Length of on-street bicycle } \\
\text { network }\end{array}$ & County, City GIS & + \\
\hline & & Length of trails & County, City GIS & + \\
\hline & $\begin{array}{l}\text { Station Built } \\
\text { Environment }\end{array}$ & $\begin{array}{l}\text { Household density, } \\
\text { employment density, } \\
\text { activity density (housing + } \\
\text { employment) }\end{array}$ & ACS & + \\
\hline
\end{tabular}




\begin{tabular}{|c|c|c|c|c|}
\hline \multirow{4}{*}{$\begin{array}{l}\text { Census Block } \\
\text { Groups within } \\
0.33 \text {-mile buffer }\end{array}$} & & Land use mix & ACS & + \\
\hline & & $\begin{array}{l}\text { Street network } \\
\text { connectivity }\end{array}$ & County, City GIS & + \\
\hline & & $\begin{array}{l}\text { Job accessibility by car in } \\
30 \text { minutes }\end{array}$ & ACS & + \\
\hline & & $\begin{array}{l}\text { Job accessibility by transit } \\
\text { in } 45 \text { minutes }\end{array}$ & ACS & + \\
\hline \multirow{4}{*}{$\begin{array}{l}\text { Census Block } \\
\text { Groups within } \\
0.33 \text {-mile buffer }\end{array}$} & \multirow{4}{*}{$\begin{array}{l}\text { Socio- } \\
\text { demographics }\end{array}$} & $\begin{array}{l}\text { Percent of population that } \\
\text { is non-white }\end{array}$ & ACS & + \\
\hline & & $\begin{array}{l}\text { Percent of households } \\
\text { under the poverty level }\end{array}$ & ACS & + \\
\hline & & $\begin{array}{l}\text { Median household income } \\
\text { of block groups }\end{array}$ & ACS & + \\
\hline & & $\begin{array}{l}\text { Percent of households } \\
\text { with no automobile }\end{array}$ & ACS & + \\
\hline \multirow{11}{*}{$\begin{array}{l}\text { Relative } \\
\text { Location } \\
\text { Variables }\end{array}$} & \multirow{10}{*}{$\begin{array}{l}\text { Cities Dummy } \\
\text { Variables }(10)\end{array}$} & Washington, DC & WMATA & \\
\hline & & New York City, NY & NYMTA and PATH & \\
\hline & & Chicago, IL & CTA & \\
\hline & & Los Angeles, CA & Metro & \\
\hline & & Portland, OR & TriMet & \\
\hline & & Philadelphia, PA & SETPA and PATCO & \\
\hline & & San Francisco, CA & BART & \\
\hline & & Minneapolis, MN & Metro Transit & \\
\hline & & Boston, MA & MBTA & \\
\hline & & Denver, CO & RTD & \\
\hline & Centrality & CBD flag & Google Maps & \\
\hline
\end{tabular}


Table 3.2. Variables and data sources for average weekday bikeshare trips (Model 2)

\begin{tabular}{|c|c|c|c|c|}
\hline SCALE & CATEGORY & VARIABLES & SOURCE & HYPOTHESIS \\
\hline Station-level & Dependent & $\begin{array}{l}\text { Rail Transit Station } \\
\text { Entries }\end{array}$ & Transit Agencies & \\
\hline \multirow{3}{*}{ 0.1-mile buffer } & \multirow{3}{*}{$\begin{array}{l}\text { Bikeshare } \\
\text { Attributes }\end{array}$} & $\begin{array}{l}\text { Number of bikeshare } \\
\text { stations in transit coverage } \\
\text { area }\end{array}$ & $\begin{array}{l}\text { Bikeshare operator } \\
\text { data }\end{array}$ & + \\
\hline & & $\begin{array}{l}\text { Presence of bikeshare } \\
\text { facility (1) interaction } \\
\text { with Bikeshare station } \\
\text { activity }\end{array}$ & & + \\
\hline & & $\begin{array}{l}\text { Number of average } \\
\text { weekday bikeshare trips }\end{array}$ & County, City GIS & + \\
\hline \multirow{3}{*}{ 0.33-mile buffer } & \multirow{3}{*}{$\begin{array}{l}\text { Bicycle } \\
\text { Network }\end{array}$} & $\begin{array}{l}\text { Presence of bikeway } \\
\text { network }(0.25,0.33 \text { miles })\end{array}$ & County, City GIS & + \\
\hline & & $\begin{array}{l}\text { Length of on-street bicycle } \\
\text { network }\end{array}$ & County, City GIS & + \\
\hline & & Length of trails & County, City GIS & + \\
\hline \multirow{7}{*}{$\begin{array}{l}\text { Census Block } \\
\text { Groups within } \\
0.33 \text {-mile buffer }\end{array}$} & \multirow{5}{*}{$\begin{array}{l}\text { Station Built } \\
\text { Environment }\end{array}$} & $\begin{array}{l}\text { Density: Housing density, } \\
\text { population density, } \\
\text { employment density, } \\
\text { activity density (housing + } \\
\text { employment) }\end{array}$ & ACS & + \\
\hline & & Land use mix & ACS & + \\
\hline & & $\begin{array}{l}\text { Street network } \\
\text { connectivity }\end{array}$ & County, City GIS & + \\
\hline & & $\begin{array}{l}\text { Job accessibility by car in } \\
30 \text { minutes }\end{array}$ & ACS & + \\
\hline & & $\begin{array}{l}\text { Job accessibility by transit } \\
\text { in } 45 \text { minutes }\end{array}$ & ACS & + \\
\hline & Socioeconomic & $\begin{array}{l}\text { Percent of households } \\
\text { with no automobile }\end{array}$ & ACS & + \\
\hline & & Washington, DC & Capital Bikeshare & \\
\hline
\end{tabular}




\begin{tabular}{|c|c|c|c|}
\hline \multirow{9}{*}{$\begin{array}{l}\text { Relative } \\
\text { Location } \\
\text { Variables }\end{array}$} & \multirow{9}{*}{$\begin{array}{l}\text { Cities Dummy } \\
\text { Variables (10) }\end{array}$} & New York City, NY & CitiBike \\
\hline & & Chicago, IL & Divvy \\
\hline & & Los Angeles, CA & Metro \\
\hline & & Portland, OR & Biketown \\
\hline & & Philadelphia, PA & Indego \\
\hline & & San Francisco, CA & GoBike \\
\hline & & Minneapolis, MN & Nice ride \\
\hline & & Boston, MA & Hubway \\
\hline & & Denver, CO & B-Cycle \\
\hline
\end{tabular}




\subsection{Cities}

The database contains data pertaining to ten cities with twelve transit agencies, ten bikeshare operators, and seven commuter rail operators, as shown in table 3.3.

Table 3.3. Characteristics of US cities in the study

\begin{tabular}{l|c|l|l|l|l|l}
\hline CITY & $\begin{array}{l}\text { MSA 2017 } \\
\text { POPULATION }\end{array}$ & $\begin{array}{l}2016 \\
\text { RIDERSHIP }\end{array}$ & $\begin{array}{l}\text { RAIL } \\
\text { RAPID } \\
\text { TRANSIT } \\
\text { STATIONS }\end{array}$ & $\begin{array}{l}\text { SYSTEM } \\
\text { LENGTH } \\
\text { (MILES) }\end{array}$ & $\begin{array}{l}\text { BIKESHARE } \\
\text { TRIPS }\end{array}$ & $\begin{array}{l}\text { BIKESHARE } \\
\text { STATIONS }\end{array}$ \\
\hline Boston & $4,836,531$ & $167,167,900$ & 62 & 78 & $1,313,174$ & 200 \\
\hline Chicago & $9,533,040$ & $230,204,200$ & 144 & 102.8 & $3,829,014$ & 585 \\
\hline $\begin{array}{l}\text { Washington, } \\
\text { DC }\end{array}$ & $6,131,977$ & $229,595,700$ & 91 & 117 & $3,757,777$ & 487 \\
\hline Denver & $2,888,227$ & $24,871,200$ & 58 & 58.5 & 419,612 & 96 \\
\hline Los Angeles & $13,353,907$ & $112,782,300$ & 95 & 105 & 229,255 & 126 \\
\hline Minneapolis & $3,600,618$ & $23,811,200$ & 37 & 23 & 266,674 & 202 \\
\hline $\begin{array}{l}\text { New York } \\
\text { City }\end{array}$ & $20,320,876$ & $2,669,536,300$ & 431 & 245 & $16,364,657$ & 799 \\
\hline Portland & $2,453,168$ & $49,173,700$ & 97 & 60 & 311,206 & 141 \\
\hline Philadelphia & $6,096,120$ & $102,611,100$ & 63 & 50.9 & 788,907 & 107 \\
\hline San Francisco & $4,727,357$ & $129,268,100$ & 45 & 109 & 519,700 & 272 \\
\hline Total & $73,941,821$ & $3,739,021,700$ & 1,123 & 949 & $27,799,976$ & 3,015 \\
\hline
\end{tabular}

Not all cities with rail rapid transit could be included in the analysis. Reasons for exclusion from the analysis include lack of open or accessible data for 2017 and less than one year of bikeshare operations. The final list of ten cities are in the table below.

In terms of population size, New York City is the largest city followed by Los Angeles and Chicago. This order does not hold for other characteristics such as ridership, which is led by New York City, Chicago, 
and Washington, DC. In terms of bikeshare trips, the three largest cities are New York City, Chicago and Washington, DC. Minneapolis, Denver, and Portland are the mid-size cities in this study.

Large metro area populations are not good predictors of the amount of bikeshare trips, as shown in Figure 3.1, demonstrating the value of a multiple regression model. Despite Los Angeles being the second largest city, it is also the city with lowest number of bikeshare trips taken in 2017 among those in this study. While New York City is twice as large as Chicago is in population size, it also observed five times as many public transit trips and four times as many bikeshare trips. Boston had the fourth highest number of bikeshare trips despite being the seventh largest city.

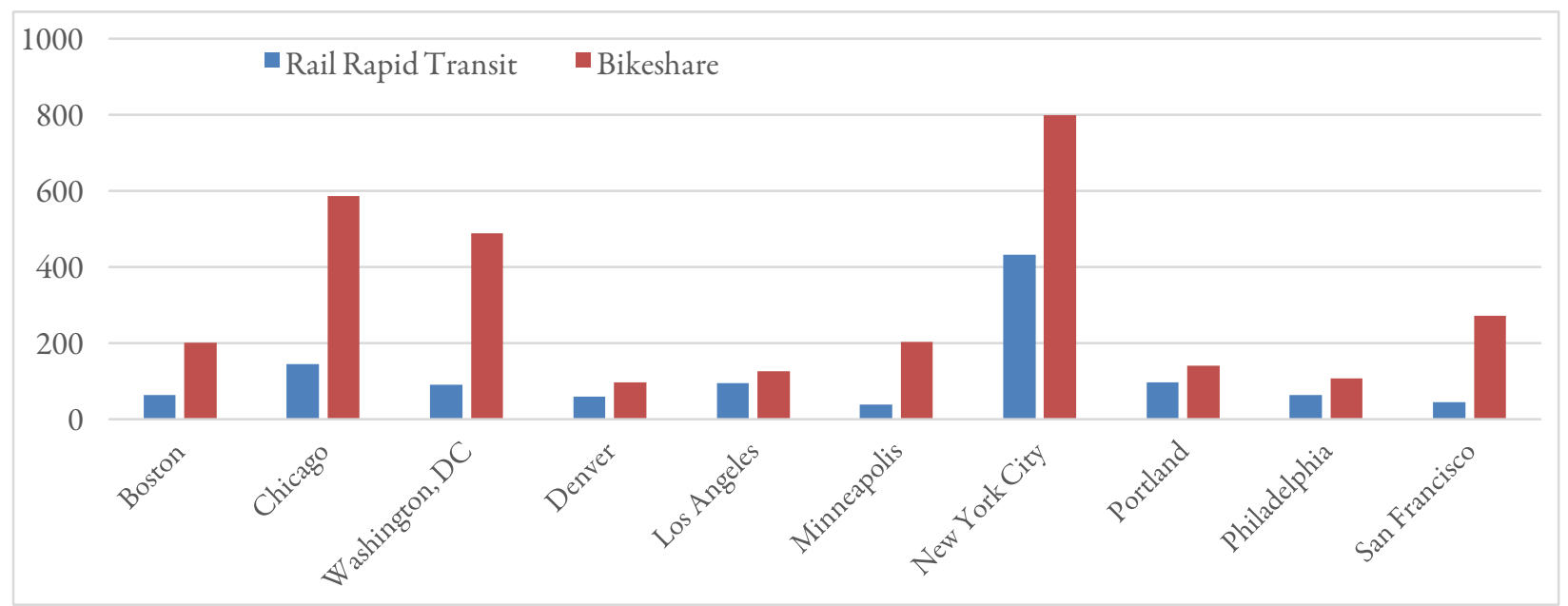

Figure 3.1. Rapid rail stations and bikeshare stations by city

In terms of supply of transit and bikeshare facilities, New York City, Chicago and Washington, DC once again stand apart from other cities. These cities have had rapid rail transit since at least the year 2000. Most cities have also possessed bikeshare for at least 2 years, the only exception being Los Angeles and Portland.

\subsection{Definition of Station Areas}

Station areas are defined by Euclidean buffers, which refer to the area contained within the circumference of a certain radius. Rail rapid transit station areas were defined by a 0.33 -mile $(530$ meter) radius. Bikeshare station areas were defined by a 0.5 -mile ( 800 meter) radius as displayed in Figure 3.2. The influence of bikeshare on transit and vice-versa is captured within a 0.1 -mile (150 meter) radius. 


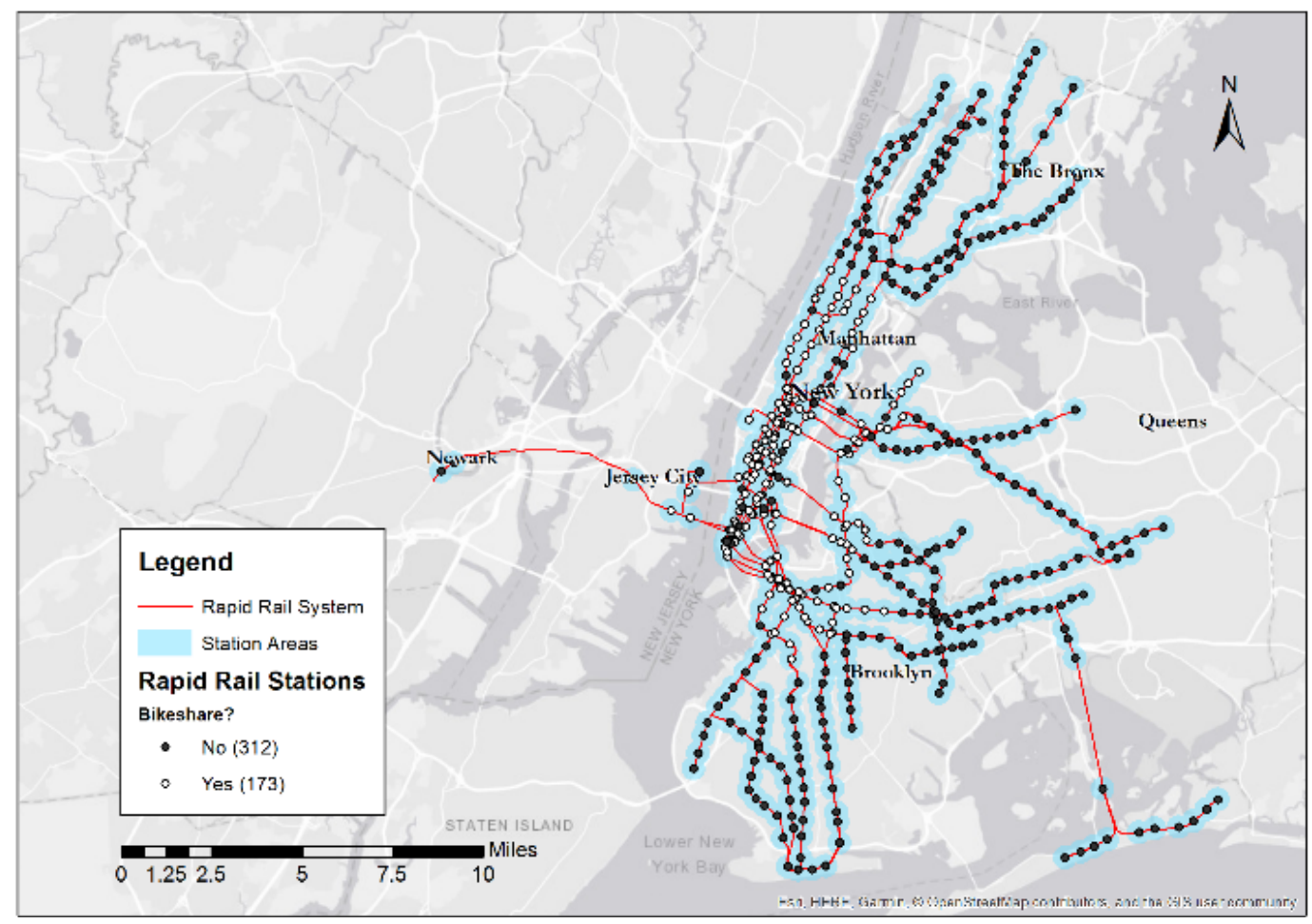

New York City

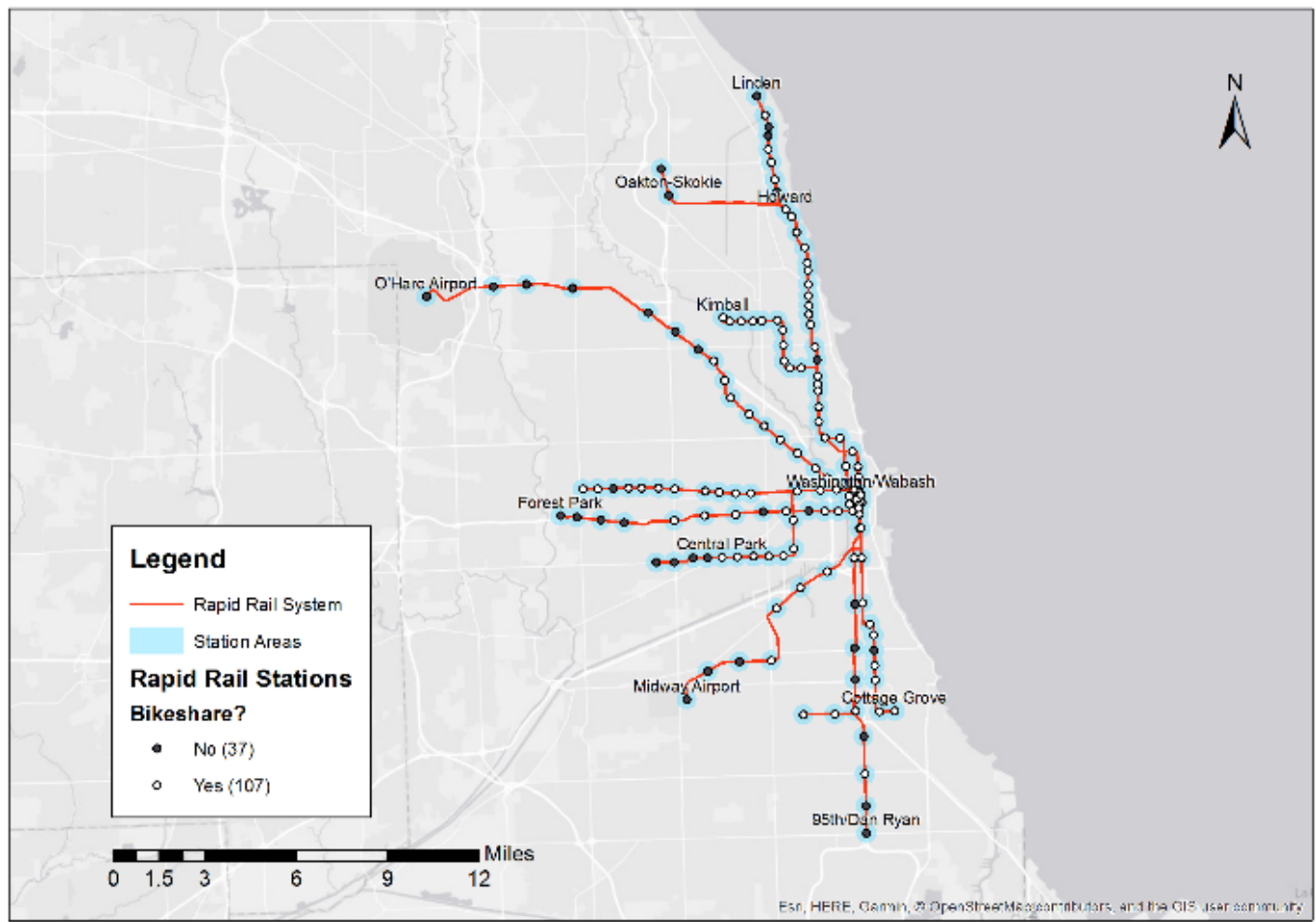

Chicago 


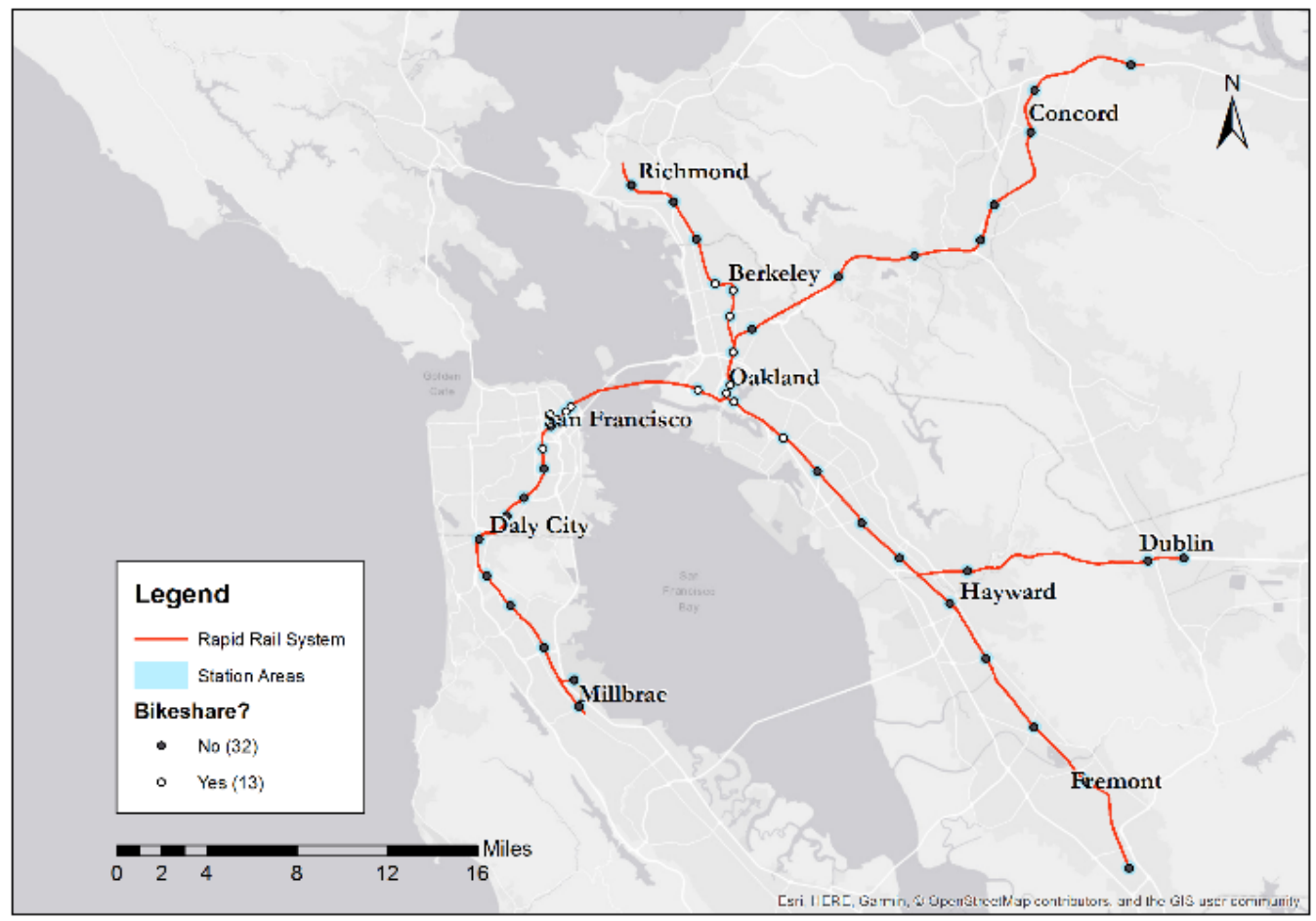

San Francisco

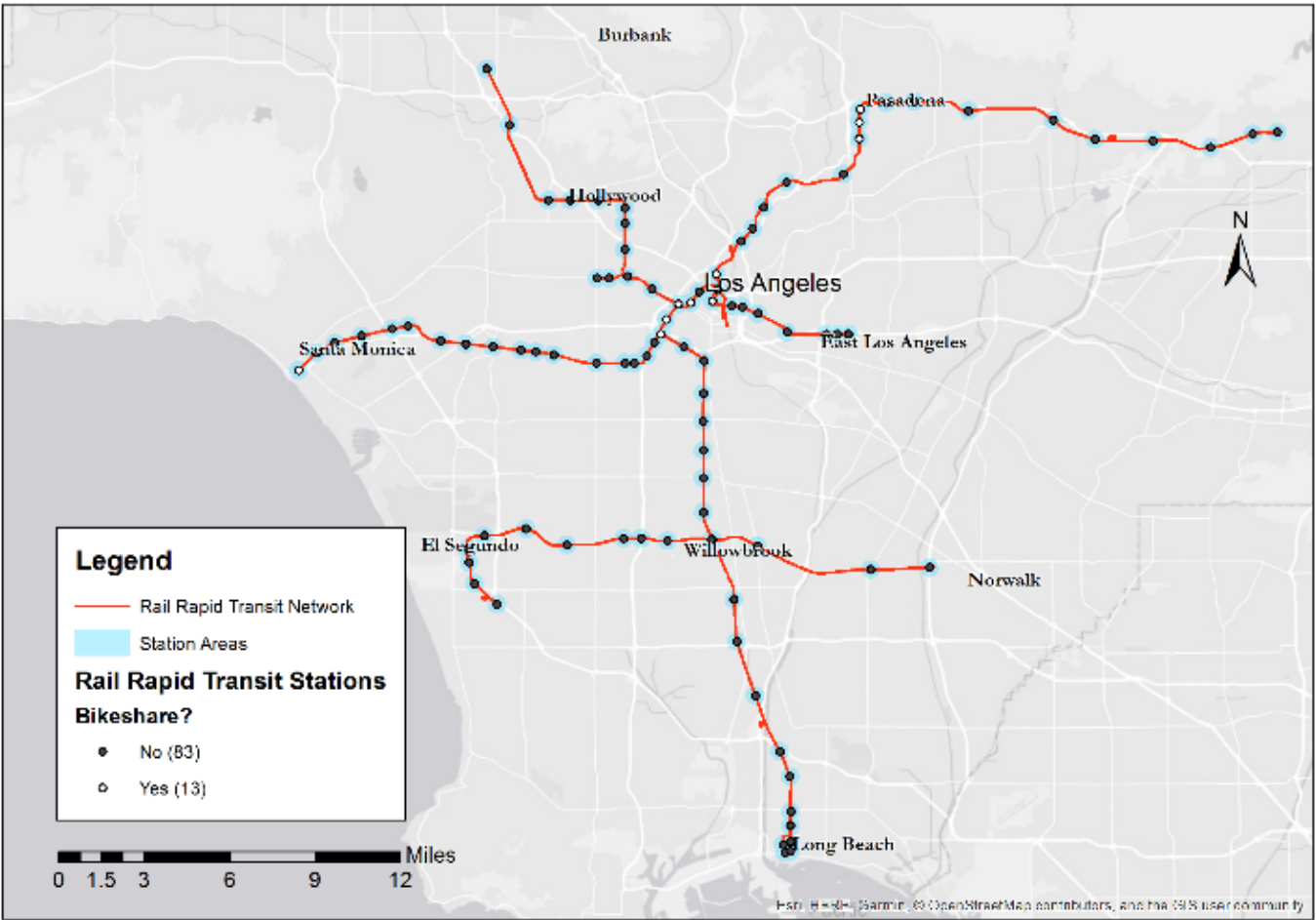

Los Angeles 


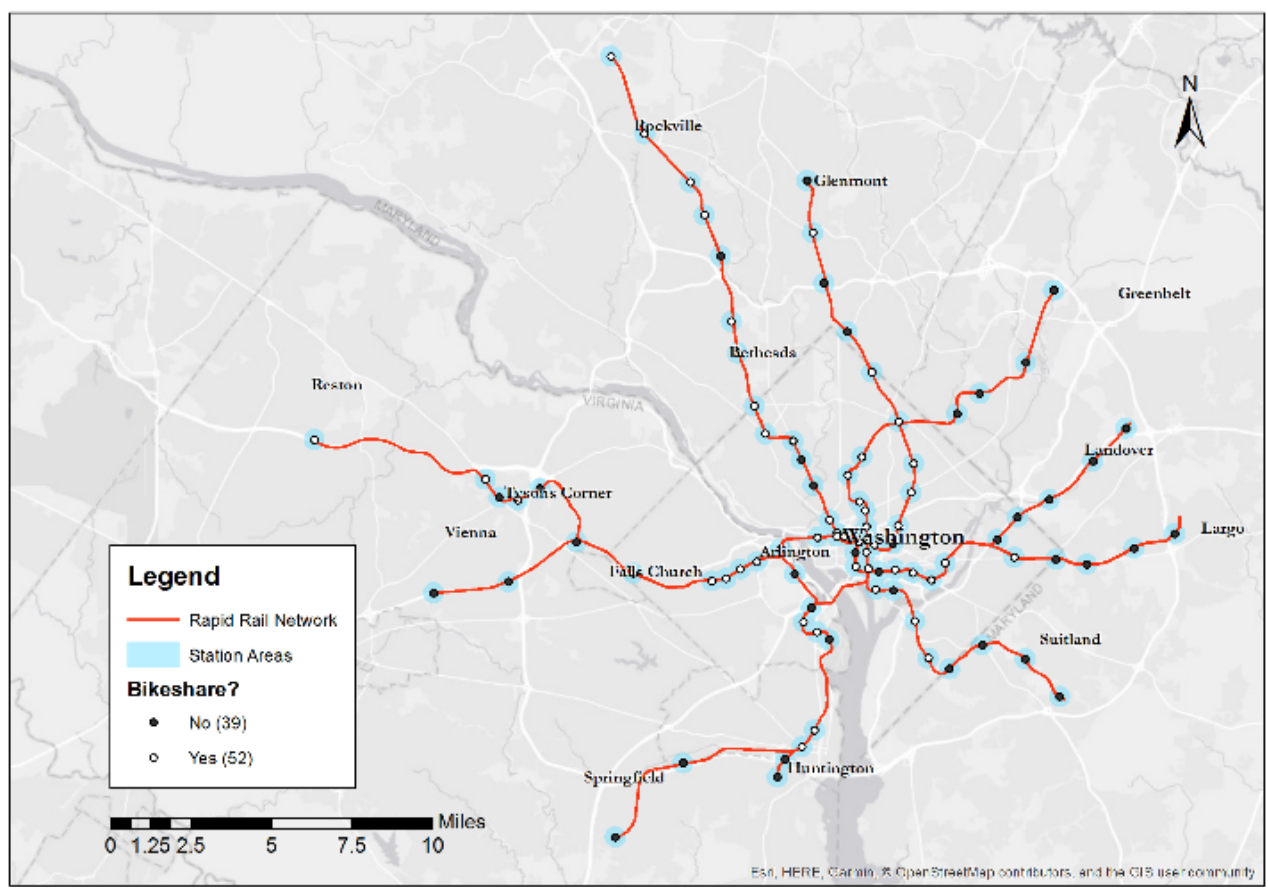

Washington, DC

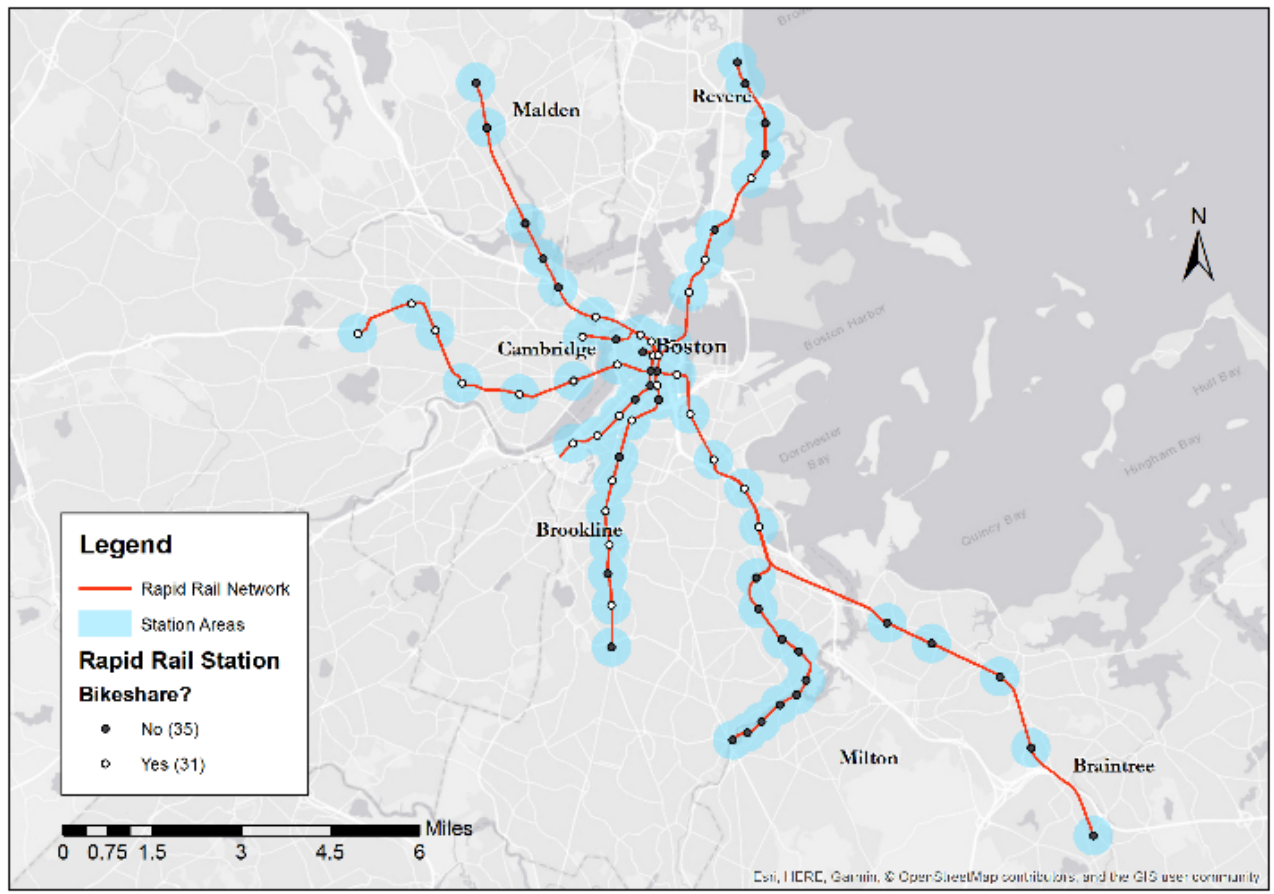

Boston, MA 


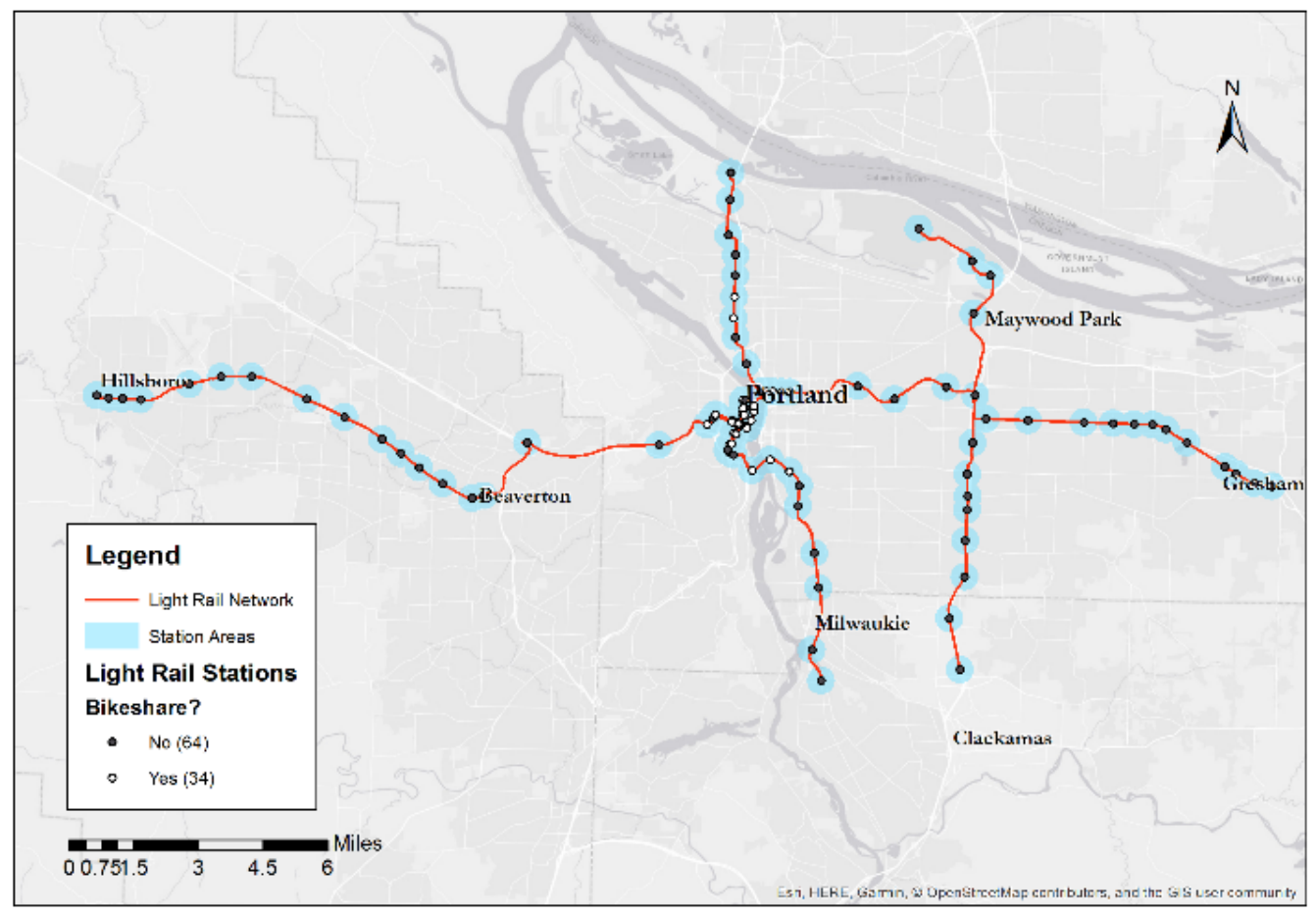

Portland

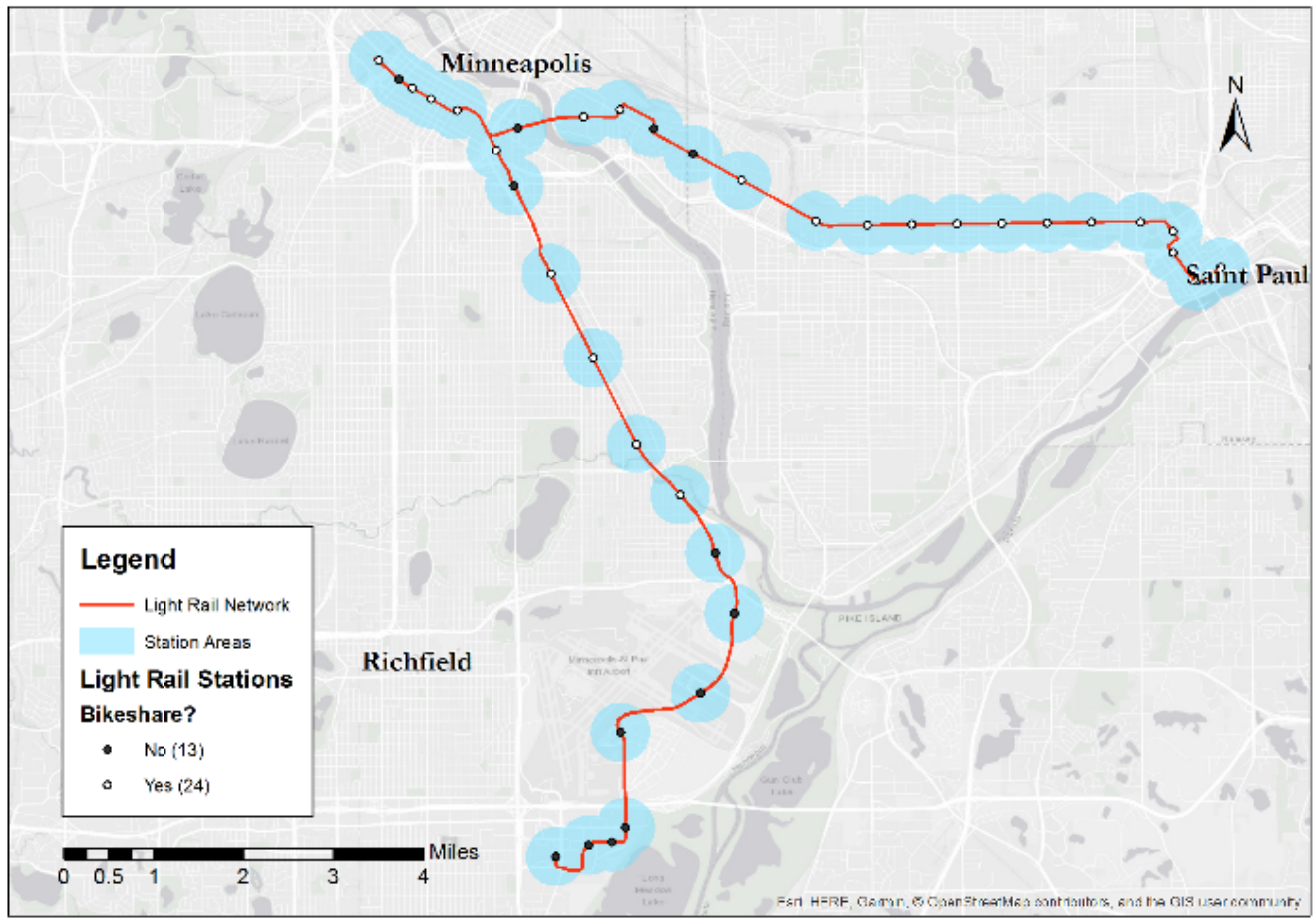

Minneapolis 


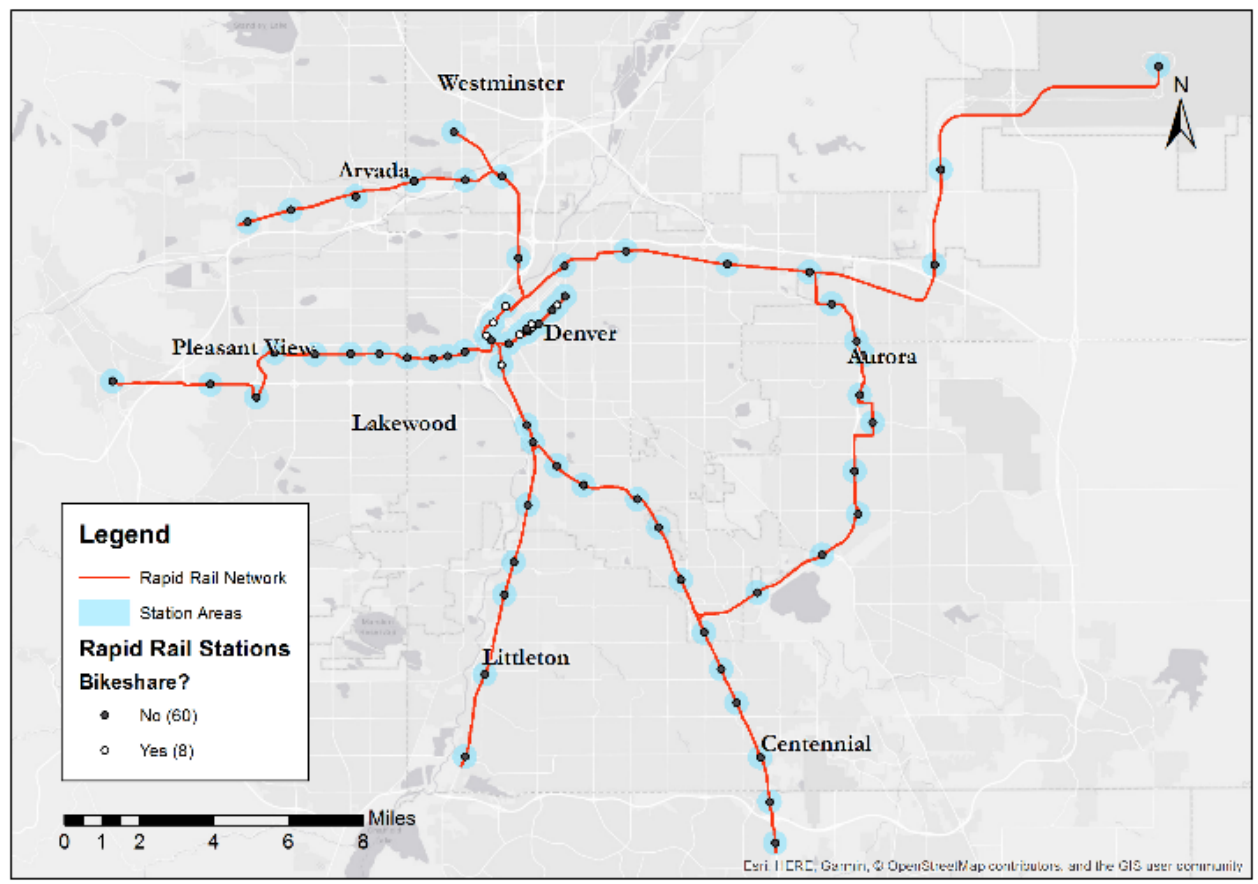

Denver

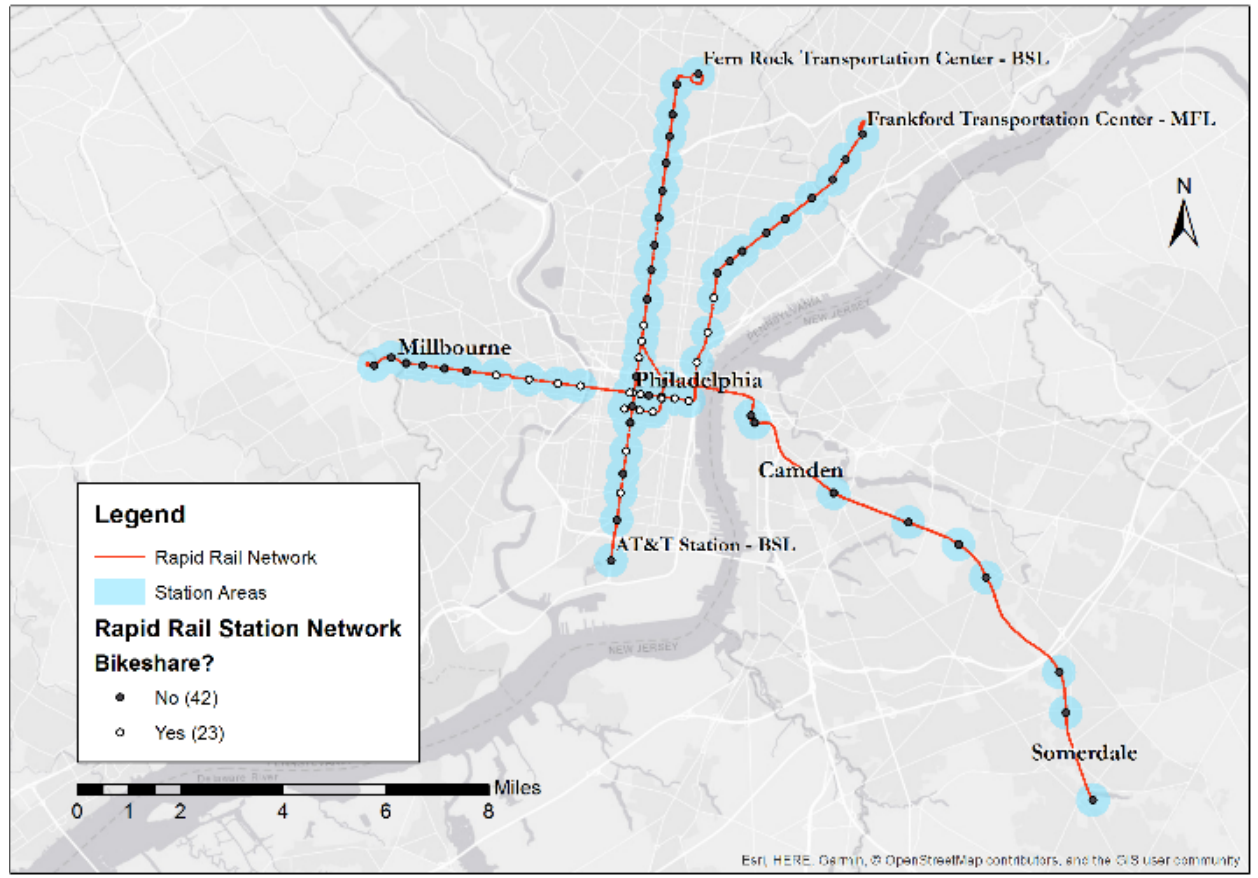

Philadelphia

Figure 3.2. Metropolitan areas and bikeshare presence at rapid rail stations 
As shown in Figure 3.2, the rapid rail transit networks vary noticeably across the dataset in terms of network coverage, the scales of the city areas, the spacing between stations, and the distribution of bikeshare docks at transit stations. New England cities (Philadelphia, New York City, Boston) have closely spaced stops, enough for 0.33-mile station area buffers to overlap, while stations in Los Angeles and San Francisco are spaced further apart. Washington, DC and Portland meanwhile have markedly greater station density in the city core or Central Business District while Minneapolis and San Francisco have stations that are spaced uniformly apart. Finally, Washington, DC and Los Angeles are the only cities that have bikeshare docks located in the inner core as well as in satellite city centers at rapid transit line terminals far from the Central Business District.

Table 3.4 Rapid rail stations with and without bikeshare by city

\begin{tabular}{l|c|c|c|c}
\hline CITY & $\begin{array}{c}\text { STATIONS WITH } \\
\text { BIKESHARE (1) }\end{array}$ & $\begin{array}{c}\text { STATIONS WITHOUT } \\
\text { BIKESHARE (2) }\end{array}$ & TOTAL (3) & $\begin{array}{c}\text { RATIO OF } \\
\text { (1) TO (3) }\end{array}$ \\
\hline Boston & 31 & 35 & 66 & 0.47 \\
\hline Chicago & 107 & 37 & 914 & 0.74 \\
\hline Washington, DC & 52 & 39 & 68 & 0.57 \\
\hline Denver & 8 & 60 & 96 & 0.14 \\
\hline Los Angeles & 13 & 83 & 37 & 0.65 \\
\hline Minneapolis & 24 & 13 & 485 & 0.35 \\
\hline New York City & 173 & 312 & 98 & 0.35 \\
\hline Portland & 34 & 32 & 45 & 0.29 \\
\hline Philadelphia & 13 & 42 & 65 & 0.35 \\
\hline San Francisco & 23 & 717 & 1195 & 0.40 \\
\hline Total & 478 & & 94 & 91 \\
\hline
\end{tabular}

Chicago is the city with the highest percentage of rail rapid transit stations with bikeshare stations to total number of rail rapid transit stations at $74 \%$ while New York City has the highest number of 
observations with bikeshare flags, referring to 312 stations with bikeshare docks within 0.1 miles of station centroid. New York City has more than three times as many stations as the next biggest rail rapid transit system in Chicago, and nearly five times as many stations as the third largest system in Portland.

Cities with the lowest percentage of stations with bikeshare docks is Denver at $9 \%$. The city with the smallest amount of stations is Philadelphia with 45 stations. The average percentage of stations with bikeshare across cities included in this study is $40 \%$.

Table 3.5 Bikeshare stations serving rapid rail stations by city

\begin{tabular}{l|c|c|c|c}
\hline \multicolumn{1}{c|}{ CITY } & $\begin{array}{c}\text { STATIONS WITH } \\
\text { RAPID RAIL (1) }\end{array}$ & $\begin{array}{c}\text { STATIONS WITHOUT } \\
\text { RAPID RAIL (2) }\end{array}$ & TOTAL (3) & $\begin{array}{c}\text { RATIO OF } \\
(1) \text { TO (3) }\end{array}$ \\
\hline Boston & 44 & 149 & 193 & 0.23 \\
\hline Chicago & 126 & 459 & 585 & 0.22 \\
\hline Washington, DC & 61 & 424 & 485 & 0.13 \\
\hline Denver & 19 & 70 & 116 & 0.10 \\
\hline Los Angeles & 12 & 104 & 201 & 0.12 \\
\hline Minneapolis & 25 & 176 & 576 & 0.18 \\
\hline New York City & 104 & 472 & 117 & 0.23 \\
\hline Portland & 27 & 90 & 120 & 0.18 \\
\hline Philadelphia & 21 & 99 & 224 & 0.09 \\
\hline San Francisco & 21 & 203 & & \\
\hline
\end{tabular}

Boston, Chicago, and Denver have the highest percentage of bikeshare stations with rapid rail transit at $23 \%, 22 \%$, and $21 \%$ of bikeshare stations. Figure 3.3 shows the number of average weekday bikeshare trips and number of docks by city. Chicago, Boston and Washington, DC are the only cities that observe more bikeshare trips per day than docks available. 


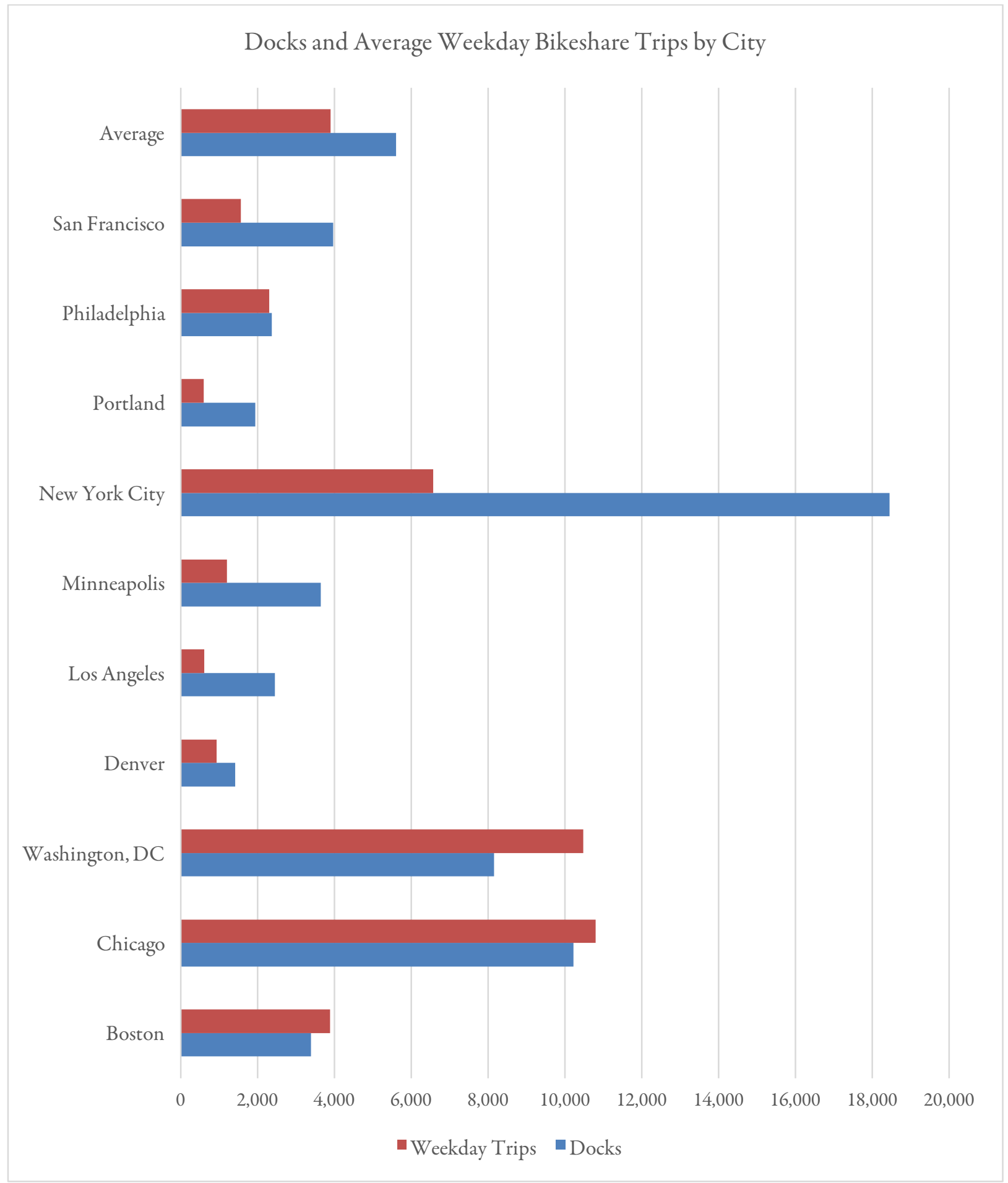

Figure 3.3. Docks and average weekday trips by City 


\subsection{Dependent Variable}

Average weekday boardings and average weekday bikeshare trips are the dependent variables for Model 1 and Model 2, respectively.

New York City an overwhelming share of observations. In Model 1 it contributes to $38 \%$ of observations, the highest median of average weekday boardings across cities, and outliers due to stations with many line transfers. In model 2 it comprises $21 \%$ of observations of average weekday bikeshare trips

The final dataset contains 1,119 observations, with some observations due to missing data from the ACS 5-year survey and some due to being located within airports and thus not able to serve bicycle accessegress trips. The high number of outliers skewed towards the lower values makes the median a better indicator of centrality.

Data were not available for the San Jose Valley Transit Authority light rail system. Thus, bikeshare and light rail stations from the city of San Jose as part of the San Francisco (Bay Area) datasets.

Each city has its own shapefile integrating American Community Survey, Smart Location Database, Accessibility Observatory, and bikeshare and rail rapid transit network characteristics. These environments enabled capturing the influence (if any) of locating bikeshare docks immediately adjacent to (within 500 feet of) transit stations.

Data were not available for the Long Beach City bikeshare system as part of the Los Angeles Metropolitan Area data collection. 
Table 3.6 Descriptive statistics of average weekday boardings by city, overall, and excluding New York City

\begin{tabular}{|c|c|c|c|c|c|}
\hline CITY & COUNT & MEAN & MEDIAN & MINIMUM & MAXIMUM \\
\hline Boston & 62 & 7,848 & 6,496 & 571 & 24,763 \\
\hline Chicago & 143 & 4,204 & 3,136 & 513 & 21,407 \\
\hline Washington, DC & 91 & 6,728 & 5,300 & 557 & 29,197 \\
\hline Denver & 58 & 3,833 & 2,203 & 289 & 30,806 \\
\hline Los Angeles & 93 & 3,825 & 2,268 & 444 & 53,248 \\
\hline Minneapolis & 37 & 2,117 & 1,628 & 220 & 5,955 \\
\hline New York City & 431 & 13,787 & 7,623 & 289 & 202,363 \\
\hline Portland & 97 & 1,273 & 978 & 345 & 6,915 \\
\hline Philadelphia & 63 & 4,955 & 3,507 & 181 & 32,243 \\
\hline San Francisco & 44 & 9,442 & 6,592 & 760 & 48,526 \\
\hline All observations & 1,119 & 8,177 & 4,530 & 181 & 202,363 \\
\hline Excluding New York City & 688 & 4,662 & 3,006 & 181 & 53,248 \\
\hline
\end{tabular}


Table 3.7 Descriptive statistics of average weekday bikeshare trips by city, overall, and excluding New York City

\begin{tabular}{|c|c|c|c|c|c|}
\hline CITY & COUNT & MEAN & MEDIAN & MINIMUM & MAXIMUM \\
\hline Boston & 193 & 20 & 17 & 0 & 116 \\
\hline Chicago & 585 & 18 & 10 & 0 & 201 \\
\hline Washington, DC & 485 & 22 & 10 & 0 & 232 \\
\hline Denver & 89 & 10 & 9 & 0 & 34 \\
\hline Los Angeles & 116 & 5 & 3 & 0 & 27 \\
\hline Minneapolis & 201 & 6 & 4 & 0 & 33 \\
\hline New York City & 576 & 11 & 7 & 0 & 99 \\
\hline Portland & 117 & 5 & 5 & 0 & 21 \\
\hline Philadelphia & 120 & 19 & 15 & 0 & 73 \\
\hline San Francisco & 224 & 7 & 4 & 0 & 47 \\
\hline All observations & 2706 & 14 & 7 & 0 & 232 \\
\hline Excluding New York City & 2130 & 15 & 7 & 0 & 232 \\
\hline
\end{tabular}




\subsubsection{Transformation of Dependent Variables}

The observations of average weekday boarding clearly do not follow a normal distribution. This is considered as a fundamental assumption in maintaining the IIND assumption of OLS regressions.

From comparing different types of transformations on the independent variable, a natural logarithm transformation brings the log of average weekday boardings closer to a symmetrical normal distribution than the highly-skewed distribution of average weekday boardings. This is shown in Figure 3.4. This is a common approach applied in the literature. It is also useful for comparing variable influence because loglog regression coefficients can be interpreted as elasticities.

The distribution of average weekday bikeshare trips is also skewed heavily to the left thus a $\log$ transformation approximates the distribution closer to a symmetrical normal distribution. 

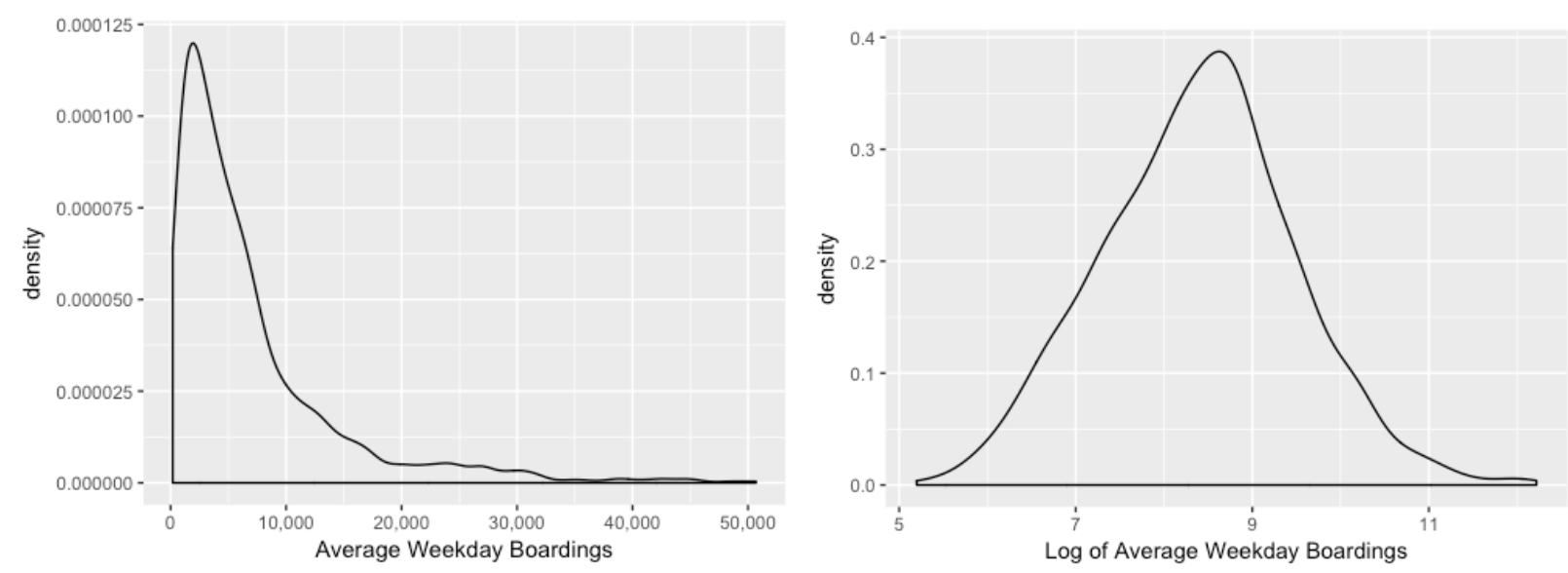

Figure 3.4. Geometric density plots of Average Weekday Boardings and Log of Average Weekday Boardings
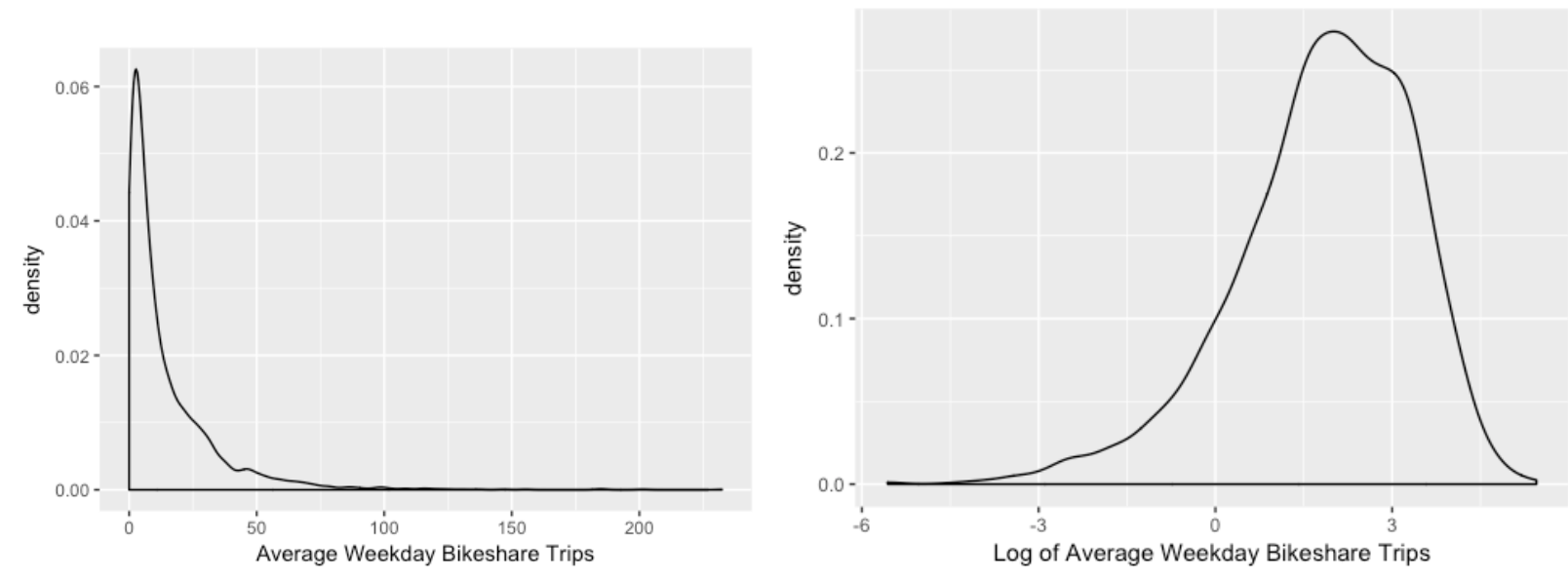

Figure 3.5 Density plots of Average Weekday Bikeshare Trips and log of Average Weekday Bikeshare Trips

\subsection{Explanatory Variables}

Both Model 1 and Model 2 incorporate socioeconomic, built environment, transit system, bikeshare system, and relative location variables. A diversity of variables used thanks to the availability of open data meant many variables were naturally correlated.

\subsubsection{Socioeconomic and demographic}

In the United States, race can be a powerful proxy to socioeconomic variables. This is well documented to be associated to decades of racial discrimination practices by transportation agencies and the real estate industry. 
Percentage of non-white population is a proxy for income, percent of households under the poverty level, and percent of car-free households. Intersection density is also

\subsubsection{Built Environment}

The built environment variables intend to measure the station areas influence on the willingness of persons to walk, bike, or take public transit. These measures include various forms of density, street network connectivity, land use mix, and jobs accessibility. Intersection density is commonly used as a proxy for activity density.

Household density, employment density, and activity density are the types of density that were calculated for each station area. Household density can be expressed with the following equation:

$$
\text { Equation: Household density }=\frac{\text { Households }}{\text { Station Area }}
$$

Activity density is expressed as the density of population and employment over an area:

$$
\text { Equation: } \text { Activity density }=\frac{\text { Population }+ \text { Employment }}{\text { Station Area }}
$$

Intersection density is the number of intersections within the given area, as expressed below:

Equation: Intersection density $=\frac{\text { Intersections, excluding automobile- } \text { oriented }}{\text { Station Area }}$ 


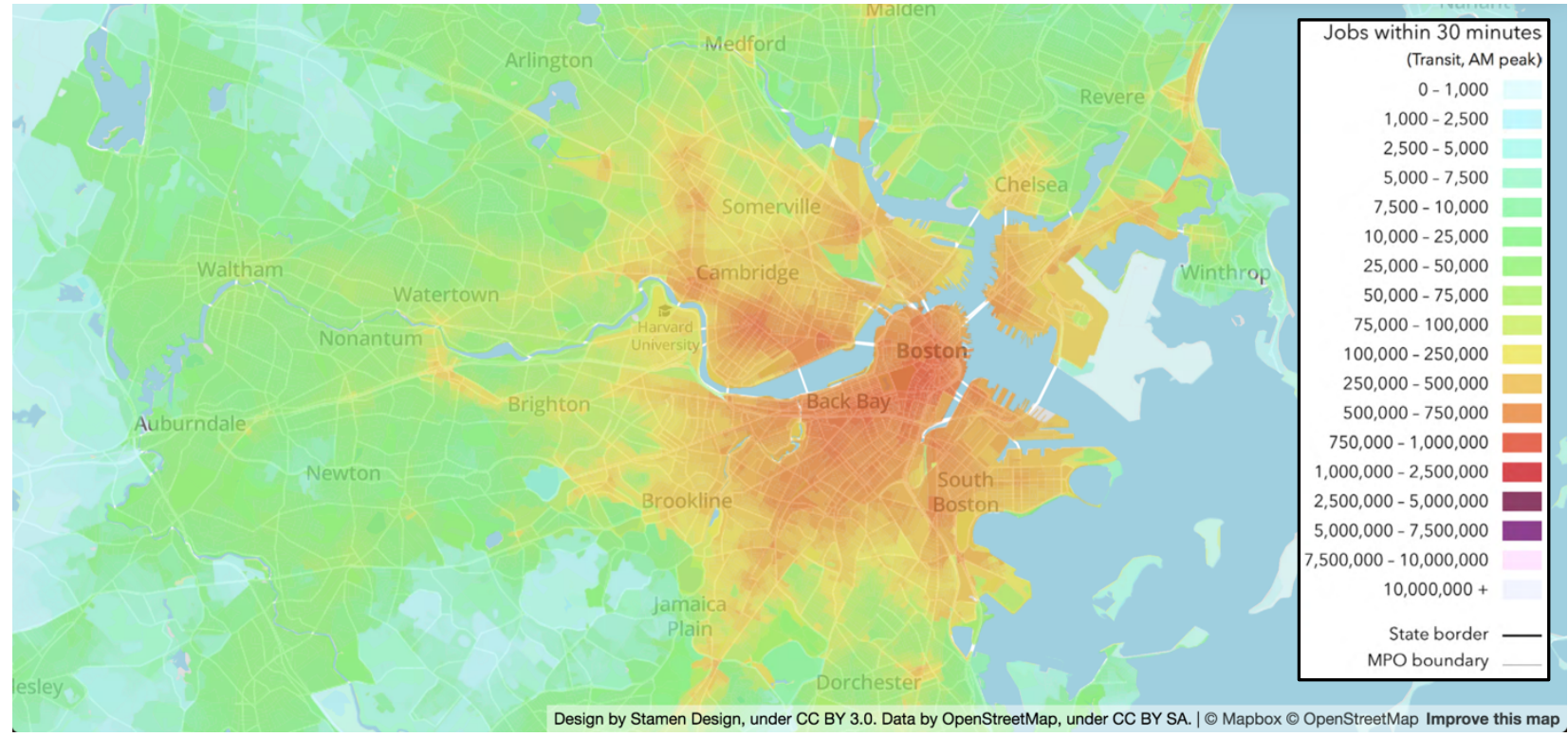

Figure 3.6. Jobs accessible by transit in 30 minutes (UMN Accessibility Observatory 2016)

Jobs accessible by transit in 30 minutes, as shown in Figure 3.6, were obtained from the University of Minnesota Accessibility Observatory was the only built environment variable from the year 2016. Other built environment data were not available at when the data collection phase took place.

The ratio of jobs accessible by car in 30 minutes to jobs accessible by transit in 45 minutes was calculated to account for the competitiveness of transit over other modes, serving as a proxy for frequent bus lines connecting at rail rapid transit stations. This was calculated using the following formula:

Equation: $\quad$ Job Accessibility Diversity $=\frac{\text { Jobs accessible by transit in } 45 \text { minutes (2014) }}{\text { Jobs accessible by car in } 30 \text { minutes (2014) }}$

\subsubsection{Transit system variables}

Transit system variables are captured at the system-level, line-level, and station-level as shown in Figure 3.7. Variables at the station level include a heavy rail flag, commuter rail transfer flag, and number of rail rapid transit lines served. Line and System variables are length of longest transit line serving a station, number of stations for the whole system, and heavy and light rail ridership for 2016. 

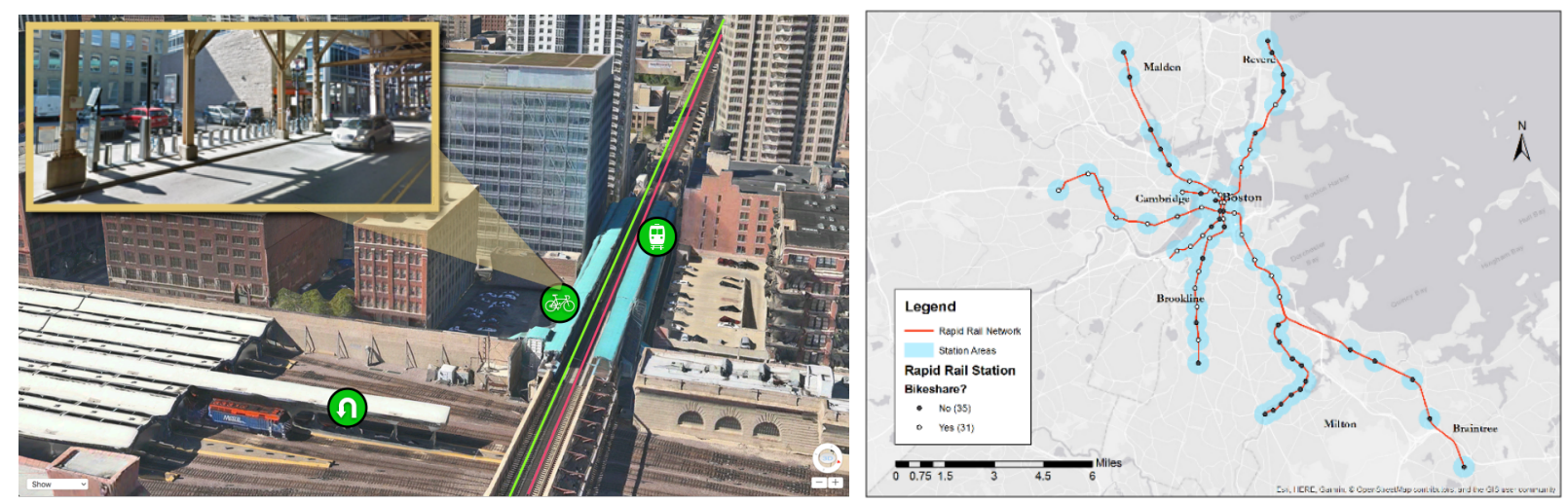

Figure 3.7. Transit system variables were collected at the station-level (left) and at the system-level (right).

\subsubsection{Bicycle and Bikeshare Facilities Variables}

Bicycle and bikeshare facility data were collected regarding the station areas as defined in Section 3.7. These include percentage of commuters that bike to work, length of miles of off-street (trails) and onstreet bicycle facilities, and presence of bicycle and bikeshare facilities.

\subsubsection{Relative Location}

Cities and central business districts are the relative location variables tested in the model.

\subsection{Cross-Validation}

A cross-validation procedure is applied to test the predictive powers of the models specified in this analysis. The three most common approaches to cross-validation are holdout, $\mathrm{k}$-fold, and bootstrapping methods. The general procedure involves splitting the data and comparing predicted values with actual observations. The difference between the predictions and the actual observations, also known as the error, is considered an evaluation of the model.

The Mean Absolute Error (MAE) is used as criteria for comparing models and is calculated in the following way:

Equation: $M A E=\frac{1}{n} \sum\left|y_{j}-x_{j}\right| \quad$ where

$n$ is number of observations

$y_{j}$ is observation for row $j$ 


$$
x_{j} \text { is predition for row } j \text { based on test set }
$$

A lower Mean Absolute Error score is indicative of better model performance.

The hold-out method is a manual approach that may miss parts of the dataset from the cross-validation while the k-fold method is comprehensive in using all parts of the dataset in evaluating the performance.

\subsubsection{Hold-out Method}

The hold-out method consists of dividing the data into training set and test set, also referred to as the hold-out set. The model parameters are estimated with the training set and used to predict the values of the dependent variable with the test set. A $25 \%$ ratio was used to split the dataset so $75 \%$ of the data were used to estimate the parameters used to predict the dependent on the hold-out set. The predictions are subtracted from the actual observations to obtain the error.

\subsubsection{K-Fold Method}

The $\mathrm{k}$-fold method is applied thanks to the caret package for $\mathrm{r}$. It is similar to the holdout method except the sample is divided into $k-1$ subsets which serve as training sets and the remainder is the test set. It is more robust because it considers all observations in the sample. 


\subsection{DESCRIPTIVE ANALYSIS}

The following model predicts average weekday boardings as a function of socioeconomic, built environment, transit service, bicycle network, and bikeshare characteristics. Descriptive statistics and data collection methodology precede an analysis of the relationship between boardings and various characteristics.

\subsection{Dependent Variables}

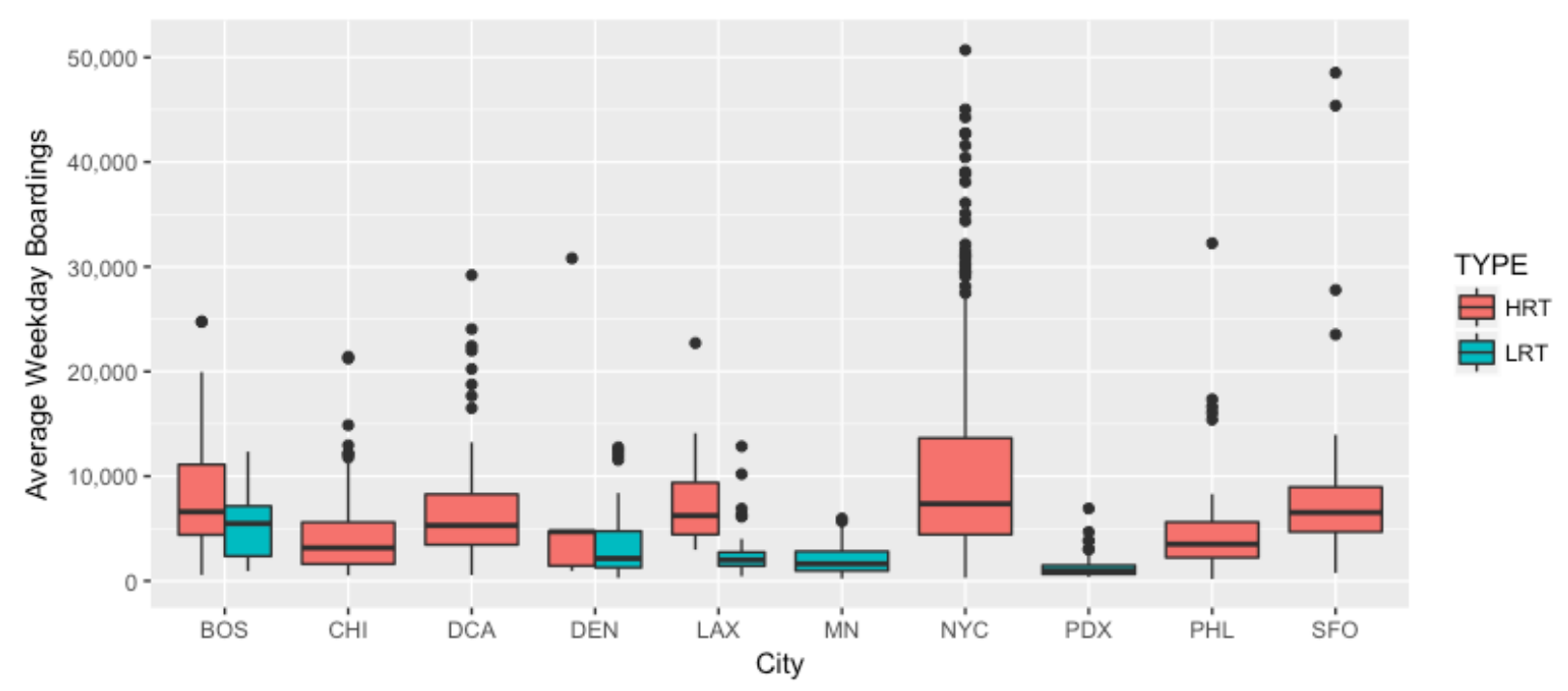

Figure 4.1. Boxplot of average weekday boardings by rail mode by city, excluding 17 outliers

The above boxplot illustrates boardings are higher on stations serving heavy rail systems, as expected since heavy rail systems provide greater capacity. Heavy rail stations also experience the most variation in average weekday boardings. To a lesser degree, we can observe younger bikeshare systems are not experiencing the same level of usage as more mature systems (Figure 4.2). 


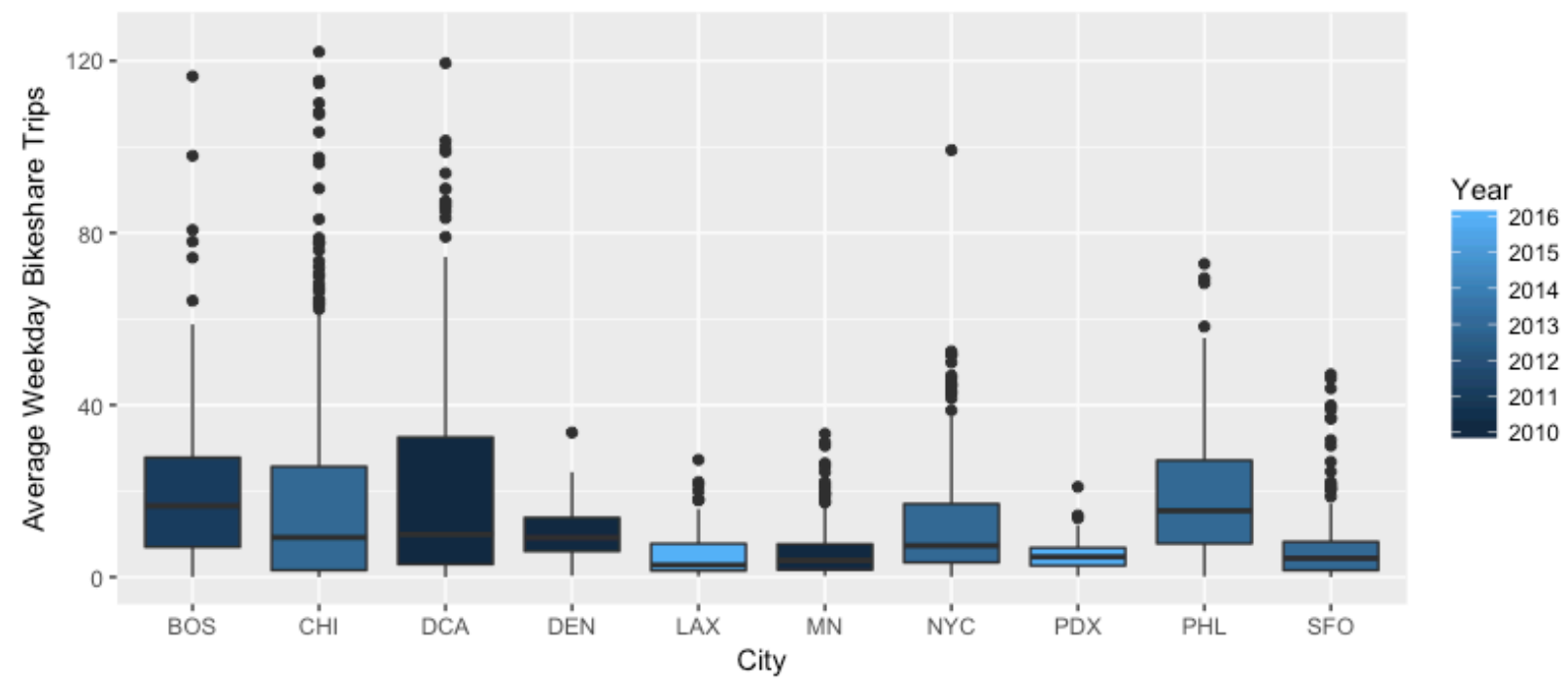

Figure 4.2 Boxplot of average weekday bikeshare trips by year of inauguration by city, excluding 9 outliers

\subsection{Explanatory Variables}

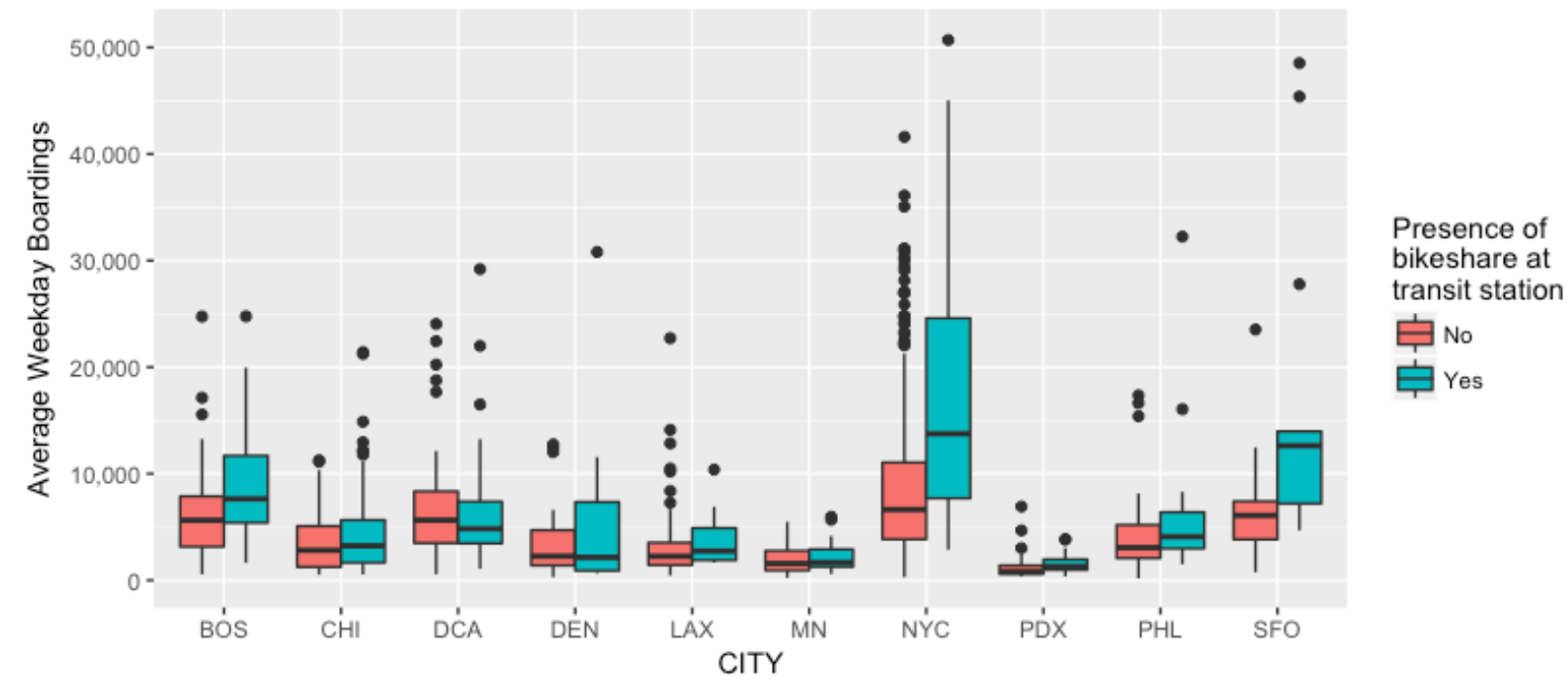

Figure 4.3. Boardings by Presence of Bikeshare by City, excluding 17 outliers

In all cities except Denver and Washington, DC, average weekday boardings exceed at stations with bikeshare versus stations without. This relationship is expected because bikeshare is often located in the city center where boardings are expected to be highest. Almost all cities note greater average weekday 
bikeshare trips where rail stations are present except Chicago, Denver, Los Angeles, and Minneapolis. One possible explanation is that bikeshare use in these cities is more recreational than utilitarian.

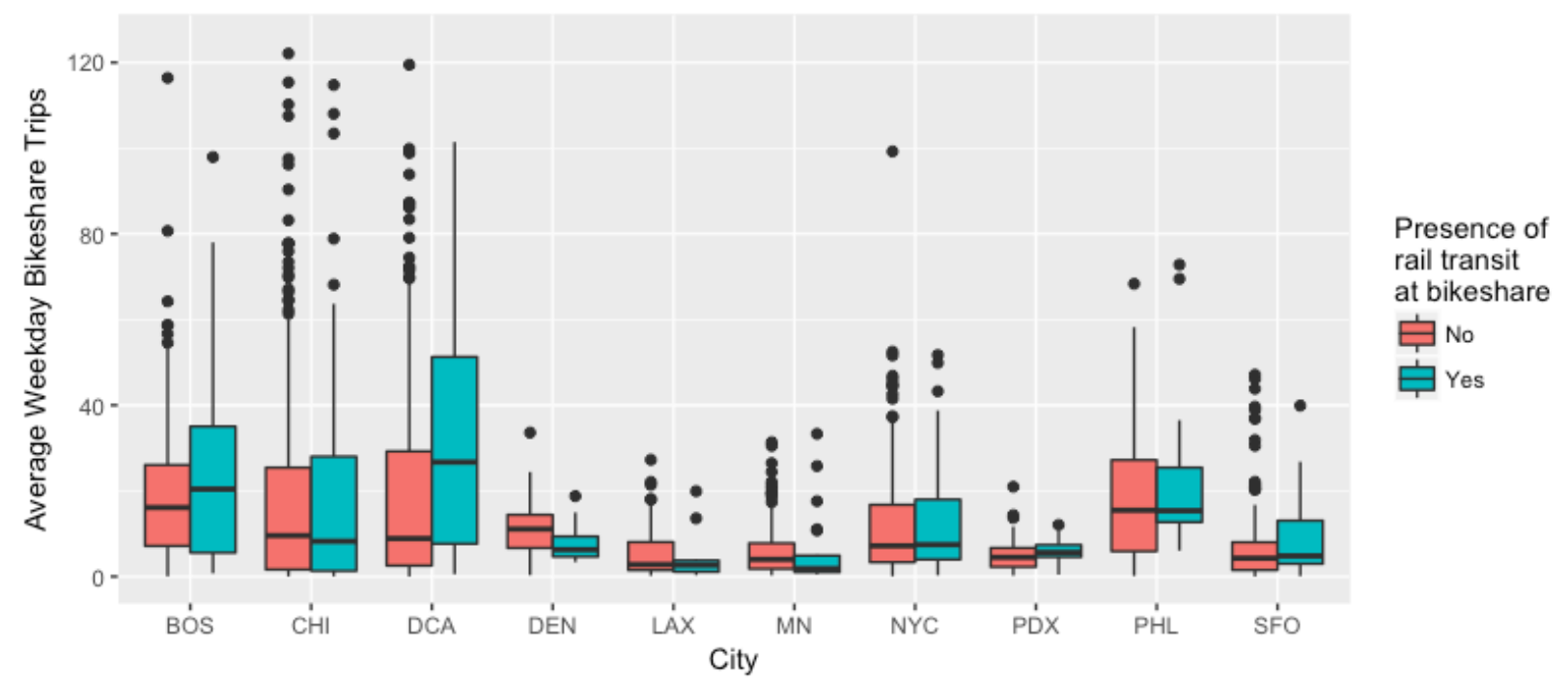

Figure 4.4 Average Weekday Bikeshare Trips by City, excluding 9 outliers 
Table 4.1. Number of observations by categorical variables in Model 1.

\begin{tabular}{|c|c|c|c|c|c|c|c|c|}
\hline \multirow{2}{*}{ CITY } & \multicolumn{2}{|c|}{$\begin{array}{c}\text { COMMUTER RAIL } \\
\text { TRANSFER }\end{array}$} & \multicolumn{2}{|c|}{$\begin{array}{c}\text { CENTRAL BUSINESS } \\
\text { DISTRICT }\end{array}$} & \multicolumn{2}{|c|}{$\begin{array}{l}\text { PRESENCE OF } \\
\text { BIKE LANES }\end{array}$} & \multicolumn{2}{|c|}{$\begin{array}{l}\text { PRESENCE OF } \\
\text { TRAILS }\end{array}$} \\
\hline & YES & NO & YES & NO & YES & $\mathrm{NO}$ & YES & NO \\
\hline Boston & 6 & 56 & 11 & 51 & 41 & 21 & 39 & 23 \\
\hline Chicago & 10 & 133 & 15 & 128 & 105 & 38 & 18 & 125 \\
\hline Washington, DC & 9 & 82 & 15 & 76 & 54 & 37 & 54 & 37 \\
\hline Denver & 1 & 57 & 4 & 54 & 32 & 26 & 33 & 25 \\
\hline Los Angeles & 1 & 92 & 5 & 88 & 49 & 44 & 2 & 91 \\
\hline Minneapolis & 2 & 35 & 5 & 32 & 35 & 2 & 29 & 8 \\
\hline New York City & 12 & 419 & 7 & 424 & 359 & 72 & 112 & 319 \\
\hline Portland & 1 & 96 & 26 & 71 & 96 & 1 & 61 & 36 \\
\hline Philadelphia & 6 & 57 & 11 & 52 & 53 & 10 & 9 & 54 \\
\hline San Francisco & 3 & 41 & 5 & 39 & 9 & 35 & 14 & 30 \\
\hline All observations & 51 & 1068 & 104 & 1015 & 833 & 286 & 371 & 748 \\
\hline $\begin{array}{l}\text { Excluding New } \\
\text { York City }\end{array}$ & 39 & 649 & 97 & 591 & 474 & 214 & 259 & 429 \\
\hline
\end{tabular}

Most cities had more rail rapid transit stations with access to bike facilities than not, with San Francisco being the only exception, likely due to many of its stations locating in the suburbs. 
Table 4.2. Number of observations by categorical variable in Model 2.

\begin{tabular}{|c|c|c|c|c|c|c|c|c|}
\hline \multirow{2}{*}{ CITY } & \multicolumn{2}{|c|}{$\begin{array}{l}\text { COMMUTER RAIL } \\
\text { TRANSFER }\end{array}$} & \multicolumn{2}{|c|}{$\begin{array}{c}\text { CENTRAL BUSINESS } \\
\text { DISTRICT }\end{array}$} & \multicolumn{2}{|c|}{$\begin{array}{l}\text { PRESENCE OF } \\
\text { BIKE LANES }\end{array}$} & \multicolumn{2}{|c|}{$\begin{array}{l}\text { PRESENCE OF } \\
\text { TRAILS }\end{array}$} \\
\hline & YES & NO & YES & $\mathrm{NO}$ & YES & $\mathrm{NO}$ & YES & NO \\
\hline Boston & 6 & 56 & 11 & 51 & 41 & 21 & 39 & 23 \\
\hline Chicago & 10 & 133 & 15 & 128 & 105 & 38 & 18 & 125 \\
\hline Washington, DC & 9 & 82 & 15 & 76 & 54 & 37 & 54 & 37 \\
\hline Denver & 1 & 57 & 4 & 54 & 32 & 26 & 33 & 25 \\
\hline Los Angeles & 1 & 92 & 5 & 88 & 49 & 44 & 2 & 91 \\
\hline Minneapolis & 2 & 35 & 5 & 32 & 35 & 2 & 29 & 8 \\
\hline New York City & 12 & 419 & 7 & 424 & 359 & 72 & 112 & 319 \\
\hline Portland & 1 & 96 & 26 & 71 & 96 & 1 & 61 & 36 \\
\hline Philadelphia & 6 & 57 & 11 & 52 & 53 & 10 & 9 & 54 \\
\hline San Francisco & 3 & 41 & 5 & 39 & 9 & 35 & 14 & 30 \\
\hline All observations & 51 & 1068 & 104 & 1015 & 833 & 286 & 371 & 748 \\
\hline $\begin{array}{l}\text { Excluding New } \\
\text { York City }\end{array}$ & 39 & 649 & 97 & 591 & 474 & 214 & 259 & 429 \\
\hline
\end{tabular}

Commuter rail systems in Boston, Chicago, Washington, DC, New York City, and Philadelphia play a greater role in urban transit with more stations with bikeshare presence. 


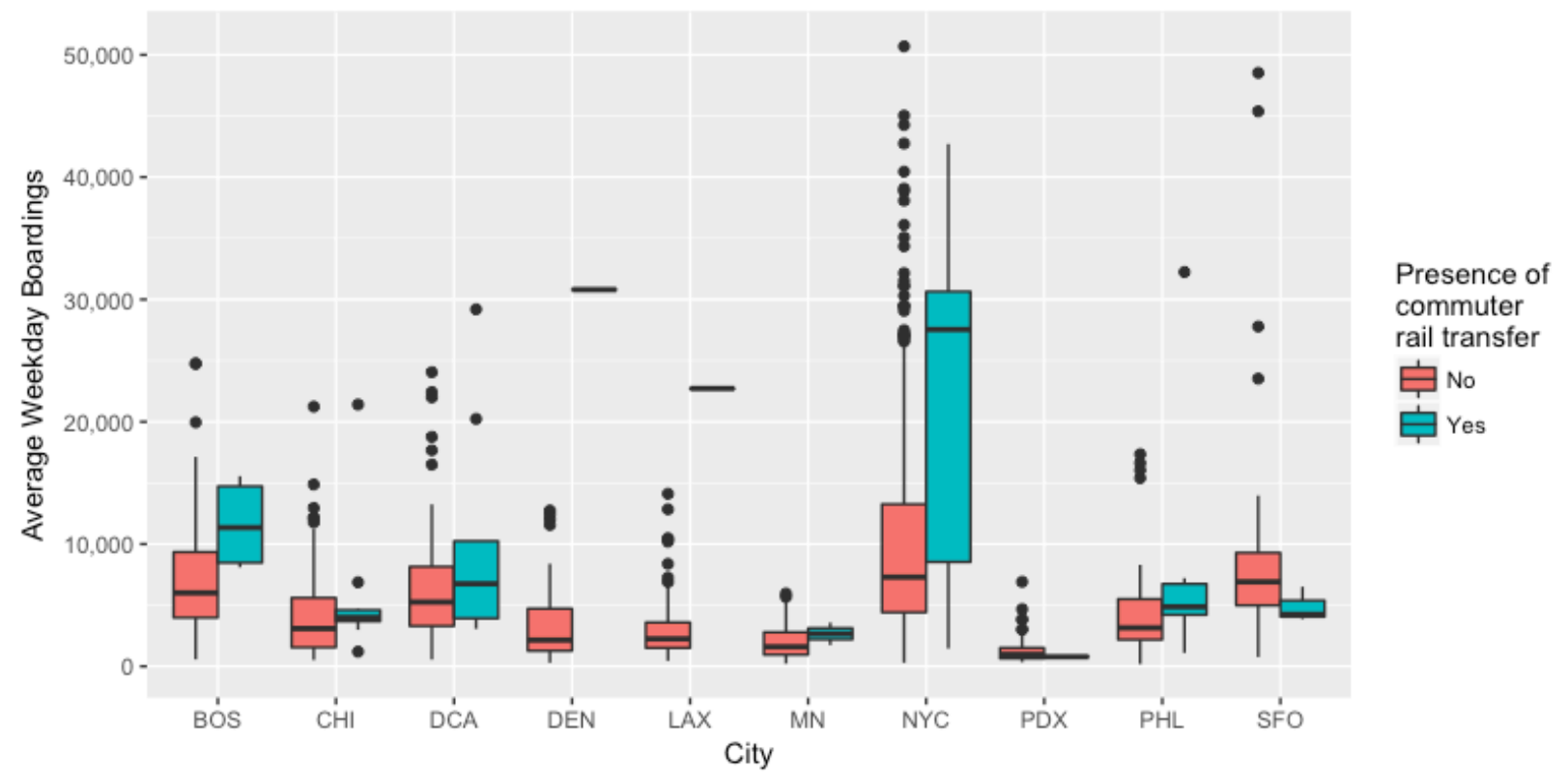

Figure 4.5. Boxplot of average weekday boardings by commuter rail transfer ability by city

Cities with excellent regional rail systems also boasted higher average weekday boardings at rail rapid transit stations with commuter rail transfers than not. Portland and Minneapolis barely exhibit a difference because they lack regional rail systems.

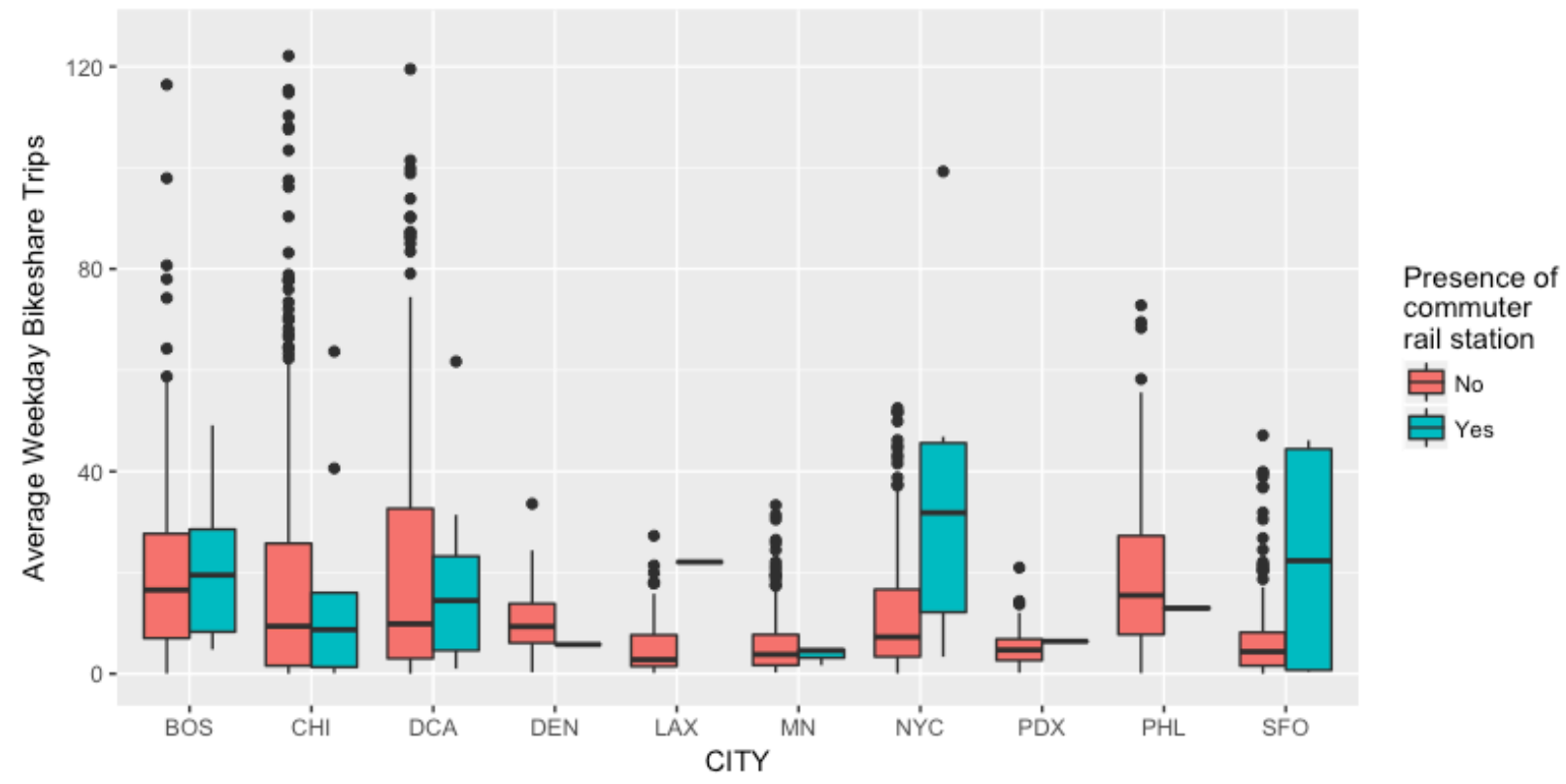

Figure 4.6 Boxplot of average weekday bikeshare trips by commuter rail transfer ability by city 


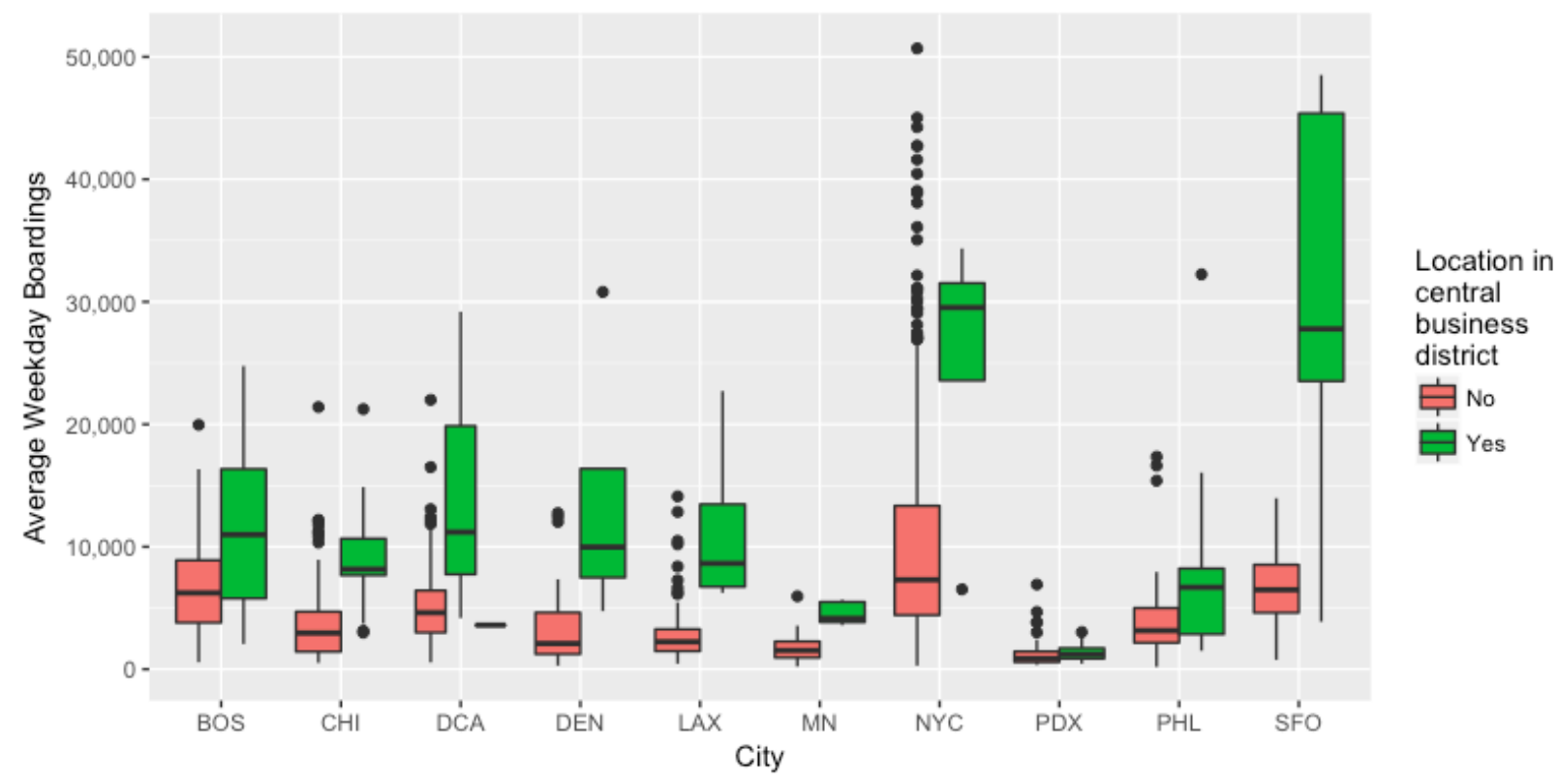

Figure 4.7. Boxplot of average weekday boardings by location of station in the central business district by city The expected increase in average weekday boardings at stations in central business districts holds for all cities except Portland, likely due to the greater proportion of stations in the downtown area as a function of the whole system.

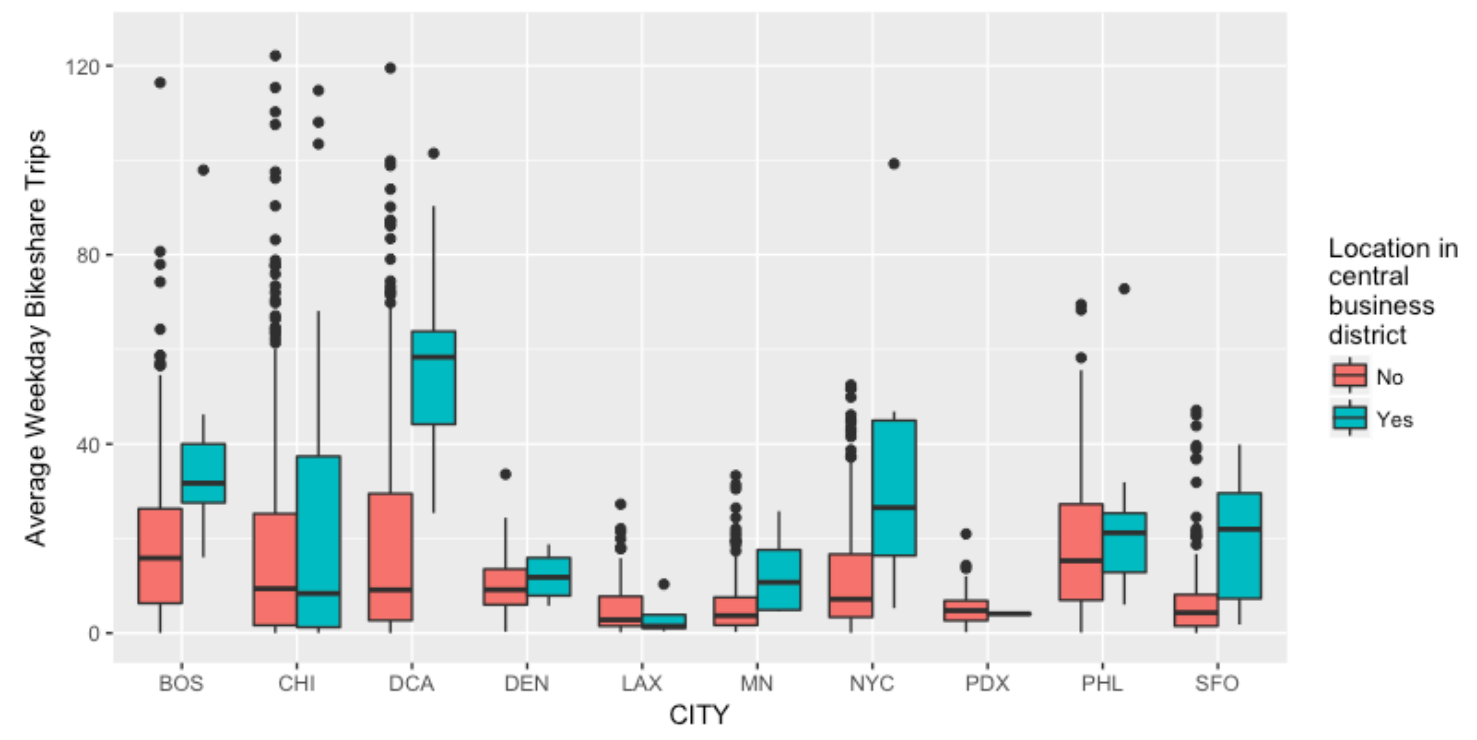

Figure 4.8 Boxplot of average weekday bikeshare trips by location of station in the central business district by city 


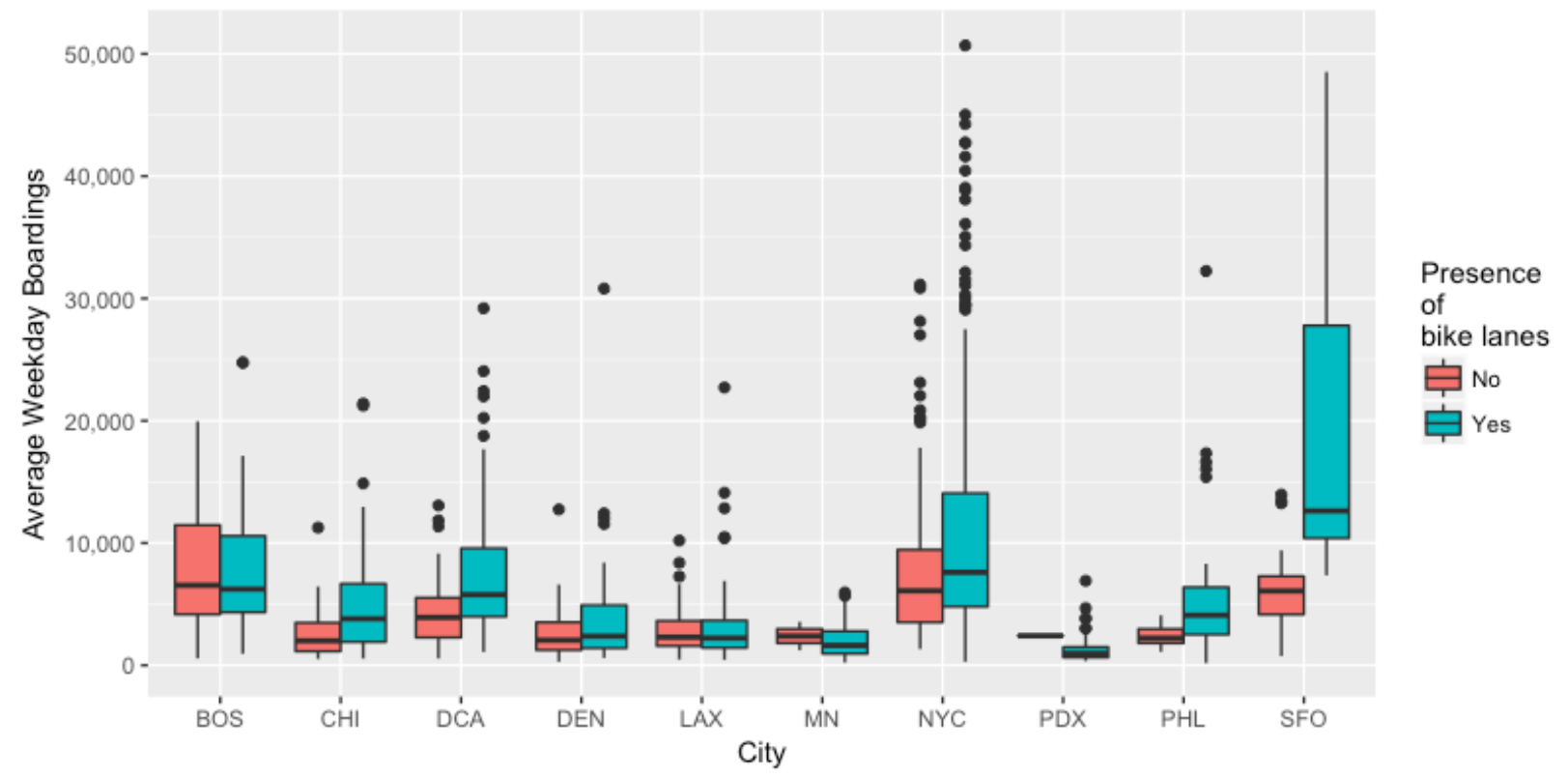

Figure 4.9. Boxplot of average weekday boarding by presence of bike lanes by city

Chicago, DC, New York City, Philadelphia, and San Francisco show greater average weekday boardings at stations where bike lanes are present than not. Portland and Minneapolis, the smallest cities and the only ones with systems that are exclusively light rail, show the opposite trend.

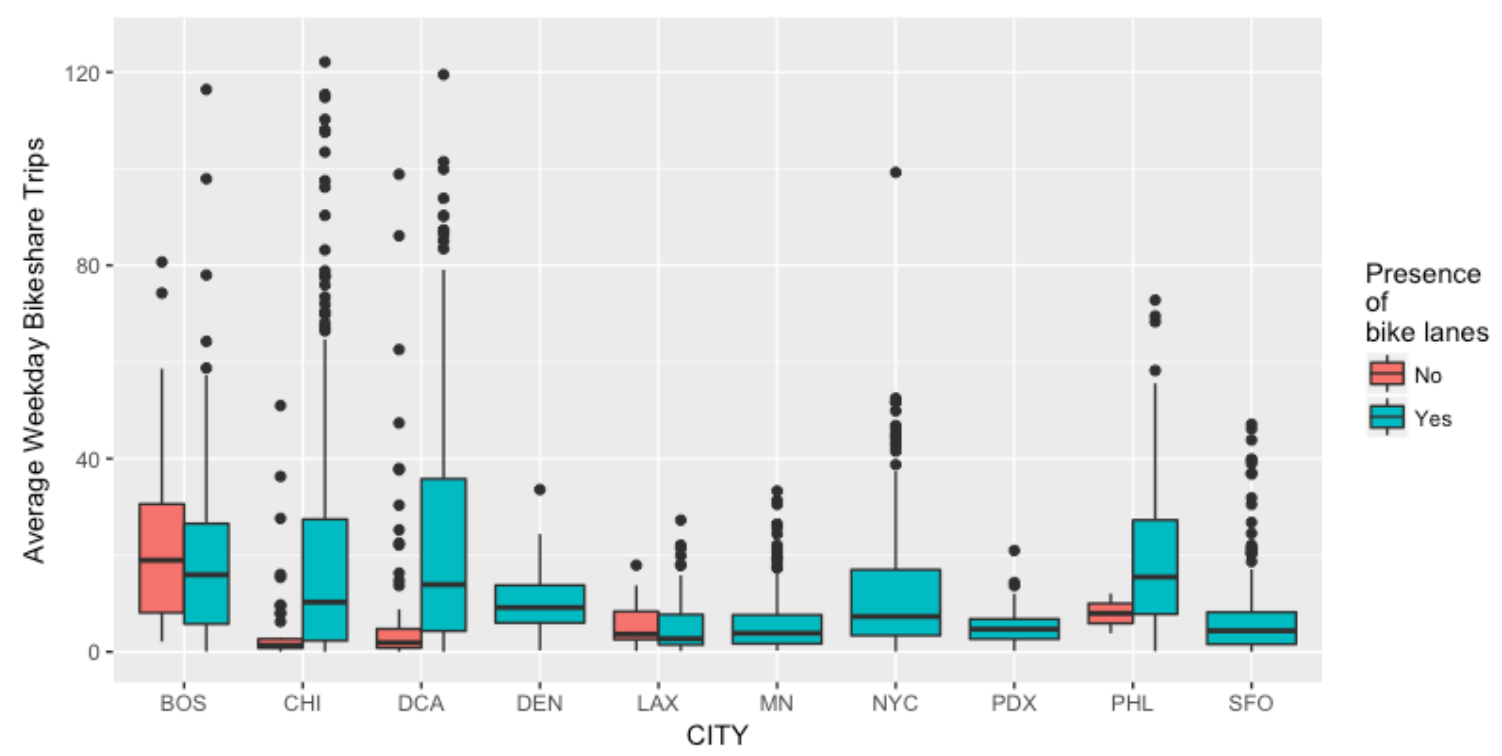

Figure 4.10 Boxplot of average weekday bikeshare trips by presence of bike lanes by city 


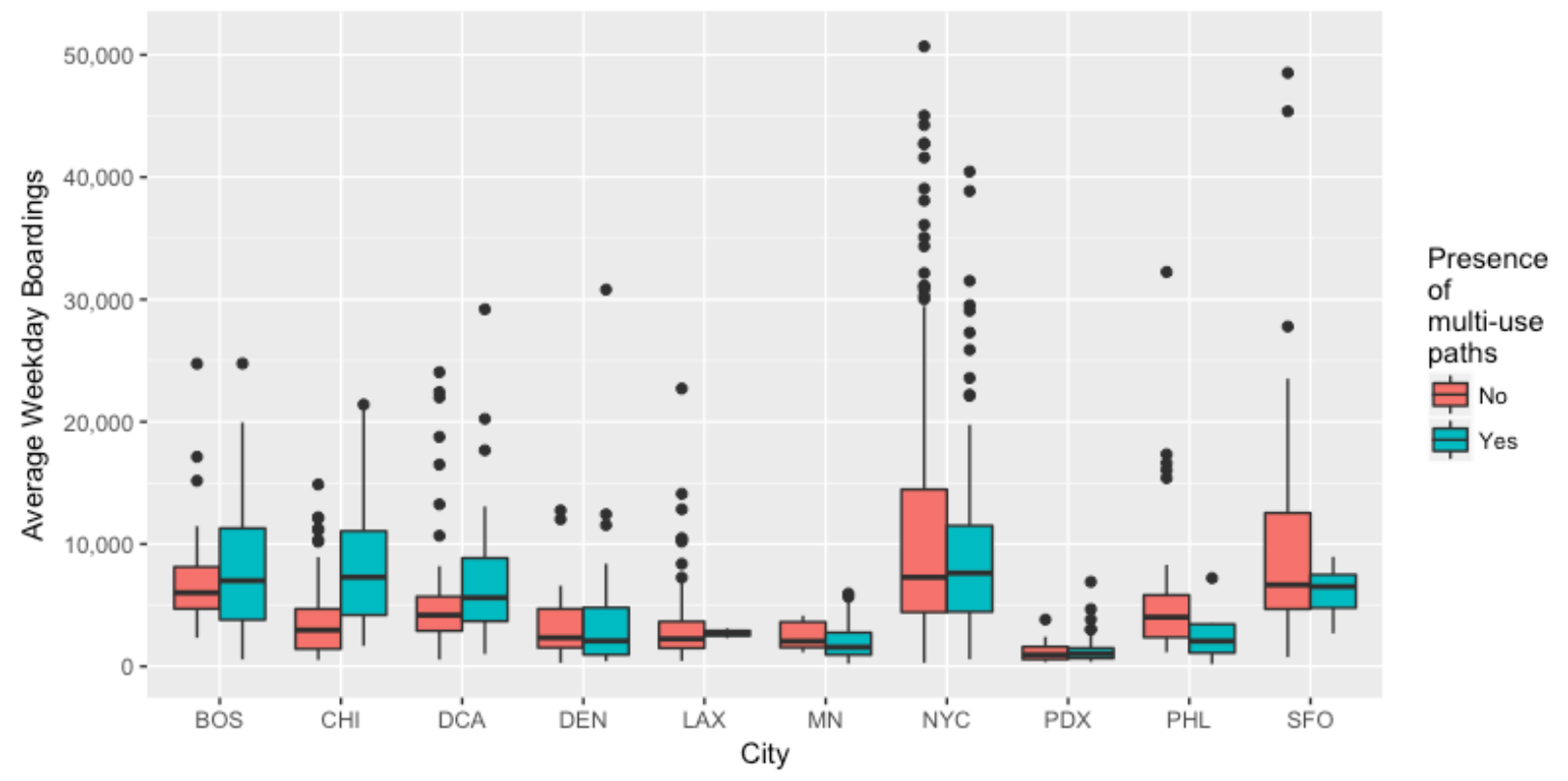

Figure 4.11. Boxplot of average weekday boardings by presence of multi-use path by city

Boston, Chicago and Washington, DC show more activity in the presence of multi-use paths, while Minneapolis and Philadelphia show a decrease. Other cities exhibit a negligible difference.

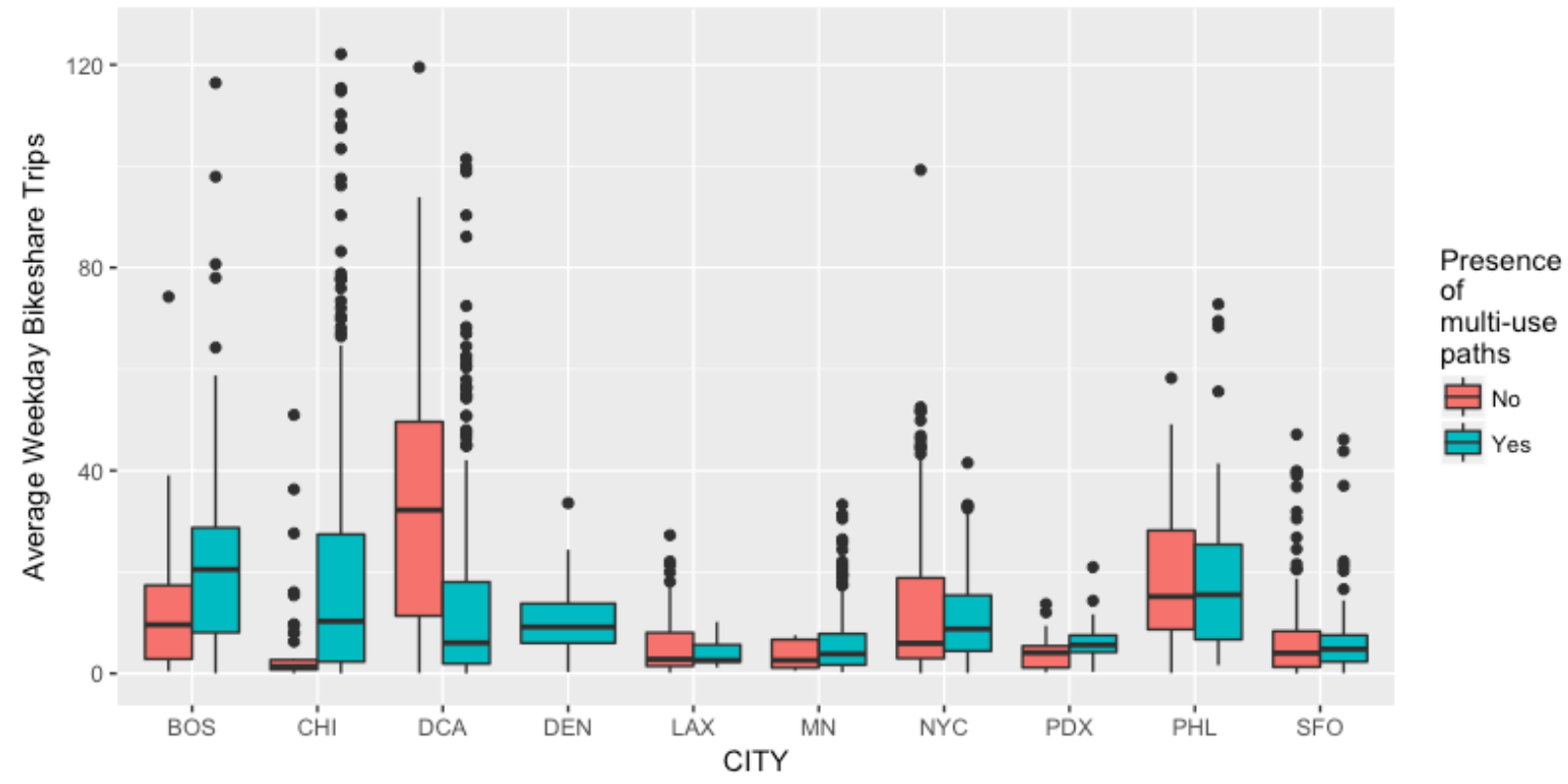

Figure 4.12 Boxplot of average weekday bikeshare trips by presence of multi-use paths by city 


\subsection{Relationships between Bikeshare and Rail Rapid Transit Variables}

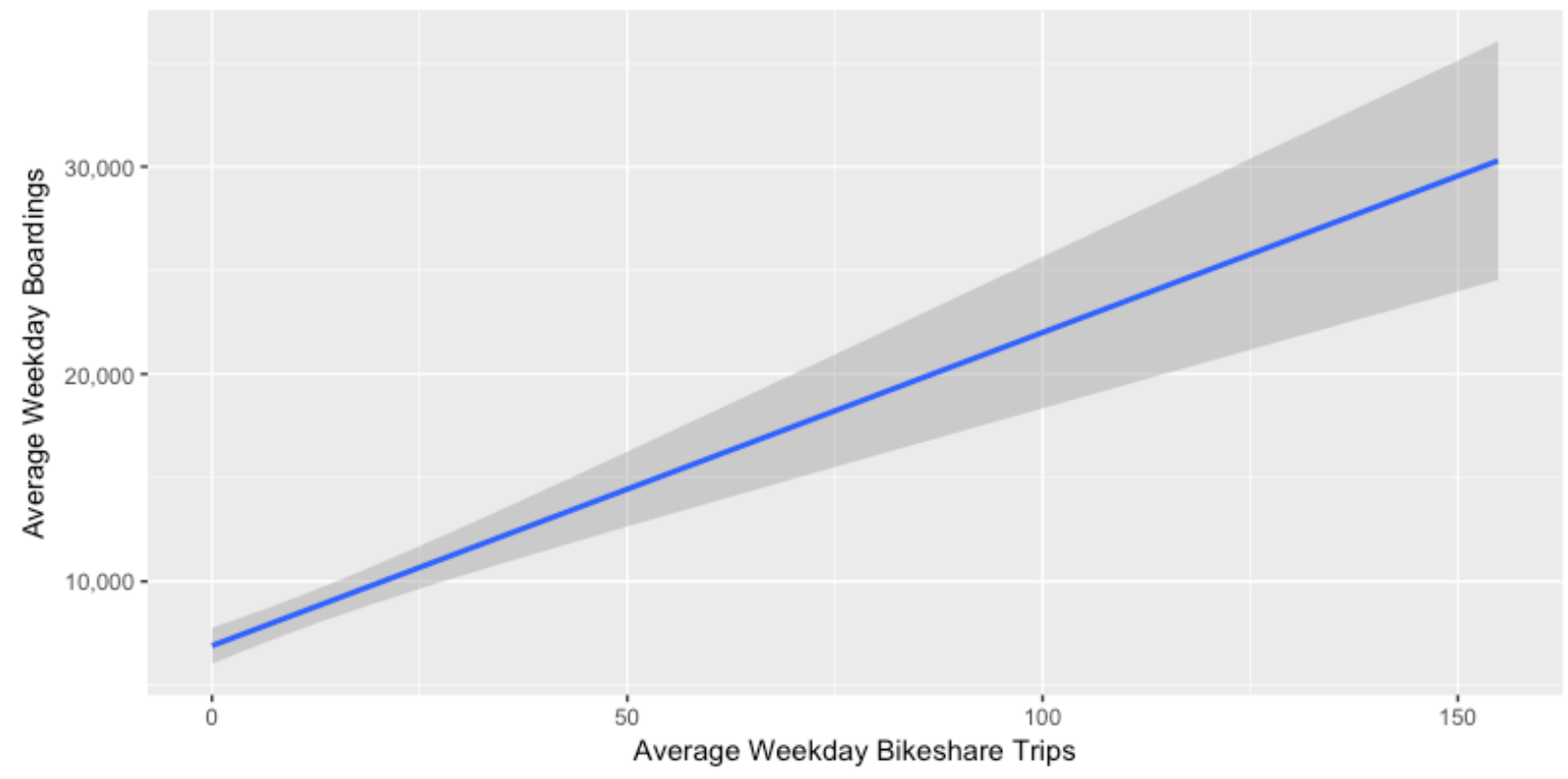

Figure 4.13. Average Weekday Boardings by Average Weekday Bikeshare Trips

A positive relationship can be observed between the average weekday boardings and average weekday bikeshare trips originating within 0.1 miles of transit stations as shown in Figure 4.13. Figures 4.14 and 4.15 illustrate how the linear regression model between the dependent variables and significant predictors expected from the literature varies by presence of bikeshare at rail rapid transit stations and by presence of rail rapid transit at bikeshare stations. 


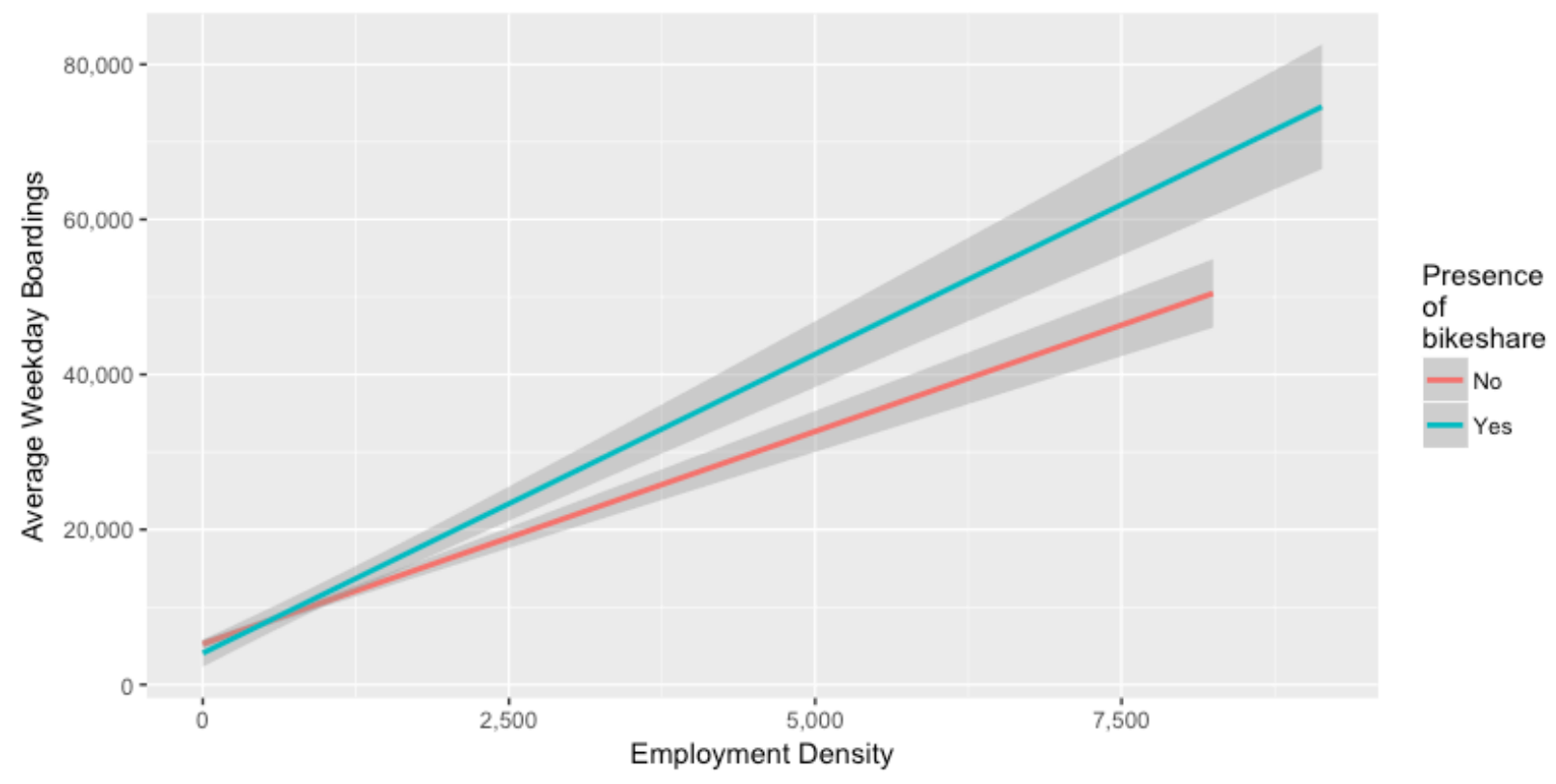

Figure 4.14 Employment Density by Average Weekday Boardings by presence of bikeshare

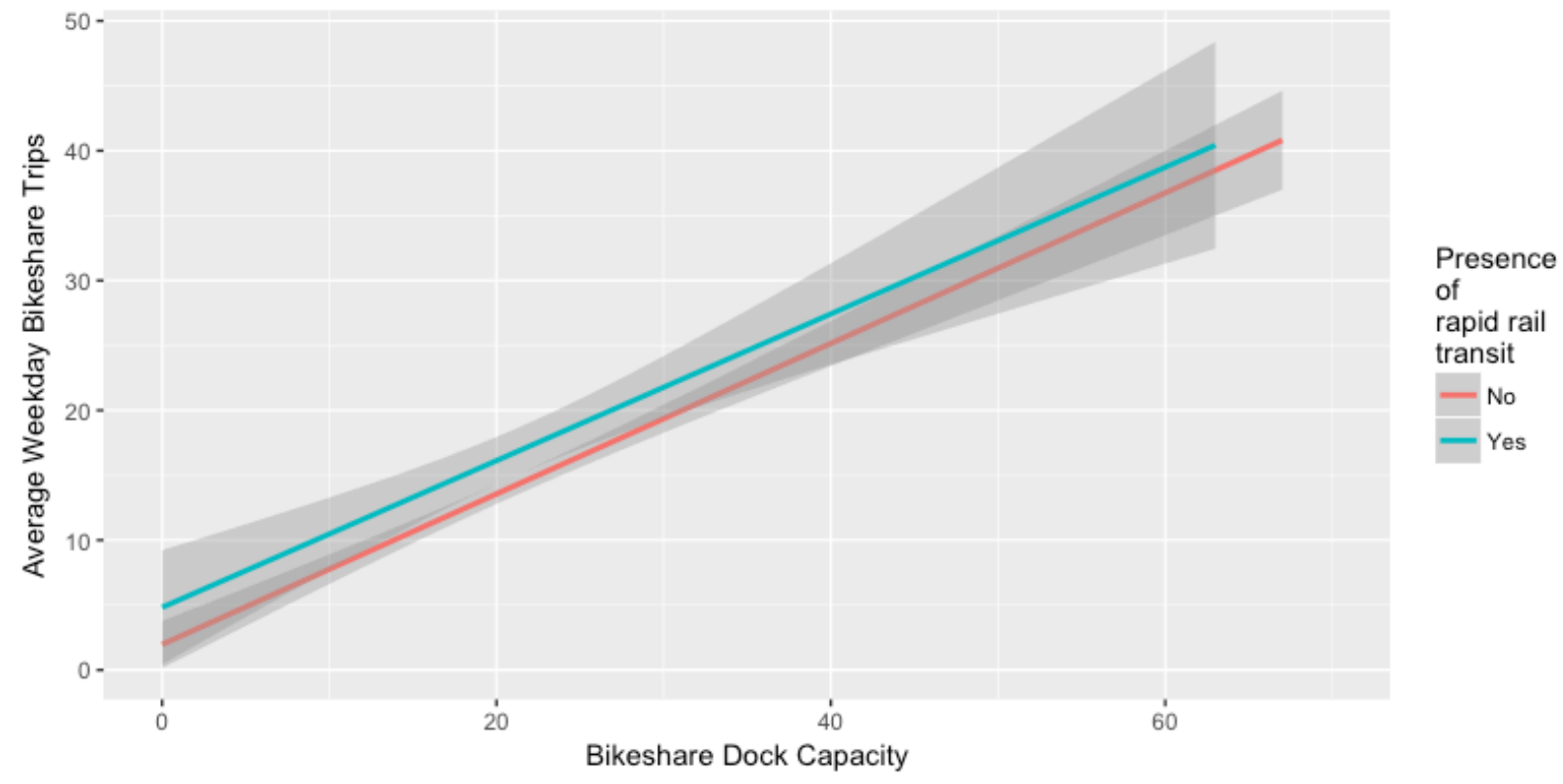

Figure 4.15 Average Weekday Bikeshare Trips by Bikeshare Dock Capacity by presence of rail rapid transit 


\subsection{RESULTS}

\subsection{Model of rapid rail station boardings}

Table 5.1. Unadjusted model of boardings results of backward and forward selection based on AIC ( $n=1106)$

\begin{tabular}{|c|c|c|}
\hline VARIABLES & COEFFICIENT & SIGNIFICANCE \\
\hline \multicolumn{3}{|l|}{ Dependent $=\log ($ Average Weekday Boardings $)$} \\
\hline Intercept & 4,625 & $* * *$ \\
\hline Heavy rail flag & 0.634 & $* * *$ \\
\hline $\log (\%$ working age population $)$ & 0.464 & $* * *$ \\
\hline Log(Household density) & 0.141 & $* *$ \\
\hline Commuter rail flag & -0.297 & $* *$ \\
\hline Central Business District flag & -0.146 & . \\
\hline Log(Employment density) & -0.182 & $* *$ \\
\hline $\log$ (Activity density) & -0.165 & \\
\hline $\log ($ Intersection density) & -0.133 & $* * *$ \\
\hline $\log ($ Regional diversity $)$ & -0.0811 & $* *$ \\
\hline Number of bikeshare docks at rail rapid transit station & 0.008 & $* * *$ \\
\hline Ratio of jobs accessible by transit to jobs accessible by car & -0.092 & . \\
\hline Bikeshare dock at station flag & -0.262 & $* * *$ \\
\hline Presence of trails & -0.071 & \\
\hline Number of rapid rail lines & 0.264 & $* * *$ \\
\hline MSA Population & $2.789 e-08$ & * \\
\hline 2016 annual ridership & $1.095 \mathrm{e}-09$ & $* * *$ \\
\hline Log(Median household income) & 0.120 & $* *$ \\
\hline $\log (\%$ of population is non-white $)$ & 0.0535 & \\
\hline
\end{tabular}




\begin{tabular}{l|c|c}
\hline Number of stations in rail rapid transit system & -0.00954 & $* * *$ \\
\hline Log(Jobs accessible by transit within 45 minutes) & 0.153 & $*$ \\
\hline Miles of rail rapid transit for longest line & 0.00318 & $*$ \\
\hline Denver dummy variable & 0.251 & $*$ \\
\hline Boston dummy variable & 0.176 & \\
\hline Adjusted R2 & 0.6358 & $*$ \\
\hline
\end{tabular}
${ }^{* * *} p<0.01,{ }^{* *} p<0.05,{ }^{*} p<0.1$

Bikeshare dock capacity and bikeshare dock at station flag are correlated (0.63) and the direction of the bikeshare flag variable is counterintuitive so this variable was dropped. Number of stations, route length, and annual transit ridership are very highly correlated ( $>0.9)$. Jobs accessible by transit was highly correlated $(>0.7)$ with other employment variables. Thus, these variables are dropped in the final model. The final model shown in Table 5.2 shows that 9 significant variables emerge after controlling for the variables under study. 
Table 5.2. Parsimonious model variables

\begin{tabular}{|c|c|c|c|c|}
\hline \multirow{2}{*}{ VARIABLE } & \multicolumn{2}{|c|}{ MODEL 1A: FULL SET } & \multicolumn{2}{|c|}{$\begin{array}{l}\text { MODEL 1B: STATIONS WITH } \\
\text { BIKESHARE }\end{array}$} \\
\hline & Coefficient & Significance & Coefficient & Significance \\
\hline \multicolumn{5}{|l|}{ Dependent: Log(Average Weekday Boardings) } \\
\hline Intercept & 4.79 & - & 3.32 & - \\
\hline Heavy rail flag & 0.768 & $* * *$ & 0.550 & $* * *$ \\
\hline $\log (\%$ of Population that is working age $)$ & 0.578 & $* * *$ & - & - \\
\hline Commuter rail flag & 0.309 & $* *$ & 0.288 & * \\
\hline Number of bikeshare docks within 0.1 miles & 0.00457 & $* *$ & 0.0119 & $* * *$ \\
\hline Log(Employment density) & 0.0806 & ** & 0.141 & $* * *$ \\
\hline Number of rail rapid transit lines at station & 0.308 & $* * *$ & - & - \\
\hline 2016 annual ridership $(100,000,000 \mathrm{~s})$ & 0.0277 & $* * *$ & - & - \\
\hline Log(Median Household Income) & 0.185 & $* * *$ & 0.271 & $* * *$ \\
\hline Length of longest line served by station (in miles) & - & - & 0.0318 & $* * *$ \\
\hline Log(Bikeshare trips initiated within 0.1 miles $)$ & - & - & 0.0730 & * \\
\hline New York City flag & - & - & 0.876 & $* * *$ \\
\hline Boston flag & - & - & 0.749 & $* * *$ \\
\hline $\mathrm{R} 2$ & \multicolumn{2}{|c|}{$0.5773(n=1106)$} & \multicolumn{2}{|c|}{$0.675(n=410)$} \\
\hline
\end{tabular}

The direction of income is counterintuitive but is likely associated with a preference shift towards urban living by wealthier individuals. 


\subsection{Diagnostic Plots of Model 1}

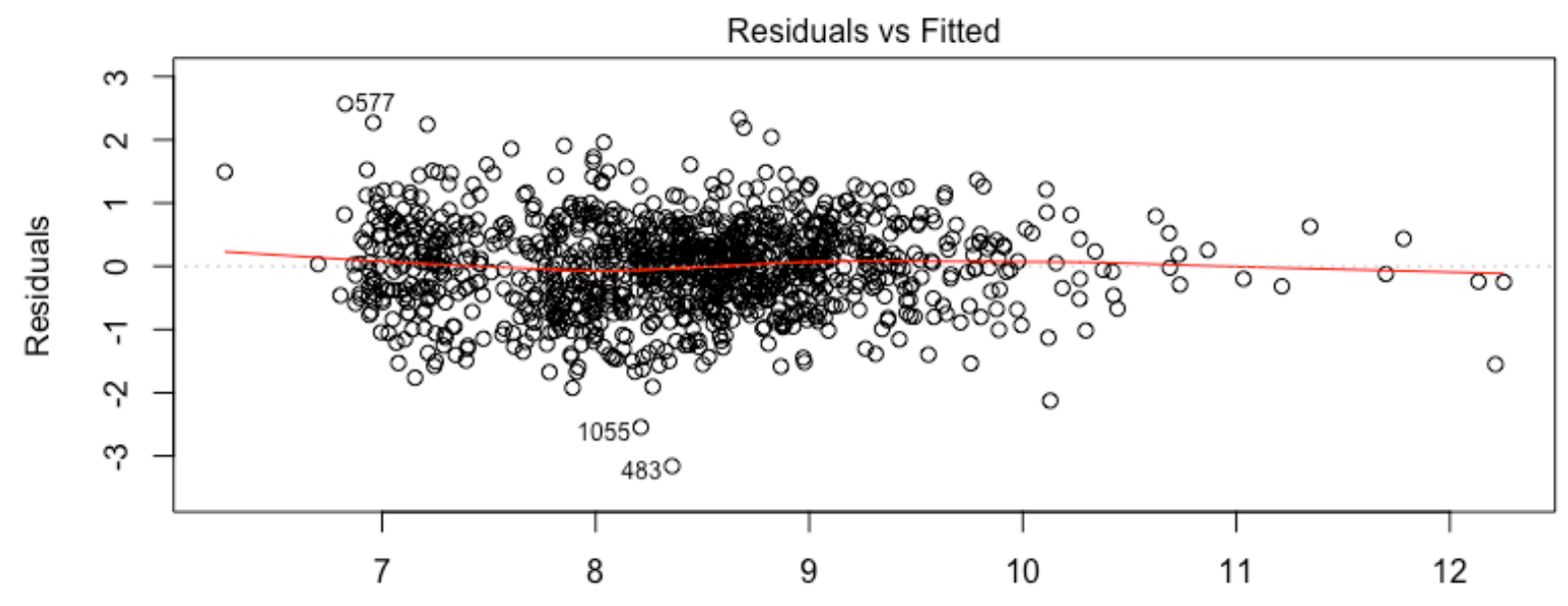

Fitted values

Figure 5.1 Plot of residuals vs. fitted values of Model 1A

The model is approximately linear complying with normality.

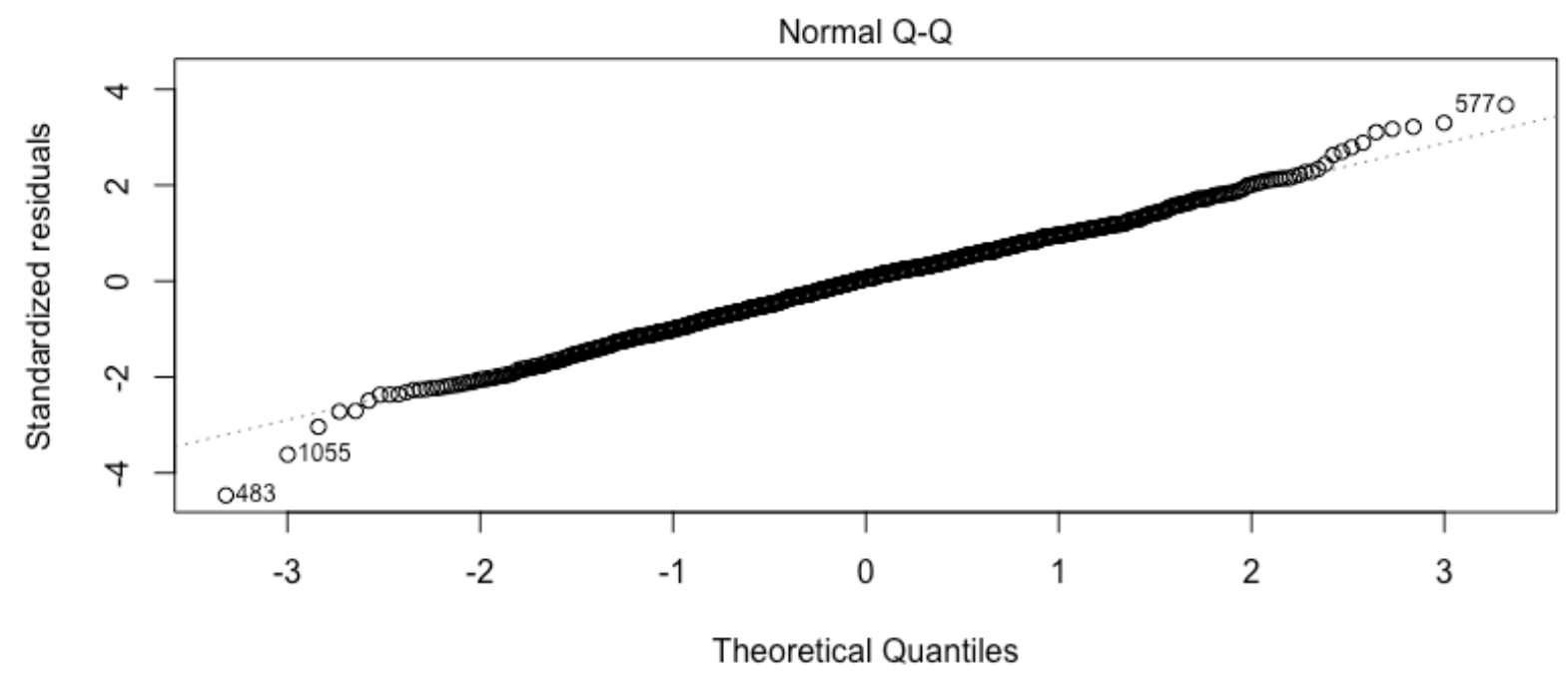

Figure 5.2 Normal Q-Q plot of Model 1A

Observations 483 and 1055 appear problematic but overall the rest of the plot appears compliant. 


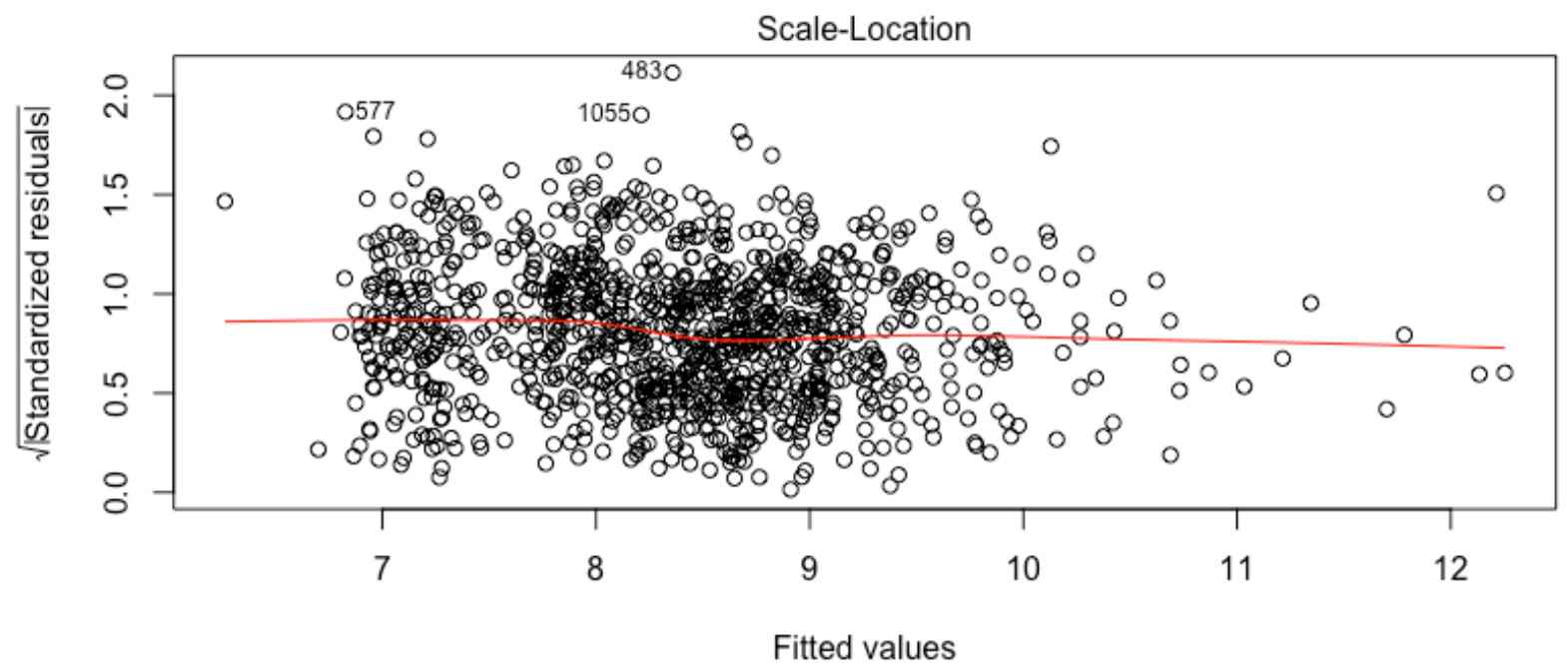

Figure 5.3 Scale-location plot of Model 1A

The observations appear to be spread randomly on the scale-location plot.

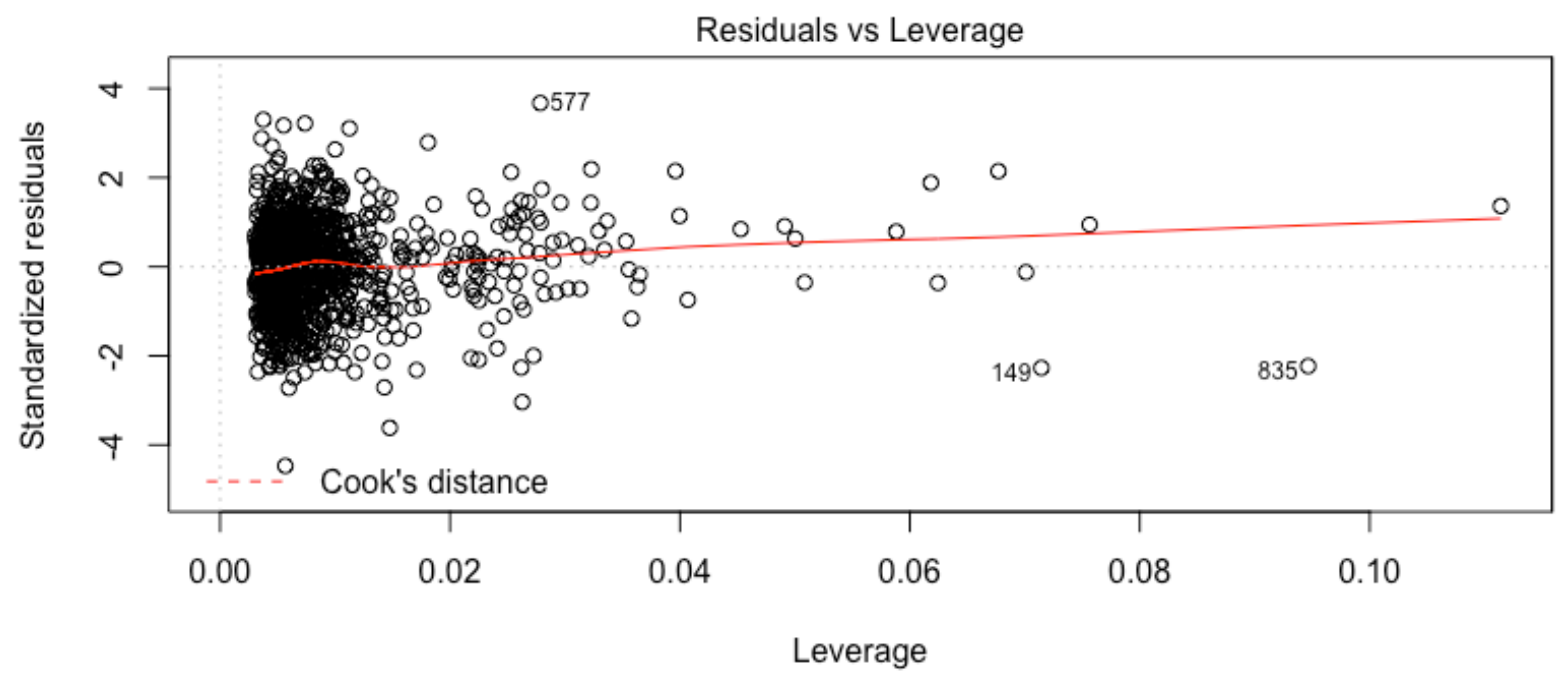

Figure 5.4 Plot of residuals vs. leverage of Model 1A

All the points are located within Cook's distance. 


\subsection{Model of average weekday bikeshare trips}

The following is the results of backward and forward selection of variables based on AIC score.

Table 5.3. Unadjusted model of square root of average bikeshare trips result of backward forward selection $(n=2,428)$

\begin{tabular}{|c|c|c|}
\hline VARIABLE & COEFFICIENT & SIGNIFICANCE \\
\hline \multicolumn{3}{|l|}{ Dependent: $\log ($ Average Weekday Trips) } \\
\hline Intercept & 79.2 & - \\
\hline Annual Bikeshare Trips & $4.98 \mathrm{e}-07$ & $* * *$ \\
\hline Log(Number of Bikeshare Docks) & $-3.15 e-03$ & *** \\
\hline Service Start Year & -0.0483 & ** \\
\hline Log(Employment Density) & 0.0343 & $* * *$ \\
\hline Log(Activity Density) & 0.312 & *** \\
\hline Log(Intersection Density) & -0.0166 & $* * *$ \\
\hline Log(Job-Population Mix) & -0.0235 & \\
\hline Log(Regional Diversity) & 0.104 & ** \\
\hline Log(Jobs accessible by car in 30 minutes $)$ & 0.593 & $* * *$ \\
\hline $\log$ (Jobs accessible by transit in 45 minutes) & 0.631 & *** \\
\hline $\log ($ Ratio of jobs accessible by transit to jobs accessible by car) & 0.630 & *** \\
\hline Log(Jobs accessible by transit, UMN Accessibility Observatory) & 0.399 & *** \\
\hline Log(Bike Commute Mode Share) & 0.392 & *** \\
\hline Miles of trails & $8.35 e-06$ & ** \\
\hline Number of rapid rail stations & -0.00335 & $*$ \\
\hline MSA Population & $-8.42 e-08$ & $* * *$ \\
\hline
\end{tabular}




\begin{tabular}{l|c|c}
\hline New York City flag & -7.21 & ${ }^{* * *}$ \\
\hline Boston flag & 0.846 & ${ }^{* * *}$ \\
\hline San Francisco flag & 0.674 & ${ }^{* * *}$ \\
\hline Presence of rapid rail station & 0.183 & $*$ \\
\hline Log(Percent of Zero-Car Households) & 0.107 & \\
\hline Adjusted R2 & 0.6634 & \\
\hline${ }^{* * *} p<0.01,{ }^{* *} p<0.05,{ }^{*} p<0.1$ & &
\end{tabular}

MSA Population was removed because it was highly correlated with other system-specific variables like Annual Bikeshare Trips and Number of Docks. After removing variables with high correlations and counterintuitive signs, we obtain the following model shown in Table 5.4. 
Table 5.4. Parsimonious model of average weekday bikeshare trips $(n=2428)$

\begin{tabular}{l|c|c|c|c}
\hline \multirow{2}{*}{ VARIABLE } & \multicolumn{2}{|c|}{$\begin{array}{c}\text { MODEL 2A: } \\
\text { USING TRANSIT FLAG }\end{array}$} & \multicolumn{2}{c}{$\begin{array}{c}\text { MODEL 2B: } \\
\text { USING BOARDINGS }\end{array}$} \\
\hline & Coefficient & Significance & Coefficient & Significance \\
\hline $\begin{array}{l}\text { Dependent: Log(Average Weekday Bikeshare } \\
\text { Trips) }\end{array}$ & & & & \\
\hline $\begin{array}{l}\text { Intercept } \\
\text { Log(Number of Docks at Bikeshare Station) }\end{array}$ & -3.22 & - & -3.16 & ${ }^{*}$ \\
\hline Log(ratio of jobs accessible by transit in 45 minutes \\
to jobs accessible by car in 30 minutes)
\end{tabular}

${ }^{* * *} p<0.01,{ }^{* *} p<0.05,{ }^{*} p<0.1$ 


\subsection{Diagnostic Plots of Model 2}

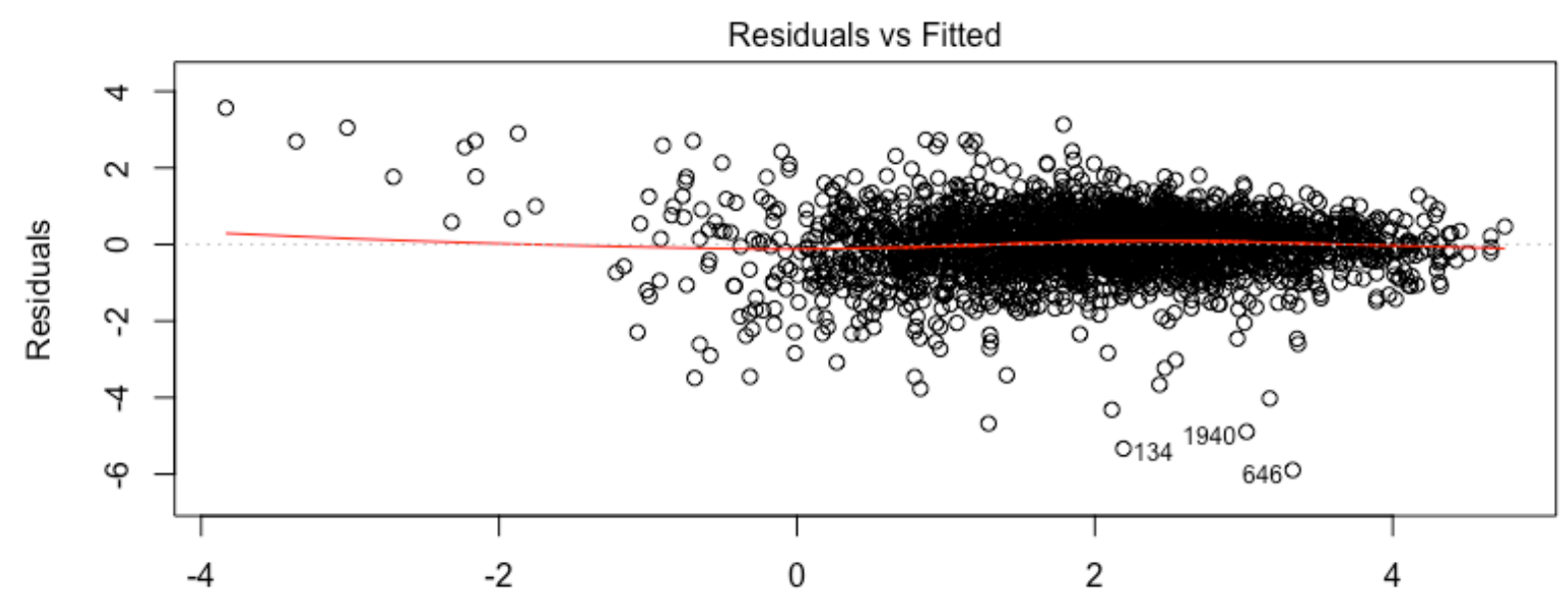

Fitted values

Figure 5.5 Plot of residuals vs. fitted values of Model 2A

The line of observations of average weekday boardings is near linear.

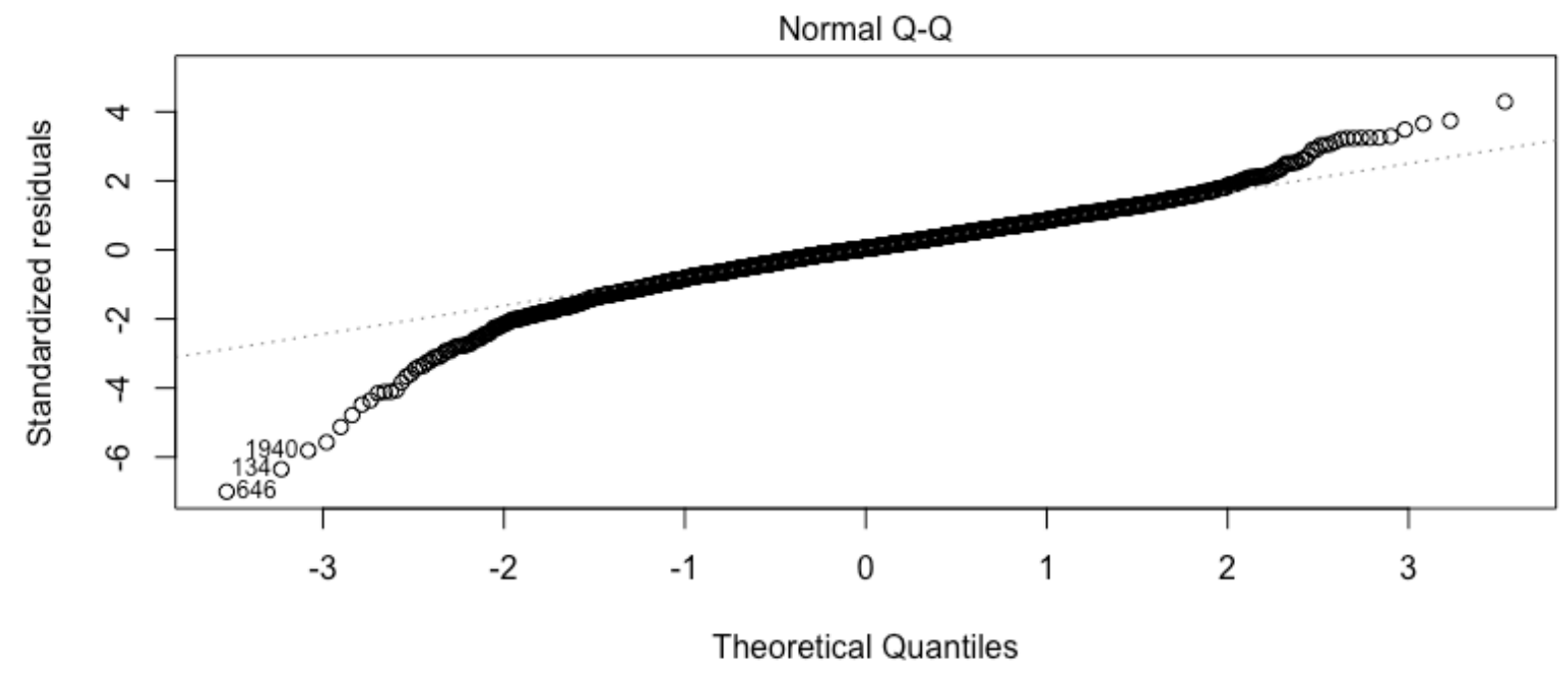

Figure 5.6 Normal Q-Q plot of Model 2A

The Normal Q-Q plot shows a heavy tail on one side bringing the normality of the residuals into question. Observations 1940, 134, and 646 persist in being problematic. 


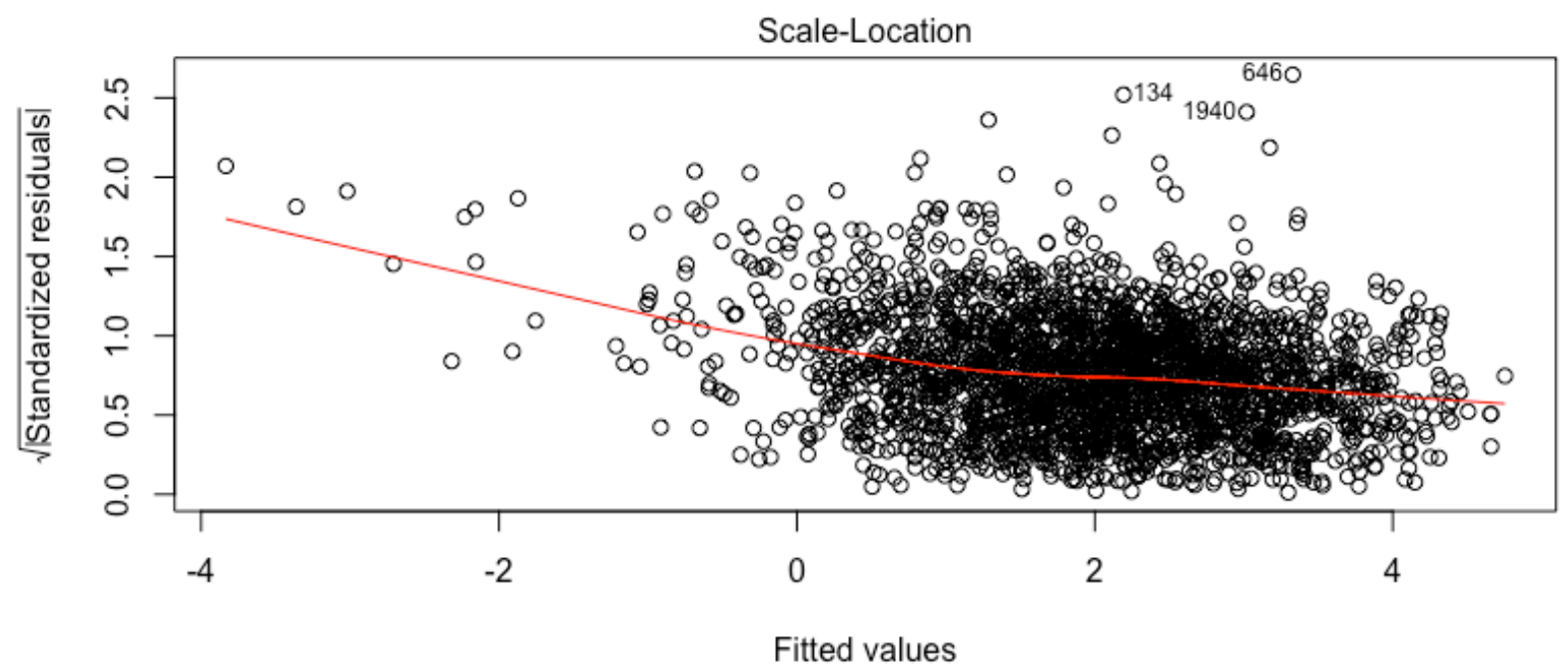

Figure 5.7 Scale-location plot of Model 2A

The scale-location plot indicates heteroscedasticity as shown by residuals that spread wider along the $\mathrm{x}$ axis.

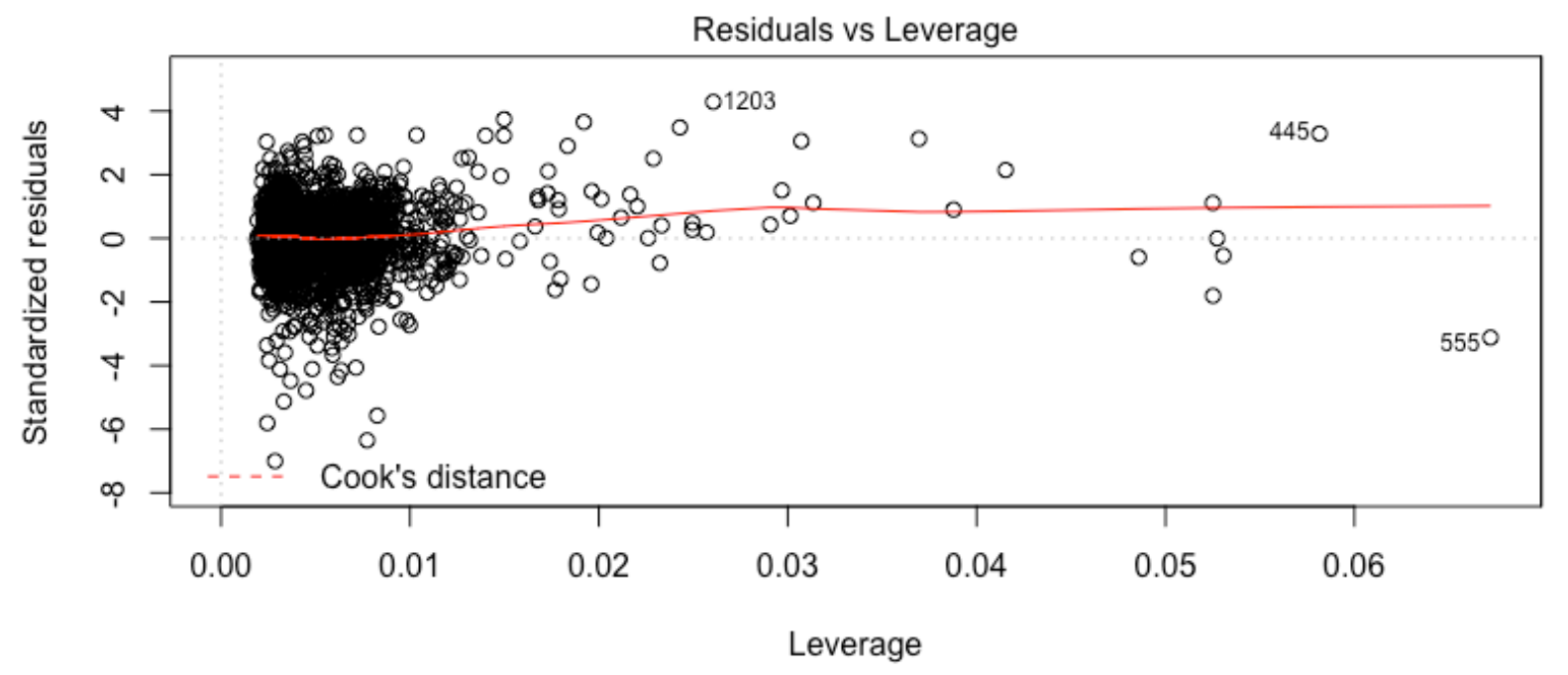

Figure 5.8 Plot of residuals vs. leverage of Model 2A

The points are located within Cook's distance. 


\subsection{DISCUSSION}

\subsection{Model of Average Weekday Boardings (Model 1)}

The results of Model 1 show that average weekday bikeshare trips was not a significant predictor of average weekday boardings. The number of docks within 0.1 miles of a rail rapid transit stations was the only bikeshare variable that emerged in the parsimonious model.

Bikeshare variables were significant in the models however they consistently demonstrated to possess a small effect size. Adding 10 bikeshare docks at transit stations is associated with a $4 \%$ increase in average weekday boardings. An additional 10 bikeshare trips originating at a transit station was associated with a $0.7 \%$ increase in average weekday boardings, as demonstrated in model $1 \mathrm{~B}$.

Transit system variables logically influence average weekday boardings. An additional rail rapid transit

line as well as a commuter rail transfer are each expected to generate on average $31 \%$ increase in average weekday boardings. A heavy rail station has an average $74 \%$ more average weekday boardings than light rail systems.

Employment also has a strong effect on average weekday boardings at rail rapid transit stations. For every 100 additional jobs within 0.33 miles of a rail rapid transit station, there are $8 \%$ additional average weekday boardings. On the other hand, a $1 \%$ increase in the percent of the population that is working age is associated with $6 \%$ increase in average weekday boardings.

Income was also associated with an increase in average weekday boardings. A 10\% increase in median household income is associated $1.9 \%$ increase in average weekday boardings. This may be due to an increase in luxury developments in central urban areas in the United States over the last decade.

The variables with negative relationships were intersection density and bikeshare dock at station flag. The negative relationship of average weekday boardings and intersection density was also observed in the literature. 


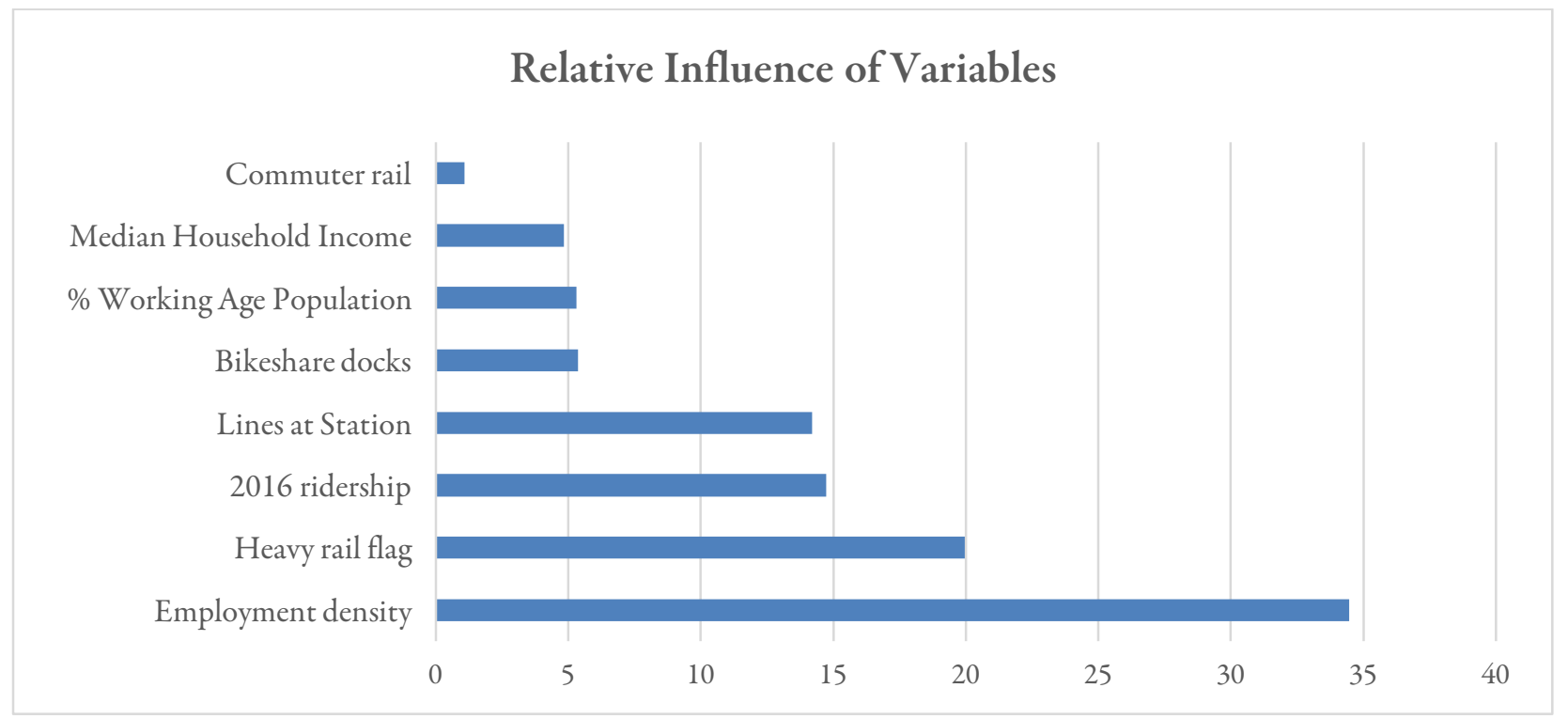

Figure 6.1 Relative Influence of Variables in Model 1A

An inspection of the relative influence shows that employment density, heavy rail flag, number of rail rapid transit lines at a station, and 2016 transit ridership (which acts as a relative location variable for each city) hold the largest explanatory power in the model.

\subsection{Model of Average Weekday Bikeshare Trips (Model 2)}

The results of Model 2 show that both the average weekday boardings at rail rapid transit stations and the presence of rail rapid transit stations variables were significant predictors of average weekday bikeshare trips, although at very small magnitudes. Every 1,000-average weekday boardings is associated with $0.765 \%$ increase in average weekday bikeshare trips. On the other hand, the presence of rail rapid transit stations are associated with $21 \%$ additional average weekday bikeshare trips.

New York City, Boston and San Francisco are the relative location variables significant in the model. New York City, Boston and San Francisco have on average less weekday bikeshare trips. It appears counterintuitive that these three large cities would experience on average less weekday bikeshare trips,

Each additional 10 docks at a bikeshare station are associated with a 10\% increase in average weekday bikeshare trips. For every 100 bikeshare docks in the system, there is an average 18\% increase average 
weekday bikeshare trips. A $1 \%$ increase in bike to work mode share is associated with a $0.4 \%$ increase in average weekday bikeshare trips.

Access to jobs and density of opportunities seem to have the greatest effect on average weekday bikeshare trips. A $5 \%$ increase in ratio of jobs accessible by transit in 45 minutes over jobs accessible by car in 30 minutes is associated with a $4.8 \%$ increase average weekday bikeshare trips. A $10 \%$ increase in number of jobs accessible by transit on the other hand is associated with a $5 \%$ increase in number of average weekday bikeshare trips.

Intersection density has a counterintuitive sign in its relation to average weekday bikeshare trips, though this is consistent with other studies. It could be due to intersection density being a strong measure of describing a person's willingness to walk over other travel modes like bikeshare.

Commuter rail was not a significant variable though is likely due to inconsistent commuter rail service quality across the cities in the study.

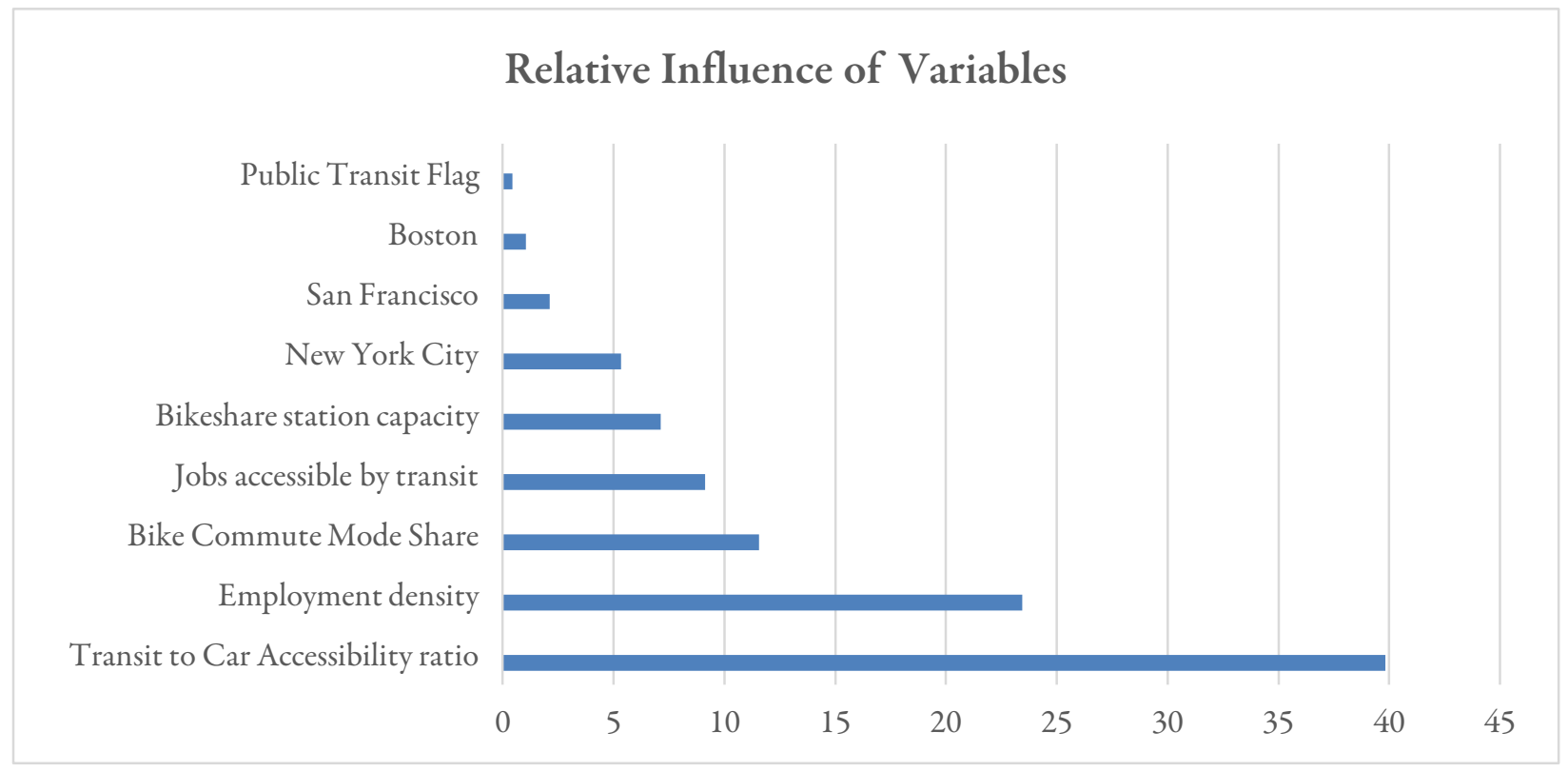

Figure 6.2 Relative Influence of Variables in Model 2A

An inspection of the relative influence of variables shows that the ratio of jobs accessible by both transit and cars, employment density, bike commute mode share, and jobs accessible by transit provide the 58 
greatest explanatory power in the model. These variables are all relative of the built environment conditions more than any other variable.

\subsection{Cross-Validation}

Cross-validation is used to assess the accuracy of the models and avoid overfitting. Table 6.1 shows the mean absolute error results of the $\mathrm{k}$-fold and hold-out methods. The k-fold method reports higher values than the hold-out method. The rail rapid transit ridership reports a lower MAE than the bikeshare trip generation model. This is expected since bikeshare systems are relatively novel concept with varying types of implementation as opposed to heavy and light rail systems in the United States.

Table 6.1 Mean Absolute Error by cross-validation method

\begin{tabular}{l|l|c|c}
\hline MODEL & DESCRIPTION & K-FOLD $(\mathrm{K}=10)$ & HOLD-OUT (25\%) \\
\hline $1 \mathrm{~A}(\mathrm{n}=1,106)$ & Average Weekday Boardings & 0.5280 & 0.466 \\
\hline $2 \mathrm{~A}(\mathrm{n}=2,428)$ & $\begin{array}{l}\text { Average Weekday Bikeshare } \\
\text { Trips using rail rapid transit flag }\end{array}$ & 0.5884 & 0.468 \\
\hline
\end{tabular}

*Note that rail rapid transit stations can have more than one bikeshare station nearby hence the greater sample size

These results suggest that both models experience an error that is on average $50 \%$ of the system-level average. This would imply that applying this model to other cities with rail rapid transit and bikeshare would expect an over or under estimation of half the total ridership. 


\subsection{Outlier Points}

The magnitude of errors is plotted by the dependent variable for Model $1 \mathrm{~A}$ to identify outlier points in the model. The error terms plotted in this section refer to the difference between actual observations and predicted values. Figure 6.3 shows this plot for Model 1A.

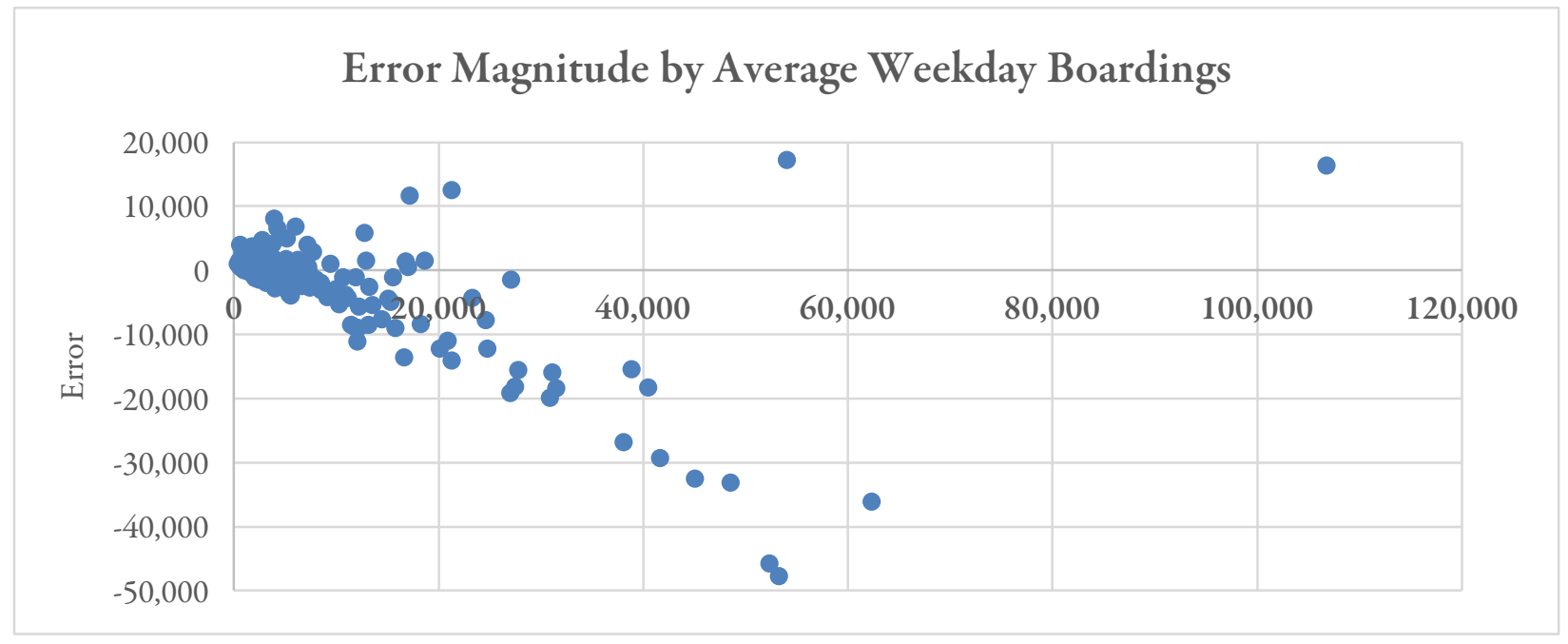

Figure 6.3. Error Magnitude by Average Weekday Boardings in Model 1A

The magnitude of errors grows as the observations with under-predictions grow in magnitude while observations with over-prediction tend to not exceed $50 \%$ of station weekday boardings or in general do not exceed 20,000. The greatest outliers are observed where multiple rail rapid transit lines converge.

Observations greater than 40,000 were related to stations with an abnormally large amount of lines converging at one location such as in downtowns or central business districts and for the most part is due to locations in New York City. Under-prediction could be due to the presence of citywide attractions such as public parks, performance venues, and major tourist destinations. Over-prediction is observed where metro stations are very close to each other (within 1,000 feet) and appear to influence the weekday ridership, consistent with Santiago and Fernandez (2016). 
Errors in Model 2A are more consistent with increasing weekday bikeshare trips as shown in Figure 6.4.

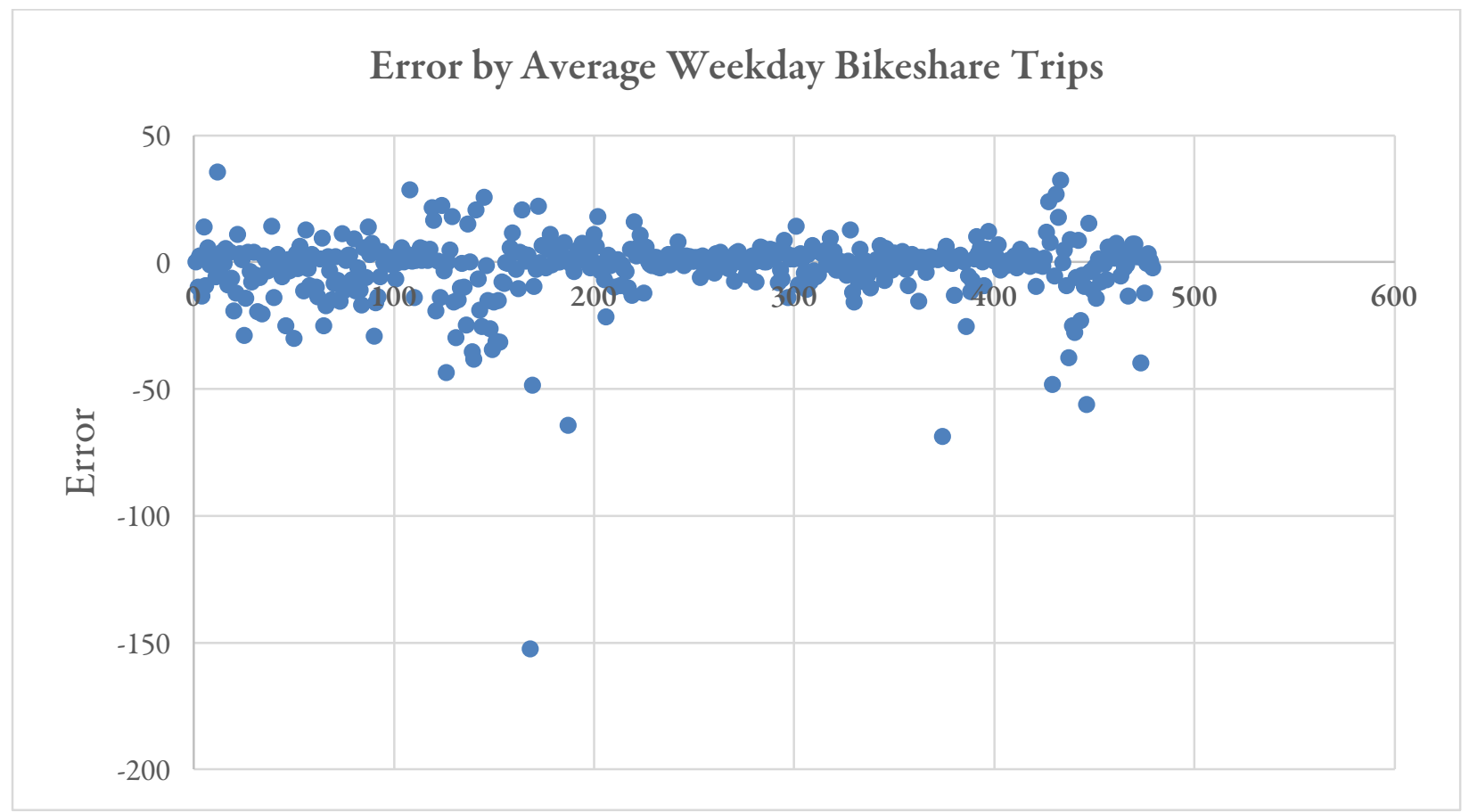

Figure 6.4 Error Magnitude by Average Weekday Bikeshare Trips in Model 2A

The magnitude of errors generally doesn't exceed 50 . Outliers greater than this are associated with being at commuter rail transit terminals and is likely due to not incorporating the commuter rail flag in this model.

Underpredictions were observed at major transit hubs such as Union Station in Washington, DC for example. This may be due to commuter rail playing a key role in attracting riders but was not significant in the model due to inconsistencies in the quality of commuter rail service across the country. This is likely due to these stations attracting riders throughout the day. 


\subsection{Limitations}

\subsubsection{Station Areas}

The station areas were calculated using Euclidian buffers. While the buffer of 0.5 miles around rail rapid transit stations is selected considering a person's willingness to walk in combination with a metro trip, the Euclidian buffers tend to exaggerate this area of influence and in areas with disconnected street networks the degree of unintended area captured is much greater. An example of this is illustrated below.

\subsubsection{Transit System Networks}

While rail rapid transit system networks in this study represent significant parts of the public transportation networks, Boston, San Francisco, Portland, Philadelphia and Boston possess streetcar systems that are extensive and undoubtedly affect the decision to use bikeshare and average weekday boardings.

\subsubsection{Built Environment Variables from Smart Location Database}

The built environment variables from the Smart Location Database (SLD) were recorded for 2010-2012. This contrasts with the average weekday boardings which were recorded for 2016 and the average weekday bikeshare trips variable which were recorded for 2017.

\subsubsection{Quality of Transit Service Variables}

Previous studies have shown the influence bus transfers, peak headways, and off-peak headways have on rail rapid transit ridership and bikeshare trips. Due to time constraints, these variables were not collected. This undoubtedly affected the ability to account for the variation in the model.

\subsubsection{Bikeshare Systems}

As mentioned in the methodology section, not all bikeshare systems have open data protocols. In the case of Los Angeles, the Long Beach bikeshare data were not incorporated because the data were not available at the time data collection was conducted. The San Jose bikeshare data were also not obtained due to lack of light rail system data. 


\subsubsection{Other variables related to the user experience}

There are numerous variables that would likely explain variation in average weekday boardings that are not accounted for here either due to lack of open data or lack of time in data collection. These can include the availability of station amenities like walkways between the transit stations and job centers as well as distance-based measures of centrality for transit stations.

\subsection{Summary}

Multiple regression models are applied to evaluate the direction of influence of socioeconomic, built environment, and other variables on average weekday boardings and average weekday bikeshare trips and estimate the magnitude of the effect on these. The main findings are that the models are able to capture the significance of bikeshare variables on transit and vice versa, but the effects are admittedly low compared to the effect of employment density, which is highly influential on both transit and bikeshare trips. The general finding for policy is that if elasticities hold, expanding bikeshare at transit stations would hold benefits for both bikeshare operators and transit agencies. 


\subsection{CONCLUSIONS}

The goal of this project was to evaluate whether bikeshare influences rapid rail boardings and whether locating a bikeshare dock at rapid rail transit stations was associated with increased bikeshare trips.

Conducting cross-sectional regression analysis consumes a great deal of time and is a data-intensive, spatial analytics operation that will continue to find itself limited to an academic setting (Daddio 2012).

The models only explain $\sim 60 \%$ of the variation in the datasets. Possible variables that could have been included in the rapid rail station boardings model are number of bus stops, frequency of transit service, and distance to center. In the bikeshare model, distance to center, a dummy variable for bikeshare systems that allow dockless operations (such as Biketown in Portland), trip duration as a proxy for commute length, and other socioeconomic variables may have served as potential improvement to the goodness of fit of the models.

The $\log$ transformation of the dependent proved to be a better fit. It also provided a convenient framework for expressing elasticities.

The effect of heavy rail to expand the radius of opportunities accessible by bike and transit was detected to be greater in magnitude than bikeshare's effect on enhancing the first and last mile experience of transit users. In other words, the models suggest that transit helps bikeshare more than bikeshare helps transit. Nonetheless, bikeshare's effect on transit was detected suggesting with greater number of bikeshare bicycles at transit stations could come greater magnitude of influence. The magnitude of effect is a question of scale.

The research questions were answered within the context of methods applied and to the degree to which these methods can provide insights on the influence of bikeshare on transit and vice versa. In the model of average weekday boardings, the supply of docks at a transit station was a significant variable. This correlation illustrates that bikeshare is being located next to high-performing rapid rail stations already but falls short of suggesting that bikeshare use influences transit ridership. The other interesting finding is that transit ridership was a significant variable in the average weekday bikeshare trips model, suggesting 
that locating bikeshare at rapid rail transit stations will yield higher rates of bikeshare trips, even after controlling for the influence of other variables.

\subsection{Policy Implications}

Although bikeshare has matured in US cities, it continues to grow signaling it still has not realized its full potential. This study highlights the potential of bikeshare in playing a role in strategies for encouraging rail rapid transit usage. Bikeshare initiatives have thus far however remained disconnected from strategies to encourage transit usage. This is to say there is room for improvement in encouraging bikeshare in conjunction with transit.

Public policies that would encourage bikeshare-and-transit trip chaining can include:

1. Integrating trip-chaining within the payment scheme

2. Provide free transfers between bikeshare and transit

3. Increase the frequency and quality of commuter rail service

4. Provide incentives to bikeshare companies that invest in cycling facilities at rail transit stations

Payment integration schemes are already available within ride-hailing apps such as Uber and Lyft. The Los Angeles Metro is the only system with free transfers between stations

\subsection{When should bikeshare complement rail rapid transit}

As the models suggest, bikeshare is most complementary in the following conditions:

1. Where jobs are available in great numbers (employment centers)

2. At major transit hubs, or where many transit services transfer

3. Where average weekday boardings are highest

4. In areas with high bike-to-work mode share

65 
5. Where connections to long-distance off-street bicycle facilities are present

6. In areas where there is significant diversity in land uses

\subsection{Future Work}

Future improvements to this modeling could come in filling the data gaps identified in the limitations section. These include capturing quality of transit service variables, up-to-date built environment variables, and the use of station area buffers that account for the travel time through the street network.

Additionally, the relationships between streetcar and bus services could also be accounted for in future studies of this nature. Finally, with the advent of dockless bikeshare systems in the past year, new studies will need to attempt to merge dock-based and dockless bikeshare operator data, as well as adapt to hybrid bikeshare business models which combine dock-specific and hub-based bikeshare station areas.

\subsection{Final Thoughts}

The aim of this project is not to prove a causal relationship between bikeshare and rail rapid transit. Its effects are widely documented in previous studies with various methods. In conducting this multiple regression analysis project, the intention was to provide an insight into the direction and magnitudes of the relationship between the rapidly evolving and relatively novel model of bikeshare with existing transit systems. The availability of open data for rail rapid transit systems was another underlying motivation for this project.

This publicly available information was used to identify national trends in bikeshare and an effort is made to persuade policymakers to find new ways to push bikeshare to new heights in the United States. 


\subsection{REFERENCES}

Altaf, S., 2017. Investigating the factors influencing the use of public bike sharing schemes for the last mile travel in Belgium (Master's thesis, UHasselt).

Barber, E. and Starrett, R., 2018. Unraveling the Relationship Between Bike Share and Rail Transit Use: A Chicago Case Study (No. 18-05682).

Buck, D. and Buehler, R., 2012, January. Bike lanes and other determinants of capital bikeshare trips. In 91 st Transportation research board annual meeting.

Caspi, O. and Noland, R.B., 2018. Bikesharing in Philadelphia: Do Lower-Income Areas Generate Trips? (No. 18-00158).

Cervero, R., Murakami, J. and Miller, M., 2010. Direct ridership model of bus rapid transit in Los Angeles County, California. Transportation Research Record: Journal of the Transportation Research Board, (2145), pp.1-7.

Cervero, R., Caldwell, B. and Cuellar, J., 2013. Bike-and-ride: build it and they will come. Journal of Public Transportation, 16(4), p.5.

Currie, G., Ahern, A. and Delbosc, A., 2011. Exploring the drivers of light rail ridership: An empirical route level analysis of selected Australian, North American and European systems. Transportation, 38(3), pp.545-560.

Daddio, D.W. and Mcdonald, N., 2012. Maximizing bicycle sharing: an empirical analysis of capital bikeshare usage. University of North Carolina at Chapel Hill.

Durning, M. and Townsend, C., 2015. Direct Ridership Model of Rail Rapid Transit Systems in Canada. Transportation Research Record: Journal of the Transportation Research Board, (2537), pp.96102.

Fernández Reyes, S., 2016. Station-level ridership on Mexico City's subway and BRT (Doctoral dissertation, Massachusetts Institute of Technology). 
Fuller, D., Sahlqvist, S., Cummins, S. and Ogilvie, D., 2012. The impact of public transportation strikes on use of a bicycle share program in London: interrupted time series design. Preventive medicine, 54(1), pp.74-76.

Gebhart, K. and Noland, R.B., 2014. The impact of weather conditions on bikeshare trips in Washington, DC. Transportation, 41(6), pp.1205-1225.

Griffin, G.P. and Sener, I.N., 2016. Planning for bike share connectivity to rail transit. Journal of public transportation, 19(2), p.1.

Ma, T., Liu, C. and Erdoğan, S., 2015. Bicycle sharing and public transit: does Capital Bikeshare affect Metrorail ridership in Washington, DC?. Transportation Research Record: Journal of the Transportation Research Board, (2534), pp.1-9.

Noland, R.B., Smart, M.J. and Guo, Z., 2016. Bikeshare trip generation in New York city. Transportation Research Part A: Policy and Practice, 94, pp.164-181.

Pucher, J. and Buehler, R., 2008. Making cycling irresistible: lessons from the Netherlands, Denmark and Germany. Transport reviews, 28(4), pp.495-528.

Pucher, J. and Buehler, R., 2009. Integrating bicycling and public transport in North America. Journal of Public Transportation, 12(3), p.5.

Ramsey K, Bell A. Smart Location Database. Washington, DC: U.S. EPA Office of Sustainable Communities; 2014.

Wang, J., 2018. Spatial Modeling of Bike Share Trip Generation in the Twin Cities (No. 18-06282). In 91st Transportation research board annual meeting.

Villwock-Witte, N. and van Grol, L., 2015. Case Study of Transit-Bicycle Integration: Openbaar Vervoer-fiets (Public Transport-Bike)(OV-Fiets). Transportation Research Record: Journal of the Transportation 
9.0 APPENDIX A: BOARDINGS AND BIKESHARE BY CITY, LINES AND CBD FLAG

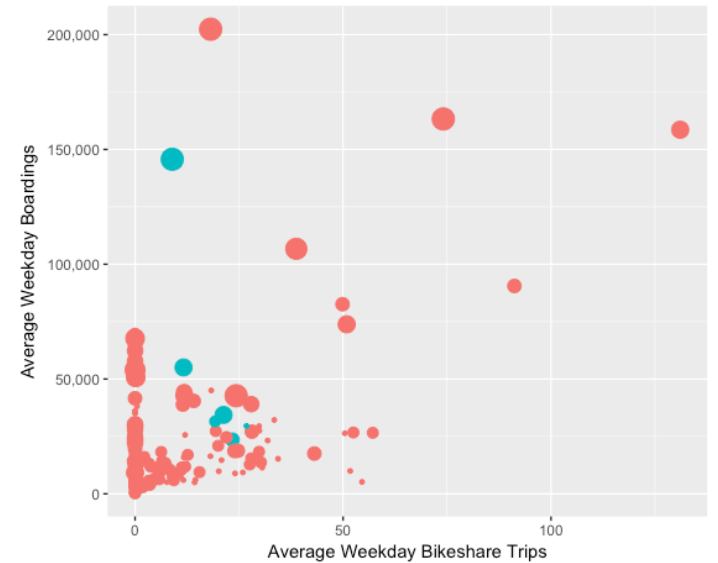

New York City

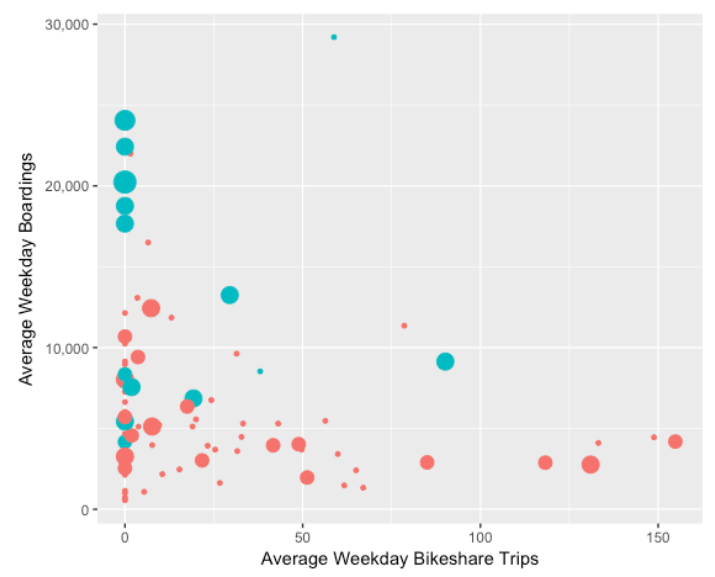

Washington, DC

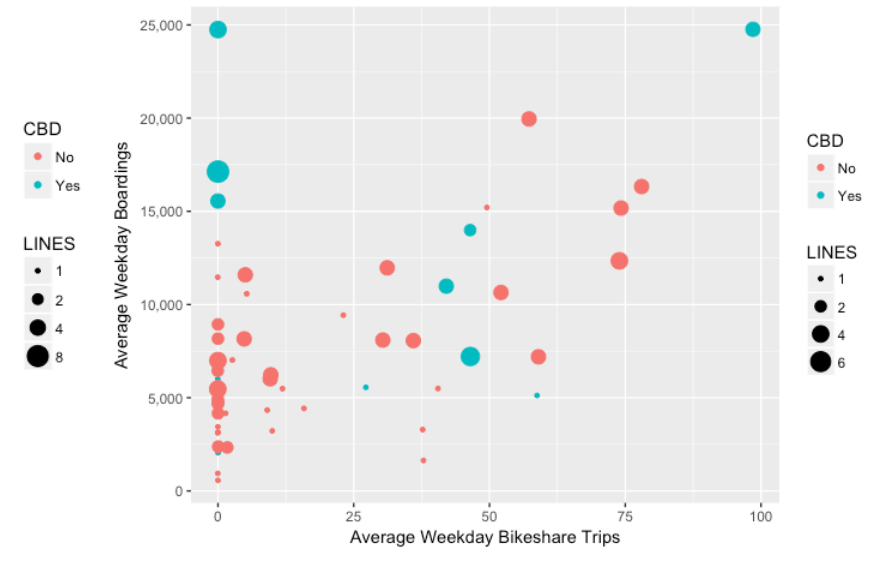

Chicago

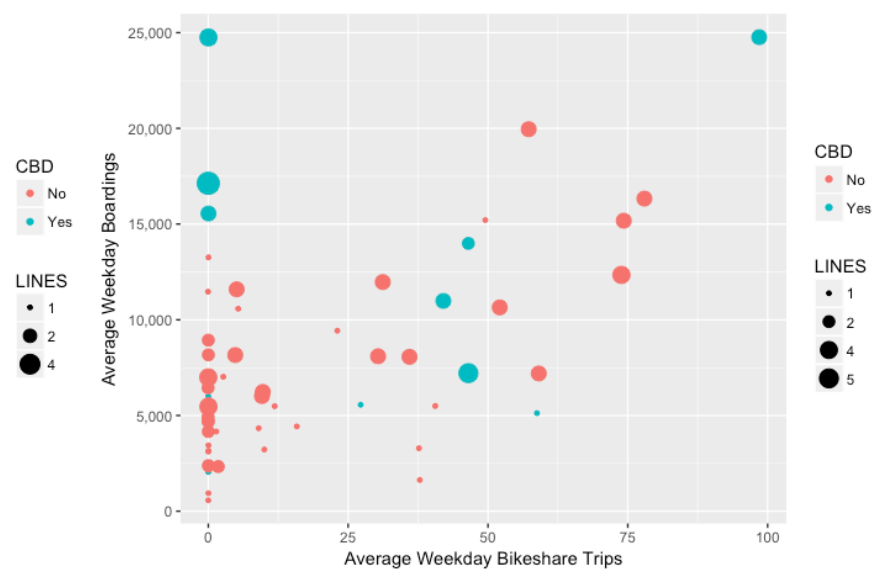

Boston 


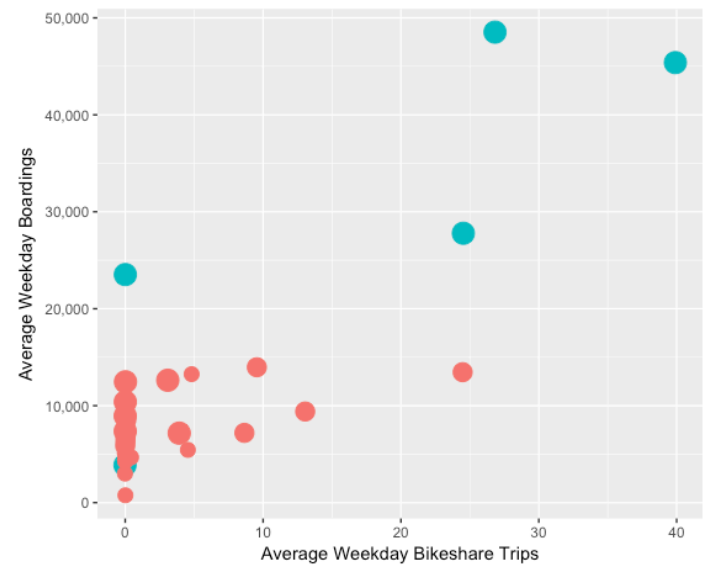

San Francisco

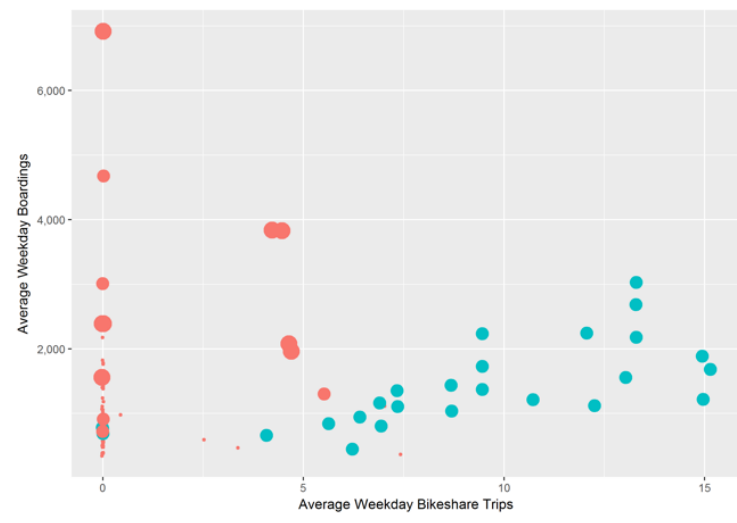

Portland

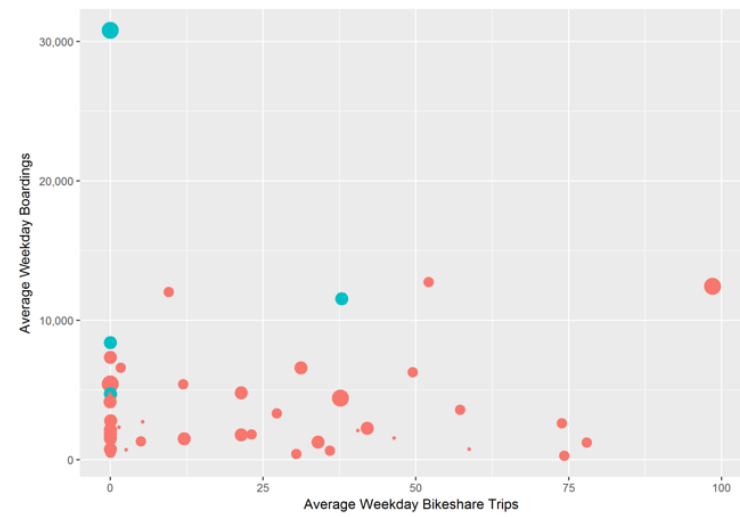

Denver

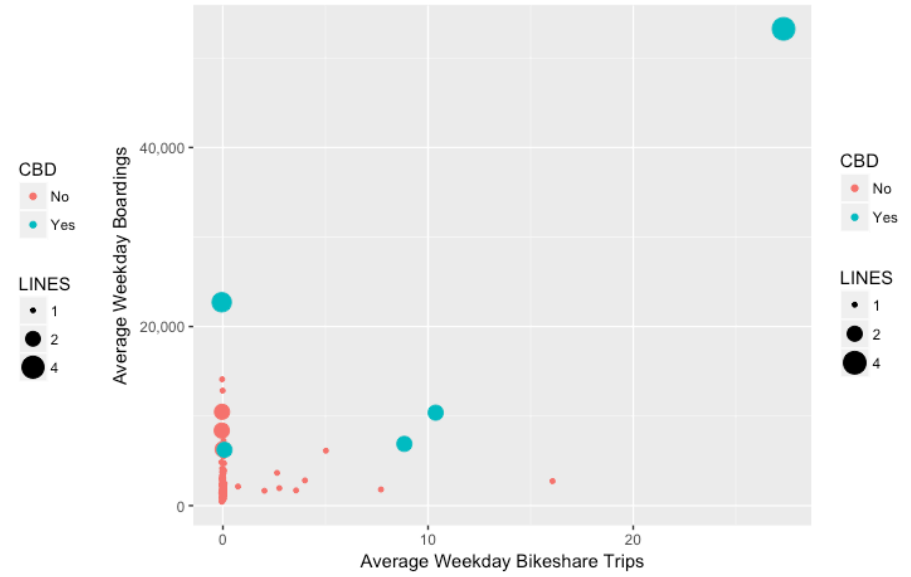

Los Angeles

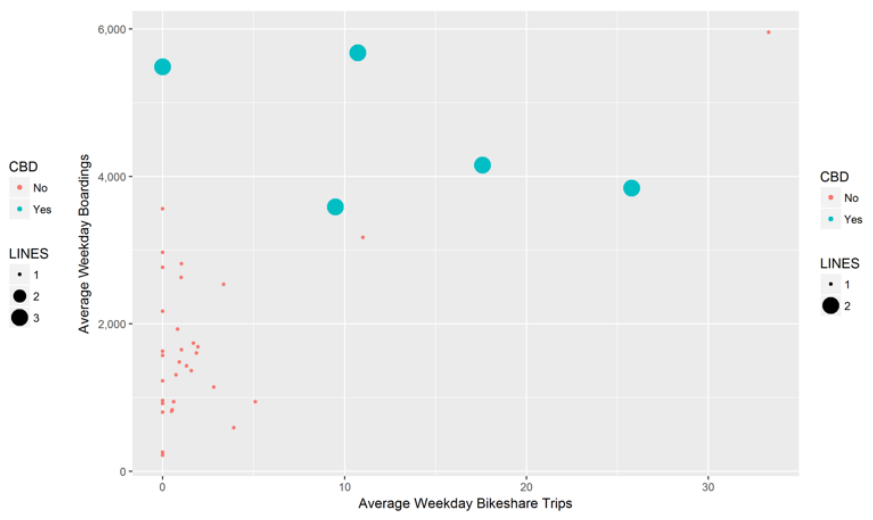

Minneapolis

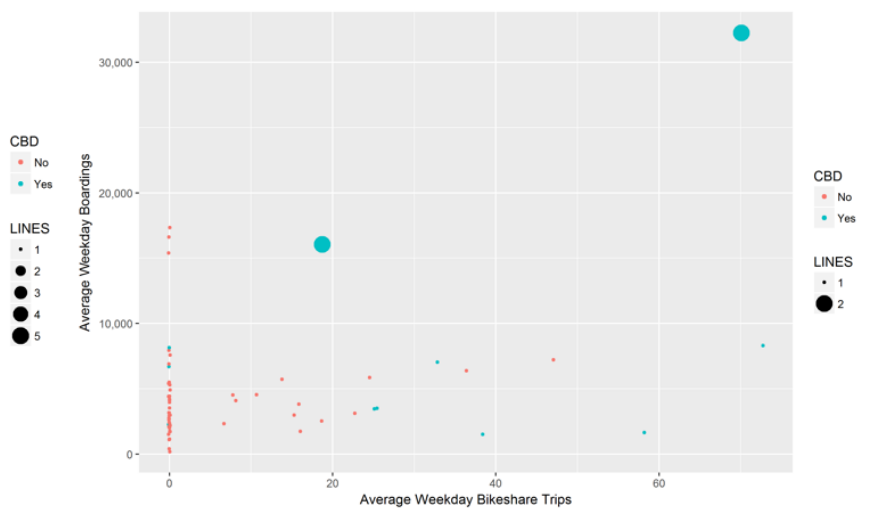

Philadelphia

Table 9.1. Bikeshare activity and average weekday boardings by number of rapid rail lines and location in central business district 